
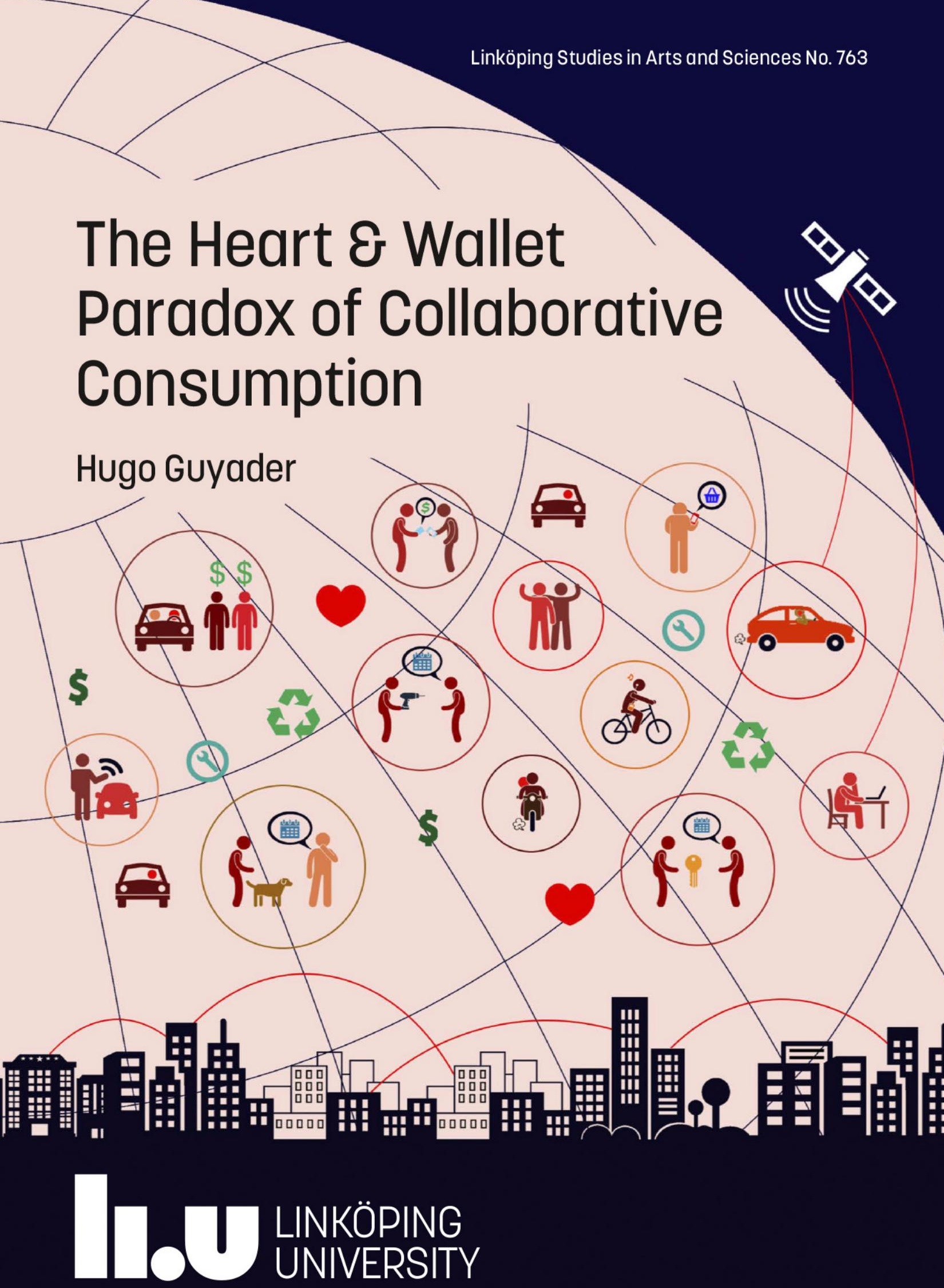


\title{
The Heart \& Wallet Paradox of Collaborative Consumption
}

\author{
HUGO GUYADER
}

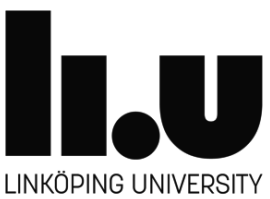

Linköping Studies in Arts and Science No. 763

Faculty of Arts and Sciences

Linköping 2019 
Linköping Studies in Arts and Science • Dissertation No. 763

At the Faculty of Arts and Sciences at Linköping University, research and doctoral studies are carried out within broad problem areas. Research is organized in interdisciplinary research environments and doctoral studies mainly in graduate schools. Jointly, they publish the series Linköping Studies in arts and Science. This thesis comes from the division of Business Administration at the Department of Management and Engineering.

Distributed by:

Department of Management and Engineering

Linköping University

SE-58183 Linköping, Sweden

Hugo Guyader

The Heart $\&$ Wallet Paradox of Collaborative Consumption

Cover: Elodie Guichaoua

Edition 1:1

ISBN: 978-91-7685-116-6

ISSN: 0282-9800

(C) Hugo Guyader

Department of Management and Engineering 2019

Printed by:

LiU-Tryck, Linköping, 2019 




\section{Abstract}

Collaborative consumption is a peer-to-peer (P2P) exchange of goods and services facilitated by online platforms. This phenomenon is driven by technologies that make it easier and cheaper to redistribute and share the use of existing but underutilized private resources. It is embedded in the paradigm shift in society towards access-based consumption, in opposition to acquisition and private individual ownership. Firms take on the new role of enabler of collaborative consumption by developing online platforms and smartphone apps that facilitate $\mathrm{P} 2 \mathrm{P}$ exchanges between people in their roles of peer providers and consumers.

Collaborative consumption is anchored to two opposite logics of consumption: sharing and market exchange. This results in the Heart \& Wallet paradox with its tensions between a pro-social orientation and communal norms on the one hand, and a for-profit orientation and market norms on the other hand. While diverse societal and regulatory aspects of the so-called "sharing economy" are discussed in popular debate, scholars have yet to catch up on the theoretical implications from these influences on business activities and consumer behavior.

This thesis aims to improve the understanding of collaborative consumption by contributing to the conceptualization of this new phenomenon as intertwined with coexisting sharing and market logics. The research is based on two papers taking the perspective of the firms operating online platforms that facilitate collaborative consumption, and two papers taking the perspective of the peer providers and consumers participating in $\mathrm{P} 2 \mathrm{P}$ exchanges. The context of shared mobility (i.e. P2P car rental, ridesharing) is explored through three cases, using interviews with online platform managers and participants in collaborative consumption, participant observation, a netnography, a cross-sectional survey of platform users, and document analyses.

This thesis situates collaborative consumption in the access paradigm, based on the temporal redistribution and monetization of private resources facilitated via online platforms, while nurturing the feelings of communal belonging and the sharing ethos embedded in $\mathrm{P} 2 \mathrm{P}$ exchanges. Investigating the tensions of the Heart \& Wallet paradox of collaborative consumption, I highlight the opposing rationales between the sharing logic of the original nonmonetary practices initiated by grassroots communities and the market logic of platform business models. I further emphasize the key function of communal identification for participants and the role of perceived sharing authenticity - the pitfalls of sharewashing for firms. This thesis contributes to service research by advancing the understanding of P2P exchanges and the conceptualization of collaborative consumption. 



\section{Sammanfattning}

Kollaborativ konsumtion bygger på P2P-utbyte (peer-to-peer) av varor och tjänster genom online-plattformar. Detta fenomen drivs på av teknologi som gör det enklare och billigare att dela användningen av befintliga men underutnyttjade privata resurser. Det är inbäddat i paradigmskiftet i samhället mot tillgångsbaserad konsumtion, i motsats till privat ägande. Företag får en ny roll som underlättare av kollaborativ konsumtion där privatpersoner istället intar rollerna som både leverantörer och konsumenter.

Kollaborativ konsumtion är förankrat $\mathrm{i}$ två motsatta logiker: delning och varuutbyte. Detta resulterar i Heart \& Wallet-paradoxen med spänningar emellan en pro-social orientering som bygger på gemensamma normer, och en vinstdrivande orientering baserad på marknadsnormer. Medan det funnits en debatt kring den så kallade "delningsekonomin" och dess samhälleliga och legala implikationer, så har den akademiska debatten ännu ej hunnit ta fart kring dess påverkan på affärsverksamhet och konsumentbeteende.

Avhandlingen syftar till att förbättra förståelsen av kollaborativ konsumtion genom att bidra till konceptualiseringen av detta fenomen där delningslogik och marknadslogik samexisterar. Avhandlingen är baserad på två artiklar som undersöker kollaborativ konsumtion från ett företagsperspektiv och två artiklar där begreppet studeras ur de deltagande individernas perspektiv. Kontexten "shared mobility" (d.v.s. privat biluthyrning, samåkning) undersöks i tre organisationer med hjälp av intervjuer med anställda på onlineplattformar och deltagare i kollaborativ konsumtion, deltagarobservationer, en nätnografi, en tvärsnittsundersökning av plattformsanvändare och dokumentanalyser.

Avhandlingen placerar kollaborativ konsumtion i paradigmet kring studier av tillgång till tjänster, där den temporära omfördelningen $\mathrm{i}$ tid och monetariseringen av privata resurser underlättas via online-plattformar, samtidigt som den gemensamma tillhörigheten och det "delningsetos" som finns inbäddat i P2P-utbyten uppmuntras. Genom att undersöka spänningarna i Heart \& Wallet-paradoxen i kollaborativ konsumtion, belyser jag motsättningarna mellan delningslogiken från gräsrotsrörelsen och marknadslogiken i plattformsaffärsmodellerna. Vidare diskuterar jag den centrala rollen av "communal identification"-upplevelsen av autencitet vid delning av resurser för kollaborativ konsumtion. Avhandlingen bidrar till tjänsteforskningen kring tillgång till tjänster genom en ökad förståelse av P2P-utbyten och en konceptualisering av kollaborativ konsumtion. 



\section{Acknowledgements}

I would not have survived my PhD studies alone, and I am grateful for all the people who helped me along the way. Thanks everybody. Five years is a long period to dedicate to one project (almost $20 \%$ of my life!), with some explicit things to do (like writing this book) but much more tacit knowledge to acquire (the craft of doing good research). A few people need to be acknowledged in particular for their helpful guidance or support in getting there.

First, I am grateful to my supervisors for their patience, motivation, knowledge, and support in overcoming numerous obstacles I have been facing through these years. My main supervisor, Lars Witell is the main responsible for all this. Lars is the most humble and casual professor I have met. I learned a lot of the tricks of the trade of doing research from our informal discussions and in-between-doors supervision. Thank you Lars for giving me the opportunity to begin my $\mathrm{PhD}$ studies, introducing me to the very friendly service research community, and sharing your expertise on writing, publishing, and academia in generaland the glimmers of hope for my academic career. My co-supervisor Mikael Ottosson also has his share of responsibility for what I could achieve. Mikael is not only not a great coauthor, but also a great mentor - and a great leader for the division! Thank you Mikael for looking out for me, giving me hands-on feedback, setting clear objectives, and providing academic guidance for younger researchers.

I would also like to thank Mike Brady, not only for making my visit possible at the College of Business of Florida State University, but also for making sure I enjoyed and benefited from my stay. Most importantly, I am indebted to Charles Hofacker for hosting me and meeting me regularly to discuss research and guide me towards publication. I am also thankful to Martin Mende for inspiring me during the consumer behavior seminars. Thank you Mike, Charles, and Martin, for allowing me to see academia and research from the American perspective and learn firsthand from the bests.

At Linköping University, I am also grateful to Aku Valtakoski for reading and giving me feedback on my writing, particularly on a previous version of this thesis. Thanks Aku for the encouragements and perceptive comments. Many thanks to Per Frankelius too for the stimulating discussions and our co-authored article. I am also indebted to Marie Bengtsson for leading me onto the doctoral research path — and for showing me the ventilation button in the corridor and allow me to breathe during weekends.

To Christina Öberg, thank you for the insightful comments and excellent readthrough at my pre-final seminar. This thesis would also have looked different without the constructive feedback of Heiko Gebauer on yet another version of this thesis, thank you. 
I am also grateful to Mattias Jägerskog in Gothenburg not only for providing access to data, but also for introducing me to the Ouishare network and the friends at Kollaborativ Ekonomi Göteborg, and the great discussion we had since. Thanks Zlatan Dragisic for the help with the database - you have been instrumental to my research project! Many thanks to Laura Piscicelli at Utrecht University who somehow trusted me out of the blue to coauthor a paper, and diligently went through the nitty-gritty details of the review process, with great fun.

I also want to show my gratitude to my fellow $\mathrm{PhD}$ students for their nice words and support. Thank you Josefine for all the fun at work and about work, laughing at the irony of our daily struggles. Thanks Johanna for being a very helpful colleague and a good friend, you have helped a lot. Thank you also Svjetlana, Linus, Christopher, and Alaksej for all the fun talks at lunch and fika! Being a $\mathrm{PhD}$ student at FEK is not straightforward and I am grateful for such a nice group who holds up together throughout the process. Thanks also to the junior faculty at FEK, Birgitta, Besma, Henrik, Karin, Lena.

Since I moved to Sweden, I made a few friends who also had to listen to my talking about the sharing economy research, and who brought me back to enjoy moments of real life outside the office. Let's see more of each other now! Thanks Mario, Lovisa, Ljiljana, Darcy, and Johanna. Mario, you are an inspiring friend and scholar, and I am particularly grateful for the help I have received from our discussions throughout the years.

Meanwhile my French friends have stayed the same reliable great bunch of fun people to get together with and talk since we are kids! Thanks for trying to understand what the heck I'm doing in Sweden, and at the same time, thanks for taking my mind off work when needed. Spécial dédicace to Elo for the help with the cover.

Thanks as well to the few friends met during doctoral courses, service research conferences, and academic visits to Ann Arbor and Tallahassee; great to still be in touch!

Finally, my family deserves many thanks for trusting me when I chose Sweden for my exchange year back in 2010, and all the encouragements ever since. It is definitely not easy understanding the details of doing a $\mathrm{PhD}$, especially when I don't myself, but you have always been supportive, and enthusiastic about the outcomes. Thanks mom, dad, and Romain.

Last but not least, thank you too Caro.

Linköping, February 2019

Hugo Guyader 


\section{Appended papers}

Paper I Guyader H., Ottosson M., Frankelius P., and Witell L. (2019) "Identifying the Resource Integration Processes of Green Service," Journal of Service Management (forthcoming).

Paper II Guyader H. and Piscicelli L. (2019) "Business Model Diversification in the Sharing Economy: The Case of GoMore," Journal of Cleaner Production, Vol. 215, pp. 1059-1069.

Paper III Guyader H. (2018) "No One Rides for Free! Three Styles of Collaborative Consumption," Journal of Services Marketing, Vol. 32(6), pp. 692-714.

Paper IV Guyader H., Witell L., and Benoit S. (2019) "User Retention in Collaborative Consumption: The Heart \& Wallet Paradox" (working paper). 



\section{Contents}

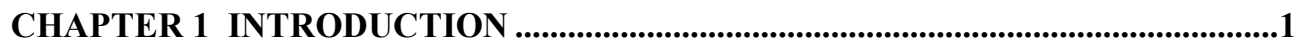

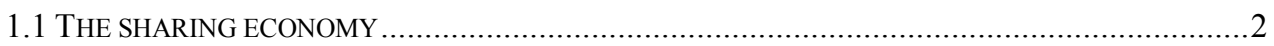

1.2 THE HEART \& WALLET PARAdOX OF COLLABORATIVE CONSUMPTION ...............................4

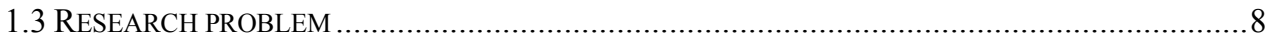

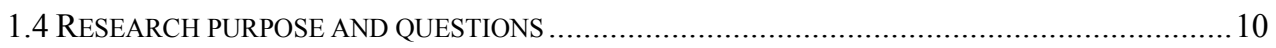

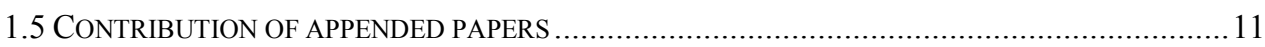

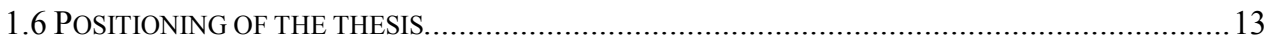

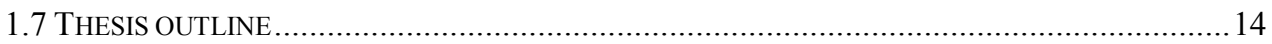

CHAPTER 2 THEORETICAL BACKGROUND ...................................................15

2.1 THE COLLABORATIVE CONSUMPTION CONTINUUM ........................................................ 16

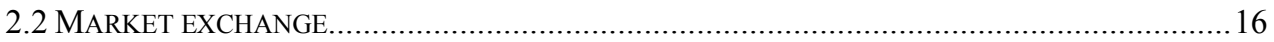

2.3 CONSUMER RESEARCH ON ALTERNATIVE MODES OF CONSUMPTION ............................... 19

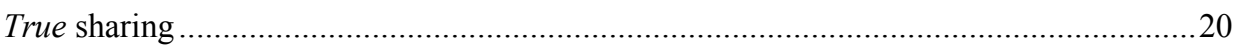

Community-based and non-monetary consumption ............................................... 22

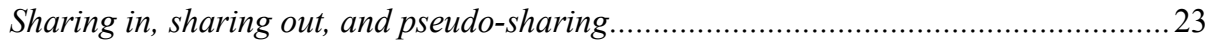

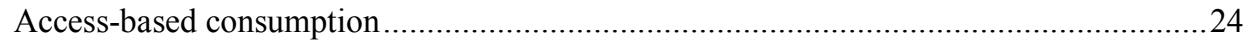

2.4 SERVICE RESEARCH ON ACCESS-BASED CONSUMPTION …............................................25

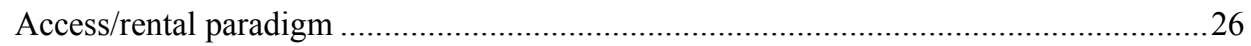

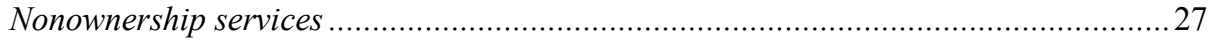

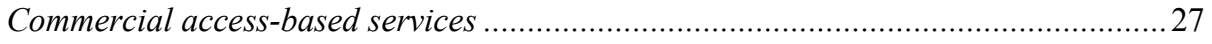

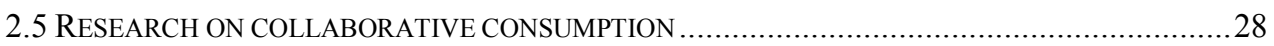

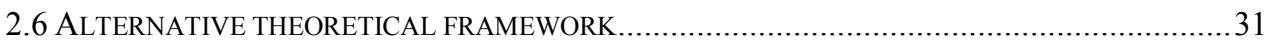

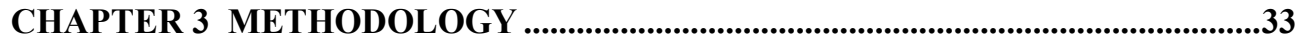

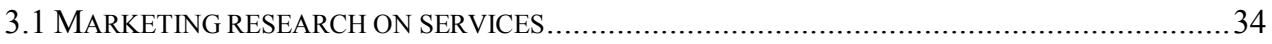

3.2 RESEARCH APPROACH: MIXED-METHOD AS RESEARCH PARADIGM ....................................35

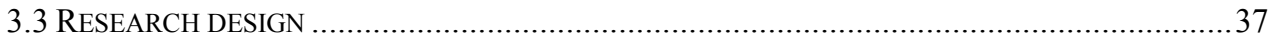

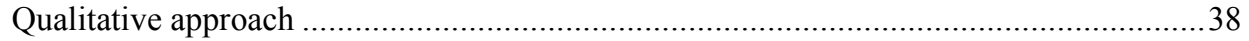

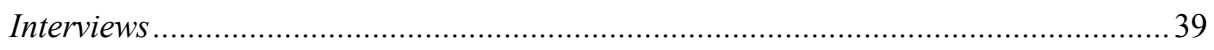

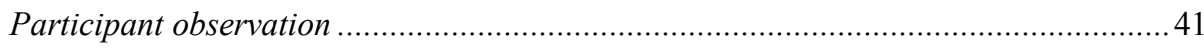

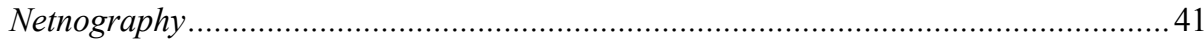

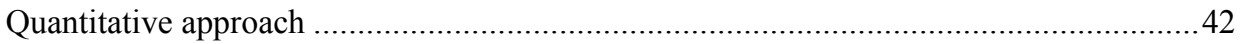

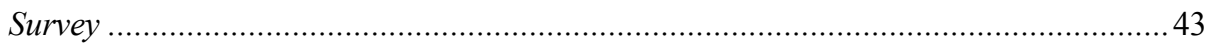

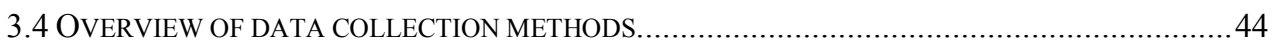

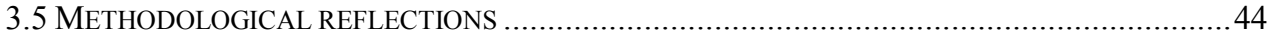

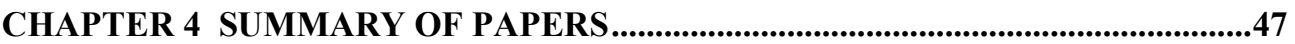


4.1 IDENTIFYING THE RESOURCE INTEGRATION PROCESSES OF GREEN SERVICE..................... 48

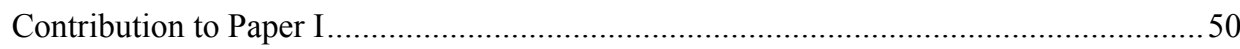

4.2 BUSINESS MODEL DIVERSIFICATION IN THE SHARING ECONOMY: THE CASE OF GOMORE .. 51

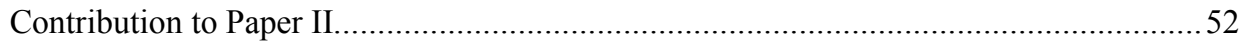

4.3 NO ONE RIDES FOR FREE! THREE STYLES OF COLLABORATIVE CONSUMPTION ...................53

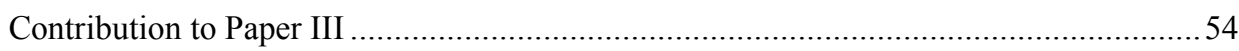

4.4 USER RETENTION IN COLLABORATIVE CONSUMPTION: THE HEART \& WALLET PARADOX . 54

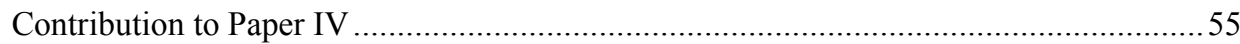

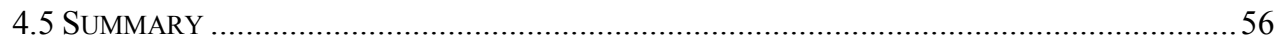

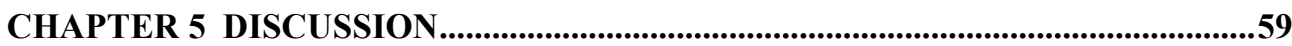

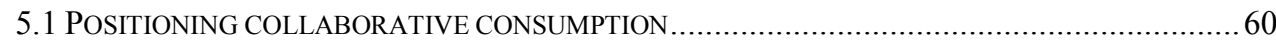

Collaborative consumption is not like commercial access-based services .........................61 61

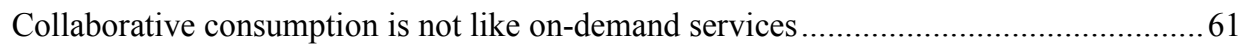

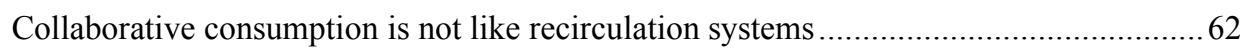

Collaborative consumption and the Heart \& Wallet paradox .........................................63

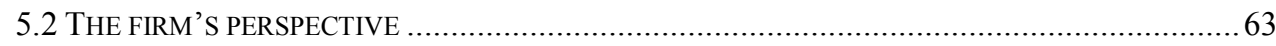

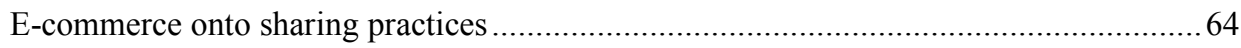

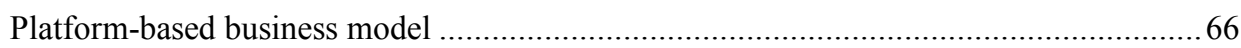

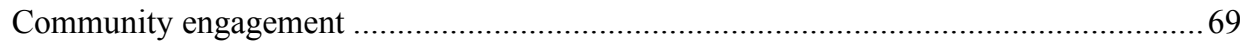

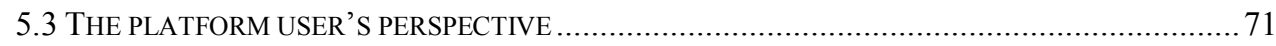

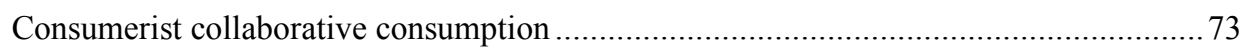

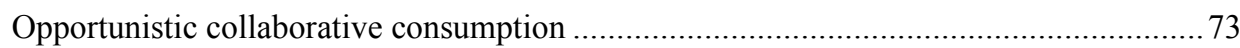

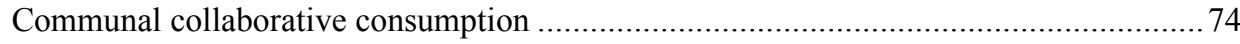

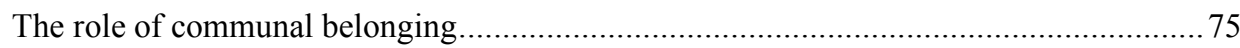

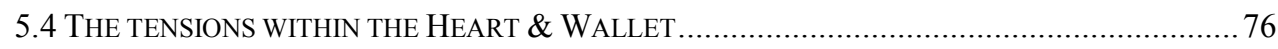

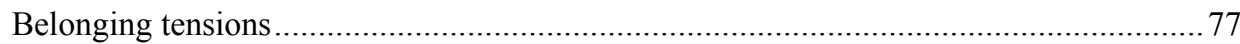

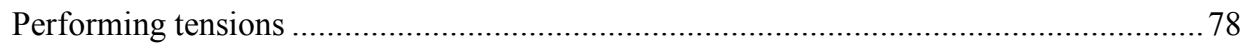

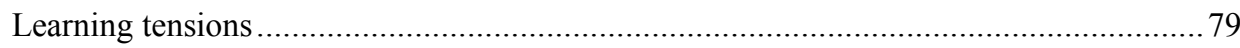

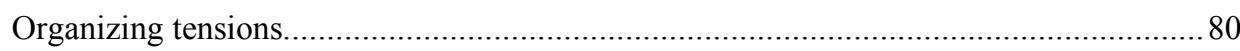

Understanding the Heart \& Wallet paradox of collaborative consumption ...................... 81

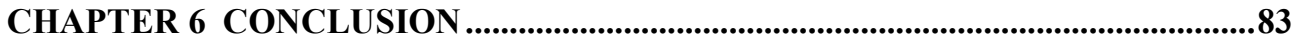

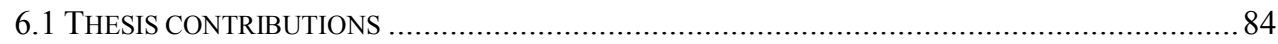

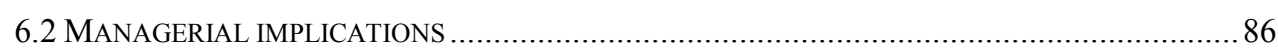

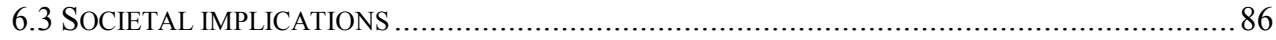

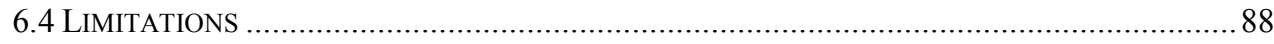

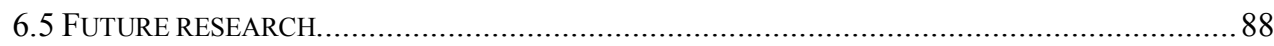

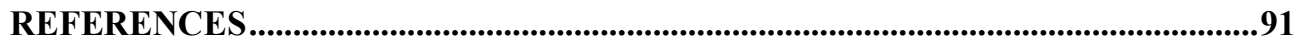

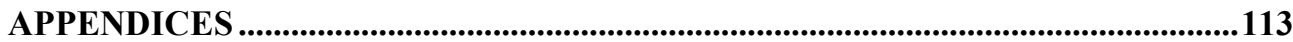




\section{Figures and Tables}

Figure 1. Commercial access-based service provision.....................................................

Figure 2. Collaborative consumption platform business model...........................................

Figure 3. The collaborative consumption continuum. ...................................................16

Figure 4. Collaborative consumption and related concepts. ..............................................31

Figure 5. Research process........................................................................................

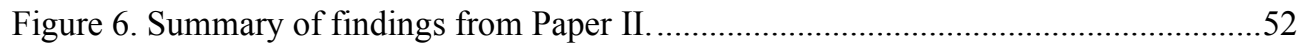

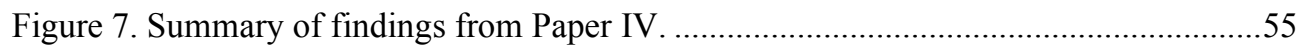

Figure 8. Differentiating collaborative consumption. ......................................................6

Figure 9. Examples of GoMore's marketing communications. ............................................68

Figure 10. Positioning the collaborative consumption styles...............................................72

Table 1. The Heart \& Wallet paradox of collaborative consumption. ...................................6

Table 2. The papers' contribution to the research questions.............................................11

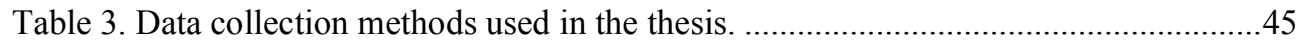

Table 4. Summary of findings from Paper I.............................................................49

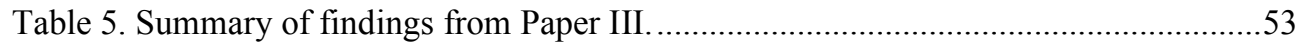

Table 6. Summary of papers. ....................................................................................5

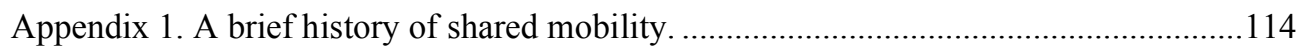

Appendix 2. From "collaborative consumption" to "gig economy"..................................116

Appendix 3. A brief history of Service Research. ......................................................117

Appendix 4. Posting ridesharing offers on BlaBlaCar's platform.....................................118

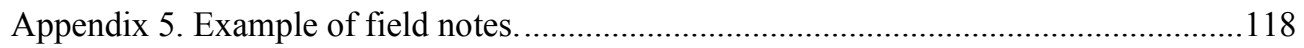

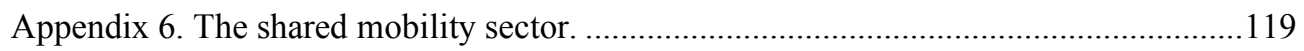

Appendix 7. Degrees of separation between platform users...........................................119

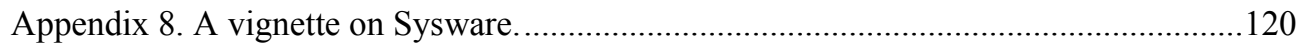

Appendix 9. BlaBlaCar: Growth from 2007 to 2017 .......................................................121 



\section{CHAPTER 1}

INTRODUCTION

On the whole, you find wealth much more in use than in ownership. - Aristotle

This chapter begins by introducing the "sharing economy" before focusing specifically on the collaborative consumption phenomenon. This introduction further defines the Heart \& Wallet paradox, which situates collaborative consumption between the opposing sharing logic and market logic. This then leads on to the research problem and purpose of this thesis: to advance the understanding of collaborative consumption in light of these paradoxical tensions. 


\subsection{The sharing economy}

Over the past decade, the "sharing economy" has been popularized as an economic revolution based on sharing (e.g., Botsman and Rogers 2010a; Buczynski 2013; Gansky 2010). ${ }^{1}$ This umbrella term can be defined as "the monetization of underutilized assets that are owned by service providers (firms or individuals) through short-term rentals" (Kumar et al. 2018, p. 148). Such rentals relate to a shift towards access-based consumption that provides temporary access to goods and services rather than traditional acquisition and ownershipbased consumption (e.g., Bardhi and Eckhardt 2012). A typical example of a commercial access-based service is found in carsharing firms. For example, Zipcar offers customers the temporary use of a car from its commercial fleet based on self-service technology (i.e. business-to-customer [B2C] relationship). ${ }^{2}$ Zipcar itself leases its fleet from diverse automotive manufacturers (i.e. business-to-business [B2B]). In essence, commercial accessbased services are offered to multiple customers who share the utilization of the same goods sequentially, but ownership remains with the firm (see Figure 1). Customers obtain the benefits of ownership without its burdens for a fixed price (e.g., membership costs) and/or a variable price (e.g., usage costs), which can be convenient and financially more attractive than ownership-based consumption with high acquisition and maintenance costs.

Alongside the provision of access-based consumption through the use of a firm's resources, firms have also developed online platforms that facilitate peer-to-peer $(\mathrm{P} 2 \mathrm{P})^{3}$ exchanges between people who use their private resources; this is called collaborative consumption (e.g., Albinsson and Perera 2018; Belk 2014b; Benoit et al. 2017; Habibi et al. 2016; Hamari et al. 2016; Hartl et al. 2016). Collaborative consumption is defined as an "activity whereby a platform provider links a consumer that aims to temporarily utilize assets with a peer service provider who grants access to these assets and with this delivers the core service" (Benoit et al. 2017, p. 220). Ridesharing and accommodation rental are popular examples of collaborative consumption. For example, BlaBlaCar is an online platform that enables drivers to fill otherwise empty seats with passengers heading in the same directionthis is also referred to as Hitchhiking 2.0 (e.g., Casprini et al. 2018). Similarly, Airbnb makes it possible for homeowners to offer part, or the entirety, of their accommodation for $\mathrm{P} 2 \mathrm{P}$ rental to guests from all over the world (e.g., Bucher et al. 2016; Mittendorf 2018; Zervas et al. 2017).

Collaborative consumption is based on a triadic relationship between the firm providing the online platform, its users in their role as peer service providers (i.e. not employees), and consumers; the latter are both peer members of the same networked community (Andreassen et al. 2018; Baden-Fuller et al. 2017; Benoit et al. 2017; Breidbach and Brodie 2017; Einav et al. 2016; Ertz et al. 2018b; Kumar et al. 2018). New technologies and their adoption (e.g., the Internet, GPS, Web 2.0, and smartphones) can thus be seen to 


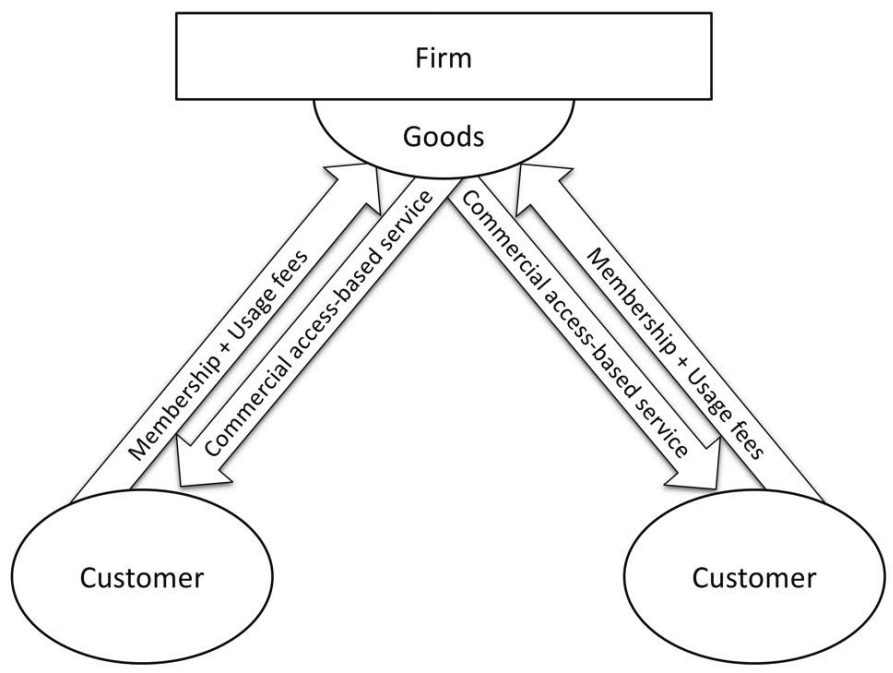

Figure 1. Commercial access-based service provision.

have enabled new forms of consumer cooperation both online and offline. Peer providers increase the utilization of their resources (i.e. compensating ownership costs and sharing usage costs), and consumers find cheaper alternatives in $\mathrm{P} 2 \mathrm{P}$ exchanges than traditional market offerings.

Collaborative consumption is situated within the access-based consumption paradigm: resources are exchanged temporarily, without a permanent transfer of ownership (e.g., Benoit et al. 2017; Eckhardt and Bardhi 2016; Habibi et al. 2016; Lamberton 2015, 2016). Without tangible resources, the firm's role is different from that of owning and maintaining physical assets: their online platforms act as facilitators of P2P exchanges (see Figure 2). Firms develop matchmaking algorithms, trust and screening mechanisms, compensation/pricing schemes, reservation systems, secure payment options, smartphone apps, and geolocalization services, and they offer complementary insurance and additional customer services (Benoit et al. 2017; Einav et al. 2016; Field et al. 2018; Kumar et al. 2018; Perren and Kozinets 2018).

For facilitating P2P exchanges, firms charge a fee on either or both sides of the dualsided market-i.e. a platform business model (e.g., Andreassen et al. 2018; Breidbach and Brodie 2017; Kumar et al. 2018). ${ }^{4}$ Balancing supply (i.e. peer providers and underutilized resources) and demand (i.e. aggregating demand and segmenting consumer needs) is a critical issue for the viability of such matchmaking businesses (Evans and Schmalensee 2010; Muzellec et al. 2015; Rochet and Tirole 2006). This directedness regarding collaborative consumption interactions (i.e. P2P exchange) is a key difference compared with commercial access-based services (i.e. B2C relationships). Moreover, the platform users can share the 


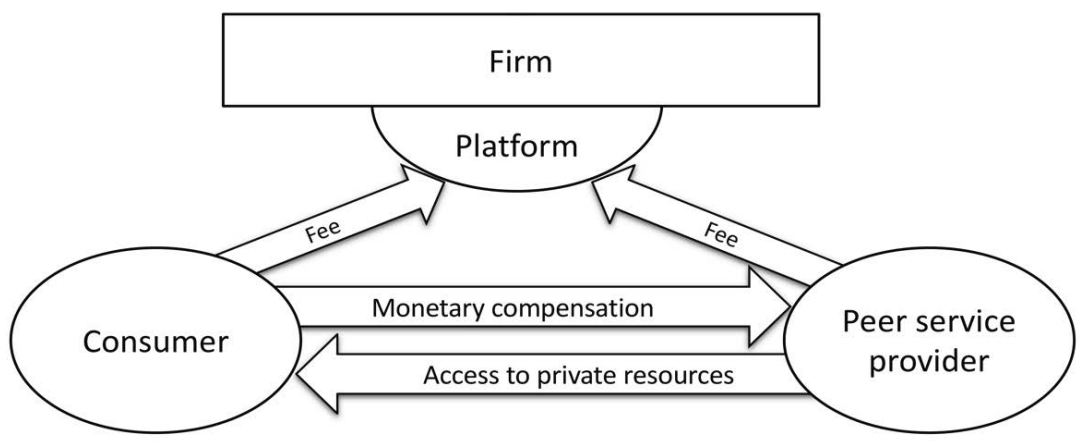

Figure 2. Collaborative consumption platform business model.

usage of private resources simultaneously (e.g., ridesharing) and not only as successive customers (e.g., carsharing).

This thesis focuses on collaborative consumption in particular as a new phenomenon in service research. The key characteristics of collaborative consumption adopted in this thesis are (adapted from Benoit et al. 2017):

- The nature of the exchanges: no ownership transfer, only temporal access to privatelyowned and underutilized resources.

- The number and type of actors: a platform provider, peer service providers and consumers using the platform as peers, which forms a triadic relationship.

- The mode of exchange: market-mediated and compensated.

\subsection{The Heart $\&$ Wallet paradox of collaborative consumption}

Researchers have pointed out that the "sharing economy" has nothing to do with true sharing (Belk 2014a, 2014b; Eckhardt and Bardhi 2015, 2016; Fournier et al. 2013; Price and Belk 2016). Instead, these new consumer behaviors based on access are pseudo sharing (Belk 2014a). In short, the term "sharing economy" is an oxymoron. Firms intend to benefit from the overall rather positive image of sharing by associating market exchanges with the prosocial values of sharing (cf. Belk 2010), and they overstate promises of communal belonging, a sense of common identity, and other positive connotations of the word "community" (cf. Williams 1976). However, collaborative consumption participants may well be disappointed by the claimed commitment to social transformation and the social connections potentially created with strangers, as online platforms can fail to create strong social ties, long-term friendships, and communal belonging (Schor 2014). Not only in practice, but in academia too, as Price and Belk (2016, p. 193) wrote: "In some of the theory and research surrounding 
'the sharing economy,' sharing is so blurred with traditional marketplace exchanges as to be indistinguishable. Or more accurately, the concepts often remain distinct, but a 'sharewashing' effort is made to blur them to the extent that marketplace exchange is touted as sharing." $"$ In other words, there is an apparent confusion around the academic concepts used to discuss the "sharing economy", which translates in a call for further research and conceptualization on the phenomenon-i.e. the $\mathrm{P} 2 \mathrm{P}$ exchanges of collaborative consumption in particular.

Firms profiting from $\mathrm{P} 2 \mathrm{P}$ exchanges are held responsible for transforming private belongings into public merchandise - the so-called transactionalization of life (cf. Iaconesi 2017). ${ }^{6}$ The "sharing economy" is a misnomer for "extending the deregulated free market into previously private areas of our lives" (Scholz 2016a, p. 3) or monetizing private possessions that were previously outside of the market (Belk 2014b; Eckhardt and Bardhi 2016; Munger 2018; Scholz 2016b; Slee 2015). In other words, people have already been dropping friends off at the airport, having them take the dogs out while they are away, or letting them use their car if necessary. Respectively, Uber, DogVacay, and Drivy are firms that have digitalized and monetized such sharing practices that used to be free. Airbnb in particular "is an old idea, being replicated and made relevant again through P2P networks and new technologies. [...] Online exchanges mimic the close ties once formed through faceto-face exchanges in villages, but on a much larger and unconfined scale" (Botsman and Rogers 2010a, p. xiv). In this Age of Access, Rifkin (2000) pointed out that "life is becoming more and more commodified" (p. 9) and that commerce, culture, communities, and private or personal relationships are becoming increasingly indistinguishable. ${ }^{7}$ Have we entered the Age of Excess where every business opportunity to increase profits has been pursued, blurring the lines between what is private and what can be bought or, to be more accurate, rented?

Collaborative consumption is a new phenomenon that is provoking turbulent adjustments to business activities and consumer behavior because of the associated socioeconomic tensions. Several studies of consumer communities and collaborative practices characterized by $\mathrm{P} 2 \mathrm{P}$ exchanges show that ideologies of solidarity, mutuality, generalized reciprocity, and communal belonging coexist with the contrasting ideologies of profit maximization, self-interest, and utilitarian motives (e.g., Corciolani and Dalli 2014; Habibi et al. 2016; Herbert and Collin-Lachaud 2017; Martin et al. 2015; Papaoikonomou and Valor 2016; Perren and Kozinets 2018; Philip et al. 2016; Prabhat 2018; Scaraboto 2015; Schor et al. 2016). However, a single perspective would fail to fully address the dynamics of collaborative consumption (Lamberton 2015), so researchers must combine both the logic of exchanges outside the market (i.e. non-monetary practices) and those that are marketmediated (i.e. monetary exchanges) when investigating access-based consumption (Eckhardt 
and Bardhi 2016) by considering 'both/and' rather than 'either/or' approaches. As such, this thesis investigates the socio-economic tensions within what I have termed the Heart \& Wallet paradox of collaborative consumption (see Table 1) in line with paradox theory (Lewis 2000; Schad et al. 2016; Smith and Lewis 2011; Smith and Tracey 2016) and based on the debate on the "sharing economy" and my research on the phenomenon during my doctoral studies.

Table 1. The Heart \& Wallet paradox of collaborative consumption.

\begin{tabular}{ll}
\hline Heart (sharing logic) & Wallet (market logic) \\
\hline Driven by altruism & Driven by yield management \\
Communal/pro-social orientation & For-profit/commercial orientation \\
Remedy for a hyper-consumerist culture & Neoliberalism on steroids \\
Praise for innovative solutions & Illusion of solidarity and precariousness \\
Public interests & Private interests of for-profit companies \\
Dispersion/decentralization & Concentration/centralization \\
Autonomy/empowerment & Control/surveillance \\
Strong social ties & Weak social ties \\
Socio-cultural exchanges (socially mediated) & Socio-technical exchanges (market mediated) \\
Intrinsic value & Extrinsic value \\
Private goods & Public goods/commodities \\
Joint possessions (shared ownership) & Access-based consumption (rental) \\
Analog (offline) & Digital (online) \\
Cooperation & Corporation \\
Homo cooperans & Homo economicus \\
Sharing as a choice & Sharing as a necessity \\
Local scale (grassroots) & Global scale (globalization) \\
Personal interactions & Impersonal interactions \\
\hline
\end{tabular}

On the one hand (the heart), collaborative consumption concerns cooperation, collaboration, decentralization, and reduced consumption, and it is thus often framed as a remedy for a hyper-consumerist culture (cf. Richardson 2015) and praised for innovative solutions to societal problems. Participants are pro-social, consider their peers as friends they can trust, and are focused on the intrinsic value of their involvement - in other words, sharing with their heart. As homo cooperans (cf. De Moor 2013; Filippova et al. 2015), they choose to participate in $\mathrm{P} 2 \mathrm{P}$ exchanges because it evokes positive emotions. As mentioned earlier, organizations developing online platforms emphasize the sharing logic, although it is in fact a form of pseudo-sharing.

On the other hand (the wallet), collaborative consumption concerns corporation, disruption, market creation, and globalization, and it is thus often framed as neoliberalism on steroids (cf. Morozov 2013) and praised for its potential revenues (e.g., PwC 2015). ${ }^{8}$ 
Participants are commercially orientated, maximize personal outcomes, and are focused on the extrinsic value of their involvement - in other words, sharing with their wallet. As selfinterested homo economicus (cf. Eckhardt and Bardhi 2016), they participate in P2P exchanges because it is financially attractive rather than as a way of interacting with other people. Firms design platform mechanisms to generate revenues from P2P exchanges, and they compete to increase their market dominance.

Paradoxes have been defined as persistent contradictions and tensions between interdependent elements (Lewis 2000; Schad et al. 2016; Smith and Lewis 2011; Smith and Tracey 2016). As society has become ever more complex, organizations have lived and thrived through dynamic yet persistent tensions (e.g., between individual and team performance, globalization and localization, and the short and long term), and scholars have effectively investigated phenomena through the lens of paradox theory to enrich existing theories in their discipline. Paradox is a meta-theory with its set of key constructs and principles existing across phenomena, contexts, and theories (Poole and van de Ven 1989; Schad et al. 2016). In particular, paradox theory offered itself as insightful in the strategic management and organization literature by providing a more thorough understanding of constructs and their relationships, as well as the dynamics of organizational tensions, while also enriching extant theories and the processes of theorizing (Putnam et al. 2016; Schad et al. 2016).

Paradoxes have been used to a lesser extent in the marketing literature, although the potential of paradox theory has been denoted as highly relevant and resonant for advancing knowledge of contemporary consumer behavior (Mick and Fournier 1998). The service paradox was used to conceptualize the servitization challenges faced by manufacturing firms that fail to transition from goods to services (Gebauer et al. 2005). More recently, the tensions for firms managing cooperation and competition simultaneously (i.e. coopetition) as well as other demand and supply paradoxes (e.g., concord/conflict and integration/differentiation) in the $\mathrm{B} 2 \mathrm{~B}$ sector were investigated more dynamically and holistically through the lens of paradox theory (Gölgeci et al. 2019; Tidström et al. 2018). Hillebrand et al.'s (2015) conceptual development of stakeholder marketing theory was partly based on paradox theory to show that firms need a "paradoxical thinking" capability to acknowledge and learn from the multiple tensions between stakeholder interests (that there is not necessarily a simple solution). Ozanne et al. (2016) also employed paradox theory to clarify the complexity surrounding sustainable management - i.e. the tensions within the "triple bottom line," such as maximizing profits while minimizing the ecological footprint. O'Driscoll's (2008) review of the paradoxical tensions in marketing showed that "there is benefit in addressing many marketing phenomena in a non-exclusionary, both-and approach. Many phenomena are seemingly contradictory yet interrelated at the same time. In a poststructuralist, after modern 
world, an exclusionary, either-or approach, with one perspective or force seeking to overcome the other, is likely to be of limited use" (p. 102). The marketing discipline and service research in particular (cf. Gustafsson and Bowen 2017) could thus benefit from paradox theory to better understand these complex phenomena without intending to resolve the tensions that exist across multiple contexts, concepts, methodological approaches, and variables.

In this thesis, the lens of paradox theory is used to help overcome the contradictions between the sharing logic and the market logic that are simultaneously at play in collaborative consumption at both the individual level and the firm level. The Heart \& Wallet paradox reconciles this pluralism of theoretical concepts, approaches, and perspectives by engaging and accommodating these tensions without resolving them (O'Driscoll 2008; Schad et al. 2016; Smith and Tracey 2016). In particular, the thesis is concerned with identifying and categorizing the type of tensions found in the Heart \& Wallet paradox.

Four categories of paradoxical tensions - identified as belonging, performing, learning, and organizing (Lewis 2000; Smith and Lewis 2011) - have been used to explore and conceptualize types of paradoxes. Most management studies that use the lens of paradox theory have adopted such typological aims to discern and describe tensions within and across organizations between distinct elements and highlight their contradictory and oppositional nature (particularly learning paradoxes, such as exploration/exploitation, according to Schad et al. 2016). Sustainability research (Ozanne et al. 2016; van Bommel 2018) and servitization research (Kohtamäki et al. 2018) have also described the underlying facets of a paradox with these four categories. Paradoxes of belonging are based on the tensions between selfexpression (individual identity) and group affiliation (collective identity); paradoxes of performing are based on contradictory interests between multiple stakeholders (e.g., cooperation/competition); paradoxes of learning are created from tensions between the old (stability) and the new (change); and paradoxes of organizing result from the conflicting demands of organizational processes and structures, such as control/autonomy or alignment/flexibility (Lewis 2000; Schad et al. 2016; Smith and Lewis 2011; Ozanne et al. 2016).

\subsection{Research problem}

Botsman and Rogers (2010a, 2010b) popularized the entire "sharing economy" under the term collaborative consumption. ${ }^{9}$ They distinguished three systems:

- Product-service systems: commercial access-based services, wherein the firm uses its own resources to provide services to customers. 
- Redistribution markets: online platforms facilitating P2P exchange based on both temporal access and ownership transfer of private resources, both online and offline, with or without money.

- Collaborative lifestyles: online platforms enabling P2P exchanges of "less tangible assets such as time, space, skills, and money" (2010b, p. 30).

However popular, this conceptualization is problematic, as some of the academic literature has used the terms interchangeably without distinguishing between the diversity of firm roles and consumer behaviors. Collaborative consumption has been used to refer to practices that are not compensated monetarily, such as cases of borrowing that are non-market mediated or swapping that are free (e.g., Albinsson and Perera 2012), or practices that are not based on temporary access, such as recirculation platforms facilitating a permanent change of ownership (e.g., Ertz et al. 2018a, 2018b; Lindblom et al. 2018), or practices that are not based on P2P exchanges or private resources, such as commercial carsharing services that enable a sequential shared utilization of a firm's cars (e.g., Hwang and Griffiths 2017), and that do not concern existing and underutilized assets but new assets on the market offered by freelancers and independent contractors who are professionals and do not only seek compensation for underutilization (cf. Acquier et al. 2017; Belk 2014b; Frenken and Schor 2017).

The misleading conceptualization and confusing findings regarding collaborative consumption is a multi-fold problem due to its many interrelated aspects.

1. The "sharing economy" context relates to both $\mathrm{P} 2 \mathrm{P}$ exchanges between people using their own private resources (i.e. collaborative consumption) and between a firm's resources and customers (i.e. commercial access-based services).

2. $\mathrm{P} 2 \mathrm{P}$ exchanges can be provided by either private individuals (i.e. collaborative consumption) or trained professionals (i.e. on-demand services in the gig economy).

3. P2P exchanges based on access can either involve money (i.e. rental) or not (i.e. borrowing).

4. P2P exchanges can involve either a permanent transfer of ownership (i.e. recirculation systems) or only temporary access to private resources (i.e. rental/borrowing), which are eventually restituted.

5. Organizations can be for-profit (i.e. firms) or non-profit (i.e. grassroots movements).

6. Monetary involvement in $\mathrm{P} 2 \mathrm{P}$ exchanges can be a compensation (i.e. cost sharing scheme) or a remuneration (i.e. for-profit orientation).

While using the terms sharing economy and collaborative consumption interchangeably is understandable in the popular debate as a way to bait readership, the misleading use of these terms in academic literature reveals a lack of understanding regarding which phenomenon is actually under investigation. In particular, previous research that failed 
to take into consideration the access dimension (i.e. no transfer of ownership) and the P2P dimension (i.e. not B2C) of collaborative consumption naturally yielded opposing results and confusing terminology.

\subsection{Research purpose and questions}

The purpose of this thesis is to advance the understanding of the tensions between the sharing and market logics of collaborative consumption. To do so, two perspectives are adopted regarding the Heart \& Wallet paradox: (1) the firm's perspective as an enabler of collaborative consumption, and (2) platform users' perspectives (also called participants and, more precisely, peer providers and consumers).

The firm's perspective considers how owners of online platforms in the access paradigm seek to benefit from adapting the rules of e-commerce to privately-owned and underutilized resources. They aim to disrupt traditional industry incumbents by leveraging online platforms in a cost-efficient and convenient way. Firms often face a problem of reaching a critical mass of platform users to balance and match consumer needs with a supply of peer providers. The more platform users there are, the more potential matches and thus commissions. To attract and retain users on their platforms, firms nurture the sharing logic of collaborative consumption, even though there is monetary compensation (i.e. not true sharing). Firms facilitating collaborative consumption operate along the blurred lines of the Heart \& Wallet paradox. The first perspective has the following research questions:

RQ 1. How are private resources monetized by firms through collaborative consumption?

RQ 2. How do firms stimulate the sharing logic of collaborative consumption?

The second perspective considers platform users who participate in P2P exchange without the firm's direct involvement-i.e. users who are not trained employees but equal members of a network (i.e. peers) aggregated by online platforms and who can take on two roles. This dichotomy between peer providers and consumers means that each role entails different tasks and objectives for collaborative consumption and that the same platform user can switch between roles over time. Most often, collaborative consumption participants become members of the online community governed by the firm when registering their profile on the platform; i.e. they are likely to share feelings of belonging to a community. Whereas firms eventually develop digital algorithms and computer systems that are reliable, collaborative consumption participants are all unique people. They are the ones who enact the actual practices, who conduct the $\mathrm{P} 2 \mathrm{P}$ exchanges, and who carry their understanding into 
the phenomenon of interest - this is the Heart \& Wallet paradox of collaborative consumption. The second perspective has the following research questions:

RQ 3. What are the effects of monetary compensation for collaborative consumption participants?

RQ 4. What is the role of communal belonging for participants in collaborative consumption?

\subsection{Contribution of appended papers}

Four papers that respond to the research questions are appended to this thesis (see Table 2). The first two papers adopt the firm's perspective, while the latter two mostly adopt the participant's perspective. The empirical material collected for the appended papers was further used in this thesis to provide an extensive discussion of collaborative consumption and the Heart \& Wallet paradox. In other words, this thesis is based on the appended papers, but it goes much further with its own contribution to better understand the studied phenomenon.

Table 2. The papers' contribution to the research questions.

\begin{tabular}{llllll}
\hline & Perspective & Practice & & & \\
\hline RQ 1 & Firm & P2P car rental, ridesharing & I & II & \\
RQ 2 & Firm & Leasing*, P2P car rental, ridesharing & II & III & \\
RQ 3 & Platform users & Ridesharing & & III & \\
RQ 4 & Platform users & Ridesharing & III & IV \\
${ }^{*}$ Leasing services are instances of commercial access-based consumption and not collaborative consumption.
\end{tabular}

Paper I aims to improve the clarity of the concept of green service in service research. It does so by identifying different resource integration processes for environmental sustainability, which entails different roles for the service firms and their customers. Importantly, Paper I demonstrates that thrift stores for secondhand goods (e.g., the Red Cross) and online platforms facilitating collaborative consumption (e.g., Skjutsgruppen and GoMore) differ regarding the terms of their access-based consumption (i.e. change of ownership or not) and exchange relationships (i.e. P2P or B2C). As such, this multiple case study contributes to the first research question to further understand how firms temporarily redistribute private resources to increase their utilization. 
Paper II is an empirical investigation of a business model portfolio in the shared mobility sector and is based on one extensive case study (GoMore). The analysis reveals the key resources and capabilities shared across multiple business models, which complement and mutually reinforce the firm's activities. Paper II further points out the difference in revenue streams between leasing contracts (i.e. commercial access-based services exhibiting sequential usage) in partnership with an external provider, and $\mathrm{P} 2 \mathrm{P}$ car rental and ridesharing services (i.e. collaborative consumption exhibiting direct interactions between peer providers and consumers) based on a matchmaking fee (i.e. platform business models). This contributes to the first and second research questions from the firm's perspective by investigating how business models are operated to monetize private resources.

Paper III identifies three styles of collaborative consumption by focusing on what people actually do when participating in the ridesharing practice (i.e. through a study of BlaBlaCar). This enables a more nuanced view than the true-sharing-or-not dichotomy. Within the same practice, some participants can adopt the communal style (embedded in the sharing logic) while others can adopt the consumerist or opportunistic styles (embedded in the market logic). As such, Paper III offers an in-depth exploration of the tensions between sharing and market exchange by highlighting the digitalization of the hitchhiking practice into ridesharing and the transformation of the grassroots movement and sharing ethos by the platform business model. It contributes mostly to the third and fourth research questions from the user's perspective by investigating how they perceive monetary contributions and communal identity — but it also responds to the second research question through the firm's role in institutionalizing practices and shaping the community.

Paper IV focuses on the role of communal belonging for online platform users for ridesharing (i.e. through a study of Skjutsgruppen). Collaborative consumption participants who identify with the community (e.g., ridesharing) are more likely to increase their platform usage. Paper IV also proposes new determinants of service satisfaction in collaborative consumption settings (i.e. cooperation from peers and service convenience). Moreover, the extent to which the collaborative consumption experience is perceived as true sharing (vs. sharewashing) increases the influence of communal identification and decreases the influence of loyalty with respect to platform usage. As such, it contributes to the fourth research question from the participant's perspective by considering not only their feelings of belonging to a community but also their use of the platform and loyalty-which are key metrics for firms. 


\subsection{Positioning of the thesis}

Literature reviews showed that publications on the "sharing economy" have increased exponentially since 2010 (Arcidiacono et al. 2018; Ertz and Leblanc-Proulx 2018; Fritze et al. 2018; Lamberton 2015). Despite this growing academic interest, the conceptual definition and understanding of the collaborative consumption phenomenon has remained "somewhat messy" (cf. Albinsson and Perera 2018, p. 6). In particular, consumer researchers argue conceptually for the distinction between sharing and other modes of consumption to reflect a return to the original meaning of the term. Cooperative activists, and a few computer science scholars, tend to argue for the consideration of technology and cooperatives as a commons and for the equitable distribution of ownership - "trying to figure out a real sharing economy" (cf. Bauwens 2018, original emphasis). ${ }^{10}$ Service researchers are not concerned by this sharewashing debate and are more interested in adapting existing theoretical models and pursuing empirical studies rather than conceptual discussions. Sustainability researchers mostly focus on the ecological impact of increasing the utilization of existing resources for a large array of collaborative economy practices. ${ }^{11}$ Although service researchers have emphasized the importance of service provision (i.e. rental business models) and value cocreation in multi-actor ecosystems, and consumer researchers have investigated alternative modes of consumption for the last two decades, there has been a lack of attention to the new role of service firms as facilitators of $\mathrm{P} 2 \mathrm{P}$ exchanges and how collaborative consumption engages participants in their roles as platform users.

By investigating the tensions between the sharing and the market logics through the Heart \& Wallet paradox, this thesis advances the understanding of collaborative consumption. As such, it contributes to the positioning of the phenomenon in relation to service research focusing on the access paradigm for B2C relationships (e.g., Hazée et al. 2017; Schaefers et al. 2016b). A recent literature review of the "sharing economy" and service research reveals a fragmented field that lacks agreement on the unit of analysis and integration between theoretical perspectives (Fritze et al. 2018). This thesis provides a broader and more coherent understanding of collaborative consumption within the access paradigm.

In particular, the empirical research included in the four appended papers responds to the latest Marketing Science Institute research priorities for 2018-2020 regarding "the implications of platform economics and the sharing economy for marketing organizations" (MSI 2018). The heart perspective on collaborative consumption contributes to the aim of service research to better understand how to develop and maintain customer communities that benefit both the members and the firm (Ostrom et al. 2015). The wallet perspective on collaborative consumption addresses service research that is concerned with different business models (Andreassen et al. 2018; Benkenstein et al. 2017; Benoit et al. 2017; 
Breidbach and Brodie 2017; Field et al. 2018), the potential for new markets through P2P exchanges (Ranaweera and Sigala 2015), the role of technology in facilitating service operations (Breidbach et al. 2018; Fehrer et al. 2018), and the professionalization of peer providers (Benoit et al. 2017).

\subsection{Thesis outline}

There are six chapters in this thesis, which are followed by the four appended papers. Chapter 2 presents the theoretical background, perspectives and concepts that underline this thesis in order to situate collaborative consumption in relation to the foundation of the marketing literature on the concept of exchange, the emergence of consumer research on non-market mediated consumption, and service research on access-based consumption. This is done to complement the theoretical perspectives used in the appended papers and to define and explain relationships between the concepts that are central to this thesis. Sharing is considered the purest form of non-market mediated practice and symbolizes the logic of the heart, and market exchange symbolizes the logic of the wallet. Chapter 3 relates to the research process and methodological approaches adopted for data collection and analysis. I present my perspective regarding the use of both qualitative and quantitative research and reflect on the research design. Chapter 4 summarizes the appended papers in the light of the specific purpose of this thesis. Papers I and II employ the case study methodology, and they are concerned with the firm perspective; Paper III is based on an in-depth exploration of the ridesharing practice, and it is concerned with both firm and platform user perspectives; and Paper IV involves a cross-sectional survey of platform users, and it is thus concerned with this perspective. The personal contribution to each paper is also specified. Chapter 5 discusses the research findings according to the two perspectives adopted in this thesis; it answers the research questions, and it situates my contribution towards better understanding the phenomenon of collaborative consumption through the Heart \& Wallet paradox. Chapter 6 concludes by reviewing the scope and limitations of this thesis and proposing some directions for future research. The appendices and a glossary of key terms and definitions are included before the appended papers. 


\section{CHAPTER 2}

\section{THEORETICAL BACKGROUND}

Every man thus lives by exchanging, or becomes, in some measure, a merchant, and the society itself grows to be what is properly a commercial society.

- A. Smith (1776)

This chapter begins by situating collaborative consumption on a continuum between sharing and market exchange, which respectively represent the two poles of the Heart \& Wallet paradox. As such, this chapter reviews the development of the marketing discipline based on exchange, the utilitarian function of trading goods (e.g., commodities), and the dynamics of markets and buyer/seller relationships. This is followed by the evolution of consumer research on alternative modes of consumption based on shared ownership, true sharing, access-based consumption, or non-market mediated exchanges. Finally, the thesis' theoretical framework of service marketing adopted to describe, understand, and explain the phenomenon of collaborative consumption is presented based on perspectives, concepts, and models, such as the access/rental paradigm, nonownership services, ${ }^{12}$ commercial sharing systems, and access-based services. 


\subsection{The collaborative consumption continuum}

As mentioned earlier, collaborative consumption practices are often referred to as the "sharing economy" phenomenon, although they are not sharing behaviors because the temporary exchanges of private resources between peer providers and consumers are monetized and organized in a digital marketplace (e.g., Belk 2014b). In short, renting is not the same as borrowing. However, P2P rental also differs from traditional market exchanges (i.e. selling/buying) not only because access to resources is only temporary, without the permanent transfer of ownership, but also because rental takes place directly between people and not from a firm. As such, collaborative consumption is not simply the new generation of e-commerce websites that allows professionals to sell goods.

Collaborative consumption resides on a continuum between the two opposite logics of sharing and market exchange (Belk 2014b; Habibi et al. 2016). In particular, Belk (2014b, p. 1597) argued that "collaborative consumption occupies a middle ground [...], with elements of both." That is, there is no exact position on the continuum and no clear conceptual boundaries for collaborative consumption (see Figure 3). However, true sharing (i.e. nonmarket mediated exchange) and market-mediated exchange (Eckhardt and Bardhi 2016; Belk 2010) are the two opposing concepts that are most relevant to better understanding the tensions embedded in the Heart \& Wallet paradox of collaborative consumption.

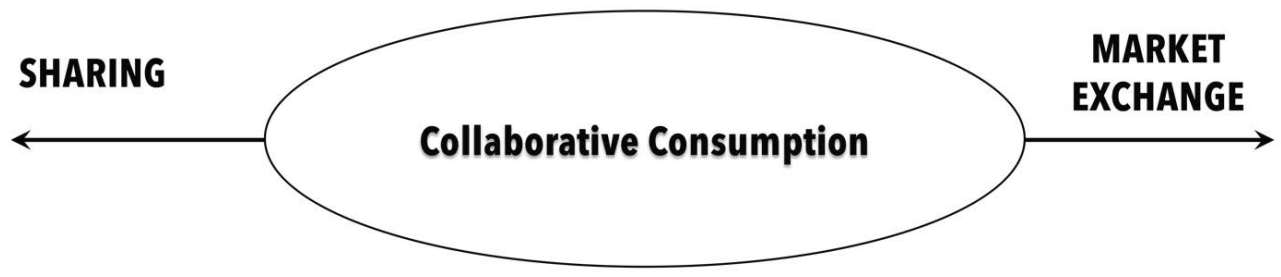

Figure 3. The collaborative consumption continuum.

Note: based on Belk (2010, 2014b) and Habibi et al. (2016).

\subsection{Market exchange}

Exchange theory has been at the heart of the conceptualization of marketing as a distinct discipline from economics, particularly by considering exchange (and later relationships) between customers buying goods and suppliers producing offerings in a balanced market (Alderson 1958; Bagozzi 1975; Bartels 1944, 1951; Houston and Gassenheimer 1987; Hunt 1976; Kotler 1972). Marketing has been considered not only as a business activity but also as an activity organized by non-profit organizations (Kotler and Zaltman 1971); this emphasizes the need to move away from a focus on markets (too narrow) to a general idea 
of exchange (Kotler and Levy 1969; Hunt 1976). From this perspective, the essence of marketing is the transaction - a "form of exchange of values between two parties" (Hunt 1976, p. 25).

In Marketing as Exchange, Bagozzi (1975) argued that the concept of exchange in marketing needed to be broadened beyond a focus on the direct transfer of tangibles and dyadic relationships (e.g., buyer/seller), stating that, "in reality, marketing exchanges often are indirect, they may involve intangible and symbolic aspects, and more than two parties may participate" (p. 32). He delineated three types of exchange: restricted, generalized, and complex. Whereas restricted exchange refers to two-party reciprocal relationships (e.g., buying/selling bread), generalized exchanges involve at least three parties in "univocal, reciprocal relationships" such that all parties benefit indirectly from exchanges made by others. A restricted exchange is represented by $\mathrm{A} \rightarrow \mathrm{B}$ (i.e. $\mathrm{A}$ and $\mathrm{B}$ are two distinct actors/parties), and a generalized exchange is represented by $A \rightarrow B \rightarrow C \rightarrow A$ (i.e. a loop). Complex exchanges are dyadic relationships in a web of relationships ( $A \leftrightarrow B \leftrightarrow C$ ). In summary, exchanges involve a transfer of something from one party to another.

In contrast to restricted exchanges, "generalized and complex exchanges are also present in relatively unconscious systems of social and economic relationships" (Bagozzi 1975, p. 34). Here, the emphasis is on the consideration of other actors and chains of relationships in marketing exchange in contrast with the myopic view of exchange as a strictly rational and dyadic economic activity. Bagozzi further argued that exchanges involve both utilitarian and symbolic value, and "it is very difficult to separate the two" (p. 36). That is, monetary practices are symbolically laden with "the social and psychological significance of the experiences, feelings, and meanings of the parties in the exchange" (p. 36).

Houston and Gassenheimer (1987) reviewed this development of marketing theory based on the concept of exchange, and they confirmed that the value of exchange resides not only in the "something of value" (i.e. the good, service, or offering) but also in the act of exchange. That is, whereas economists consider raw materials and manufactured goods as comparatively homogenous (i.e. without regard to the production source), marketers go beyond the trade in commodities to emphasize the relational aspect of exchange- even when they take place between market buyers/sellers who intend to maximize their outcomes (Alderson 1958).

Furthermore, Houston and Gassenheimer (1987) argued that all participating parties in the exchange have the shared goal of enhancing their own "potency" (i.e. value). In other words, market exchanges are driven by self-interest. For example, the sellers want to get the highest price for their goods, while the buyers want to obtain the maximum amount of goods for their money. Thus, to a certain extent, each side in such an exchange depends on the other-one buyer/seller can always look elsewhere for another exchange partner to find a 
better compromise. As such, market exchanges are characterized as impersonal and independent, as buyers/sellers can change identity, and it does not matter who buys/sells something as long as everybody maximizes their gains from the exchange (Belk 2010; Scaraboto 2015). Like Bagozzi (1975), Houston and Gassenheimer (1987) also considered value as both extrinsic (from the market, i.e. the exchange value) and intrinsic (not derived from the market); however, they also differentiated between value-in-use and inventoryvalue.

Clark and Mills (1979) used the term exchange relationship to depict the expectation of reciprocation that business partners, acquaintances, and strangers have with each other, whereas relationships between friends and family members where people care for each other are characterized as communal. It is important to note the difference between the diverse types of reciprocation or reciprocity (cf. Sahlins 1972, pp. 193-195):

1) Generalized, indefinite, or indirect reciprocity: "free gift," sharing, "help," "generosity," and putatively altruistic actions with no expectation of receiving anything in return.

2) Direct tit-for-tat reciprocity, or balanced reciprocity: direct exchange, trade, or buying/selling wherein the equivalent of the thing received is expected in return and without delay.

3) Negative reciprocity: haggling, bartering, gambling, theft, and other attempts to get something for nothing with impunity; transactions conducted towards net utilitarian advantage.

Houston and Gassenheimer (1987) differentiated between different types of exchange based on the social distance between the parties involved. They considered resource allocation practices within a household (e.g., parent-child relationship) as generalized exchange (based on generalized reciprocity) and market-mediated activities as balanced exchange (based on balanced reciprocity, such as buyer/seller transactions). However, Kotler previously considered family reallocation of resources as distinct from the concept of exchange, whereas Houston and Gassenheimer (1987) broadened the concept of exchange to integrate such practices (i.e. as generalized exchange).

One criticism of the economic theory behind marketing (i.e. capitalism) is that it has reduced diverse modes of exchange (e.g., bartering) to market exchange, "objectively and subjectively oriented towards the maximization of profit, i.e. (economically) self-interested, it has implicitly defined the other forms of exchange as noneconomic and therefore disinterested" (Bourdieu 1986, p. 46, original emphasis). There are other forms of exchange with more immaterial and symbolic benefits - i.e. there are exchanges outside of the market that are based not only on economic capital but also on cultural capital and social capital (Bourdieu 1986). In their review, Houston and Gassenheimer (1987) emphasized that the 
terms of exchange (i.e. contract) are established based on a common understanding of the reservation price among all parties - otherwise there is no exchange at all. That motivates the invention of money as a medium of exchange to facilitate trade (cf. Smith 1776 [1976]) ${ }^{13}$. That is to say that market exchanges are monetary by default. "Things of value" have a price and can be bought and sold (cf. Sandel 2012). However, it is unclear what non-monetary practices are (e.g., in barter economies based on direct reciprocity). They would not be called non-exchanges but non-market mediated exchanges (cf. Eckhardt and Bardhi 2016).

Interestingly, the American Marketing Association (AMA) removed the term "exchange" from its original 1985 definition of marketing when it was revised in 2004 - the new definition was highly criticized by the scholarly community (Gundlach 2007; Sheth and Sisodia 2006). In the subsequent 2007 revision, exchange was brought back into the definition though not as the central focus of marketing - creating, communicating, and delivering were also described as important activities (Gundlach and Wilkie 2009). In 2013, the AMA decided on the following definition for the discipline: "Marketing is the activity, set of institutions, and processes for creating, communicating, delivering, and exchanging offerings that have value for customers, clients, partners, and society at large." ${ }^{14}$ That is, marketing scholarship is no longer concerned only with buying/selling commodities.

In summary, marketing was created based on the concept of exchange and transactions between buyers and sellers, and scholars tried to integrate all forms of exchange under the marketing umbrella, including non-market mediated and not utilitarian consumer behavior. The market logic relates to monetary exchanges involving a transfer of ownership (something of value) and the goal-seeking behavior of maximizing utility (self-interest) for all independent and impersonal parties (at least two), who are satisfied from the joint maximization of all utility functions (Alderson 1958; Bagozzi 1975; Belk 2010; Eckhardt and Bardhi 2016; Houston and Gassenheimer 1987; Hunt 1976; Scaraboto 2015).

\subsection{Consumer research on alternative modes of consumption}

Within the marketing discipline, a group of researchers focus specifically on consumer behavior, i.e. how humans behave in the role of consumers; this includes not only acquisition but also usage and disposition practices and emphasizes the consumption context (cf. "the study of consummation," Holbrook 1987, p. 128). As a subdiscipline, consumer behavior research had its origins in marketing in the 1950s and marked a shift from teaching marketing management (i.e. business practitioners) to understanding consumers from a more theoretical basis (Deighton 2007; Folkes 2002; MacInnis and Folkes 2010). In summary, consumer researchers are concerned with knowledge and discovery (rather than business implications) 
in the study of the consumption of goods and services not only through markets but also through alternative modes of consumption such as sharing.

The most influential researcher on sharing in the consumer behavior literature is Belk. Prior to the Consumer Odyssey (Belk et al. 1989), ${ }^{15}$ Belk and colleagues conducted a prestudy at the Red Mesa Swap Meet in New Mexico - a fenced parking lot that served as a market on weekends and resembled a campsite and a fair - to test their qualitative research method toolbox. They conducted an ethnography of the swap meet, which they described as "a curious anachronism in contemporary U.S. buying and selling and involves substantial second order (used) good sales" (Belk et al. 1988, p. 449). The researchers found that swap meet sellers behave differently from professional sellers. For example, "sellers of personally used items are selling (or separating themselves from) the part of themselves that still adheres to the object that has been a part of their lives" (p. 465). They also argued that participants in swap meets want to be free from institutional constraints, which is interesting since they actually still endorse the institutionalized market roles of buyers and sellers.

Even though swap meets have existed for a long time, Belk and colleagues entered these environments with open eyes, making the familiar strange and exploring the sociocultural significance of these alternative markets using methods that are usually employed by anthropologists (Belk et al. 1988; Sherry 1990). Aiming to study how/what/why/where consumers consume, the Odyssey was a seminal moment not only for qualitative consumer researchers but also for the subsequent development of marketing research into diverse consumer behaviors conceptualized as different from the usual buyer/seller relationships or the traditional acquisition of goods (cf. Bradshaw and Brown 2008). In particular, Belk's research on possessions (i.e. materialism and the extended-self) led him to the conceptualization of sharing in the consumer behavior literature (Belk 2010), which has been pivotal in the development of other related concepts to discuss the phenomena at hand (e.g., collaborative consumption and non-monetary practices).

\section{True sharing}

Belk's interest in sharing was provoked by an invitation to an urban mobility seminar at ESCP Paris in 2006 called To buy or to hire consumer goods: a societal question (cf. Jallat 2006), for which he prepared a presentation on the extended self, gift giving, and possessions (Belk 2017). Belk's first conceptualization of sharing puts the emphasis on shared consumption rather than individual ownership. ${ }^{16}$ He wrote:

"In sharing, two or more people may enjoy the benefits (or costs) that flow from possessing a thing. Rather than distinguishing what is mine and yours, sharing defines something as ours. [...] all of those involved in the sharing 
have something (a share) of the costs or benefits of a thing. Sharing, as used here, includes voluntary lending, pooling and allocation of resources, and authorized use of public property, but not contractual renting, leasing, or unauthorized use of property by theft or trespass. We can share not only places and things, but also people and animals (to the extent they are ours to share), as well as our ideas, values, and time" (Belk 2007, p. 127, original emphasis).

Belk highlighted the potential for sharing by using the anthropological literature (huntergatherer societies who share food through resource allocation mechanisms, cf. Widlok 2017), as well as the recent emergence of carsharing, and the pitfalls of the Internet. Importantly, Belk attempted to define sharing as "the act and process of distributing what is ours to others for their use as well as the act and process of receiving something from others for our use" (p. 127). In summary, sharing is about shared ownership or joint possessions - not market exchanges, such as rental.

In Sharing, Belk (2010) further exposed modern sharing practices and argued that sharing is fundamentally different from market exchanges. Sharing is conceptualized as a mode of consumption that contrast with the "existing thought in the field" (p. 716), i.e. consumer behavior was tied to and dominated by the concept of market exchange. In other words, sharing is not a new behavior per se but enters the realm of consumer behavior as an alternative mode of consumption. Throughout the conceptual article, sharing is distinguished from the prototypes of gift giving and commodity exchange (i.e. buying bread from a store). Commodity exchange is simply referred to in this thesis as market exchange. Belk (2010) built on his earlier definition of sharing (Belk 2007, p. 127), ${ }^{17}$ to propose two prototypes of sharing - mothering and the pooling of resources within the family - to make it easier to compare the characteristics of sharing with gift giving and market exchange. That is, a mother shares her body, milk, care, and love with the infant without expecting anything in return, particularly not money. Specifically, "both gift giving and commodity exchange involve transfers of ownership, whereas sharing involves joint ownership, at least de facto" (Belk 2010, p. 720). As things are not owned individually but in common, there is no duality of roles (giver vs. receiver or buyer vs. seller), only mutuality. However, joint ownership alone is not sharing — for example, those "people who see themselves as using their share of these possessions for a time [...] is actually more of a self-interested commodity exchange" (Belk 2010, p. 728). That is, it is also the lack of direct reciprocity and self-interest that characterizes sharing. Moreover, unlike market exchange, sharing is likely to involve caring and love, to be interpersonal and dependent, and to create communal bonds (Belk 2010).

Social psychologists have shown that people form communal sharing relationships based on generalized reciprocity (Clark and Mills 1979; Fiske 1992). That is, "communal sharing relationships are based on a conception of some bounded group of people as 
equivalent and undifferentiated" (Fiske 1992, p. 690). This involves kindness, altruism, love, cooperation, collectivism, and shared identity, and such communal relationships are the basis for constituting a social group: exchanges within a community involve social relationships where actors participate in consumption and production with no direct reciprocity-which is in contrast with exchange relationships (Clark and Mills 1979; Fiske 1992). In line with this, Belk argued that sharing is driven by altruistic motives, a sense of commonality, indirect economic benefits, and a need for social interactions, which is embedded in trust and bonding (Belk 2010, 2014a, 2014b). That is, sharing involves communal relationships such as those that families, friends, spouses, and romantic partners tend to have (Clark and Mills 1979). Moreover, in communal sharing relationships, people treat all members of a category as equivalent (Fiske 1992), such as people sharing ownership. In other words, sharing is a socially-mediated behavior that is highly communal.

However, Belk (2007) mentioned BagBorrowOrSteal.com (i.e. the commercial rental of designer bags) and cooperative carsharing as "institutionalized versions" of sharing goods among multiple users/consumers - not within the immediate family but with strangers. Considering both cases as equal is confusing given that the first is a rental service provided by a commercial firm to successive impersonal customers, and the second is a local initiative where people pay to become members and are likely to know each other (e.g., neighbors). All the more confusing is the fact that rental (both B2C and P2P modes) is arguably marketmediated (Belk 2010), and thus it is not a form of sharing (Belk 2014a, 2014b). This apparent confusion ultimately increases the lack of conceptualization of collaborative consumption and escalates the tensions between the mixed logics of sharing and market exchange.

\section{Community-based and non-monetary consumption}

In line with the circular economy narrative of sharing usage through diverse recirculation mechanisms, but mostly facilitated by grassroots movements and non-profit organizations, diverse consumer behaviors emerged that do not involve monetary exchange and thus appear to be sharing. Examples of this are swap meets where people trade items for others (i.e. without monetary involvement), donations to charity thrift stores (i.e. without reciprocal expectation) that refurbish and resell secondhand goods (i.e. monetary exchanges), or organizations and people offering to lend their goods. Whereas swap meets are not new (cf. Belk et al. 1988), the Internet and Web 2.0 have facilitated "online-facilitated barter economies" (Belk 2014a). Examples of such online platforms include bookcrossing.com (Corciolani and Dalli 2014), freecycle.org (Kim 2017; Krush et al. 2015; Martin and Upham 2016; Nelson et al. 2007; Nelson and Rademacher 2009), landshare.co.uk (McArthur 2015), foodsharing.de or food-swapping platforms (Cruz et al. 2018; Gollnhofer et al. 2016; Schor 
et al. 2016), clothes libraries (Cruz et al. 2018; Lang and Joyner Amstrong 2018), and timebanks, such as timerepublik.com (Cruz et al. 2018; Ozanne and Ozanne 2016; Papoikonomou and Valor 2016; Schor et al. 2016).

Consumer communities performing such non-monetary practices are not primarily motivated by utilitarian concerns (e.g., financial savings) but by the feeling of social belonging and communal culture, ethical considerations, and principles of justice and fairness. Participation is driven by a wish to end the accumulation of unnecessary goods, not by throwing them away but by putting them back in the circuit of consumption. Moreover, participants in recirculation practices are motivated by anti-capitalistic and anti-consumerist ideologies, as they exchange resources without money and outside traditional markets (Albinsson and Perera 2012; Corciolani and Dalli 2014; Gollnhofer et al. 2016, 2017a, 2017b; Kim 2017; Krush et al. 2015; Martin and Upham 2016; McArthur 2015; Nelson et al. 2007; Ozanne and Ballantine 2010).

However, Belk (2014a) argued that participation in recirculation systems is not sharing. Despite their pro-social and communitarian orientation, swapping and donation platforms with no exchange of money but that still involve a transfer of ownership between traders and tit-for-tat direct reciprocity are facilitating a form of pseudo-sharing.

\section{Sharing in, sharing out, and pseudo-sharing}

Contrary to Belk, who conceptualized sharing based on the cases of mothering and household resources allocation, Benkler $(2004,2006)$ argued that "social sharing is either utterly impersonal or occurs among loosely affiliated individuals who engage in social practices that involve contributions of the capacity of their private goods in patterns that combine to form large-scale and effective systems for provisioning goods, services, and resources" (2004, p. 275). That is, this conceptualization means that sharing can also take place between strangers. Belk (2010) distinguished between acts of sharing within the extended family (e.g., siblings and parents, as well as grandparents and other family members) and outside the close family circle-described as sharing in and sharing out. Belk further defined sharing in as "extending the circle of people who can enjoy the benefits of the shared resource, [...] closer to the prototype of sharing within the family in that it involves regarding ownership as common" (p. 725). One illustration of sharing in is sharing a car among household members.

On the other hand, sharing out is defined as "giving to others [...] and is closer to gift giving and commodity exchange" (Belk 2010, p. 725). Sharing out also "preserves the self/other boundary and does not involve expanding the sphere of aggregate extended self beyond the family" (p. 726). In other words, sharing out is further away from the prototype 
of sharing as it differentiates the family and friends from strangers. One illustration of sharing out is commercial carsharing, where the use of a car is shared by different customers.

Confusingly, however, when carsharing is organized cooperatively at a local scale (e.g., 340 members in Majorna, which is a neighborhood in Gothenburg, Sweden) Belk (2010) considers it to be somehow in between sharing in and sharing out - an "instance of what has been labeled collaborative consumption (Felson and Spaeth, 1978) [...] and whether or not such collaborative consumption involves sharing in and aggregate extended self depends upon how it is consumed" (Belk 2010, p.726). In other words, the term collaborative consumption was used but not explicitly defined nor situated.

Later, Belk (2014a, 2014b) argued that collaborative consumption was not true sharing (i.e. not even sharing out) but pseudo-sharing, because of "money, egoistic motives, expectations of reciprocity, and lack of a sense of community" (2014a, p. 16). Pseudo-sharing was defined as “a wolf-in-sheep's-clothing phenomenon whereby commodity exchange and potential exploitation of consumer co-creators present themselves in the guise of sharing" (2014a, p. 7). In other words, pseudo-sharing or sharewashing (Price and Belk 2016) is to voluntarily blur the market exchanges with a sharing logic. In reality, participants in collaborative consumption are only "socially interested" by the mutual benefits of P2P exchanges, but they are not purely altruistic, as in sharing (Arnould and Rose 2016).

However, one thing that sharing and pseudo-sharing practices have in common is the societal shift away from individual ownership, material attachment, and goods accumulation towards access-based consumption.

\section{Access-based consumption}

Bardhi and Eckhardt (2012) have made a significant contribution to legitimizing consumer research on the "sharing economy" by distinguishing temporal access from private individual ownership as a mode of consumption. They defined access-based consumption as a marketmediated consumption mode of accessing resources with no transfer of ownership that is made possible by technology and peer communities - by which they meant customers using the same good sequentially rather than actual direct interactions between people as seen in the community-based and non-monetary consumption behaviors evoked in the previous section. Here, goods are made available temporarily rather than sold or donated permanently. Based on their landmark study involving 40 semi-structured interviews with Zipcar users, they conceptualized six dimensions for access-based consumption: temporality of access and usage, interpersonal anonymity, market mediation, consumer involvement (i.e. self-service), the type or nature of object accessed, and political consumerism (i.e. signaling sustainable or anti-capitalistic consumption). 
In their landmark article, Bardhi and Eckhardt (2012) showed that access-based consumption is regulated by market norms and negative reciprocity (e.g., they observed opportunistic behaviors towards the firm, the object, and other customers), that customers are motivated by self-interest and utilitarianism rather than altruistic concerns, and that they avoid identification with the car or the brand. ${ }^{18}$ This emphasizes the market logic of the "sharing economy." Importantly, they also mention that access-based consumption is close to the conceptual definition of sharing (Belk 2010) but it is nevertheless different: there is no transfer of ownership or joint ownership, and the consumer only gains access to use an object. As such, access-based consumption was not conceptualized as necessarily altruistic or prosocial, although new dimensions taking into consideration the social elements have been proposed by modifying the third dimension (i.e. consumer involvement) into consumer participation, and adding the seventh dimension of governance (Koppenhafer 2014).

In summary, "everything is a service" in the Age of Access (Rifkin 2000). That is to say, consumers find using goods on a short-term basis through service provision (e.g., rental) more convenient, flexible, and cost-efficient than acquisition and private individual ownership. The access paradigm has become a nonownership lifestyle (popular among millennials) that is focused on service experience instead of material possession. For example, the function of possessing the car as a status-signal for adulthood and autonomy has shifted to value-in-use (Rifkin 2000) rather than value-in-ownership or its inventory-value (cf. Houston and Gasseiheimer 1987).

\subsection{Service research on access-based consumption}

While marketing was established as a discipline with the exchange of goods at its core (cf. Houston and Gassenheimer 1987), the importance of service sectors in the economy continued to increase during the 1960s and 1970s. Scholars began to criticize manufacturing firms for suffering from marketing myopia (i.e. only preoccupied with converting merchandise into cash) instead of satisfying customer needs (Berry and Maricle 1973; Judd 1964; Levitt 1960). The goods vs. services debate arose (Johnson 1969) and eventually focused on service firms (Shostack 1977) with an adapted marketing nomenclature (Grönroos 1978). That is, exchanging services is different in nature from exchanging goods. The conceptualization of service as value cocreation between customer(s) and provider(s) further enabled the development of service marketing as its own discipline (see Appendix 3). Whereas the consumer behavior literature takes the perspective of the people (i.e. family and friends) who participate in access-based consumption, service research focuses on the role of organizations in enabling this new form of consumption and how firms can benefit from new opportunities for value creation. 


\section{Access/rental paradigm}

Johnson et al. (1998) were the first to consider shared usage and access from a business model perspective. ${ }^{19}$ They conceptually distinguished product-sharing services from traditional acquisition, leasing, and rental modes in the way they offer new commercial opportunities because multiple "customers have the opportunity to use the same product at different times during the same contract period" (p. 169). Their empirical study of a carsharing service launched by Daimler (i.e. customers getting access to a fleet of cars in exchange for membership and usage fees) showed that customers perceive rental costs, period of advance booking notice, return options and location flexibility, distance to parking lot, and opening hours as the most important service attributes. Johnson et al. $(1998$, p. 172) wrote that "although each vehicle is theoretically 'shared' by between three and five people, the goal is to guarantee the availability by having a vehicle stock (as long as the demand is predictable)". Hence, product-sharing services offer flexibility and convenience compared to ownership, and firms should use them to expand their portfolio of offerings and to grow and expand their market. Other than cars, goods that can be potentially shared are those that are expensive, are infrequently used, and where access can be predicted/contracted (Johnson et al. 1998).

Similar to Johnson et al. (1998), but receiving more attention, ${ }^{20}$ Lovelock and Gummesson (2004) argued that services offer the benefits of product ownership without ownership. They criticized the contemporary paradigm that differentiated services from goods based on the historic four IHIP dimensions of services for being flawed-Intangibility, Heterogeneity, Inseparability of production and consumption, and Perishability or lack of inventory (cf. Sasser et al.1978). Instead, they argued for an access or rental paradigm, in which "services offer benefits through access or temporary possession, instead of ownership, with payments taking the form of rentals or access fees" (p. 20). This is based on the definition of services as anything "other than the transfer of ownership of a tangible commodity" (Judd 1964, p. 59). As such, Lovelock and Gummesson (2004) focused on the lack of transfer of ownership in services as the basis for the access paradigm. They also identified five nonownership service categories:

- Rented goods services (e.g., renting a machine).

- Place and space rentals (e.g., manufacturing facilities).

- Labor and expertise rentals (e.g., hiring a lawyer).

- Physical facility access and usage (e.g., renting admission to a conference site).

- Network access and usage (e.g., telecommunications).

Together, both of the articles published in the Journal of Service Research emphasized how firms can leverage material assets to sell a service to customers instead of goods-i.e. offering new opportunities to satisfy customers and provide them with the benefits of ownership through rental (Johnson et al. 1998; Lovelock and Gummesson 2004). Most importantly, 
Lovelock and Gummesson (2004) envisioned the future of business activities as based on the provision of access-based consumption, through service.

\section{Nonownership services}

While nonownership was first conceptualized by Berry and Maricle (1973), Lovelock and Gummesson (2004, p. 34) dusted off the concept and used it as the basis of the access paradigm, which was defined as "marketing transactions that do not involve a transfer of ownership." Benoit (née Moeller) and Wittkowski built on the concept and posited that the burdens of ownership can be alleviated by renting goods instead. They argued that possession importance (i.e. attachment to ownership), trend orientation (i.e. trying new things), convenience orientation, experience orientation (i.e. looking for fun in consumption), price consciousness, and environmentalism would influence consumers' decision to rent rather than own (Moeller and Wittkowski 2010). ${ }^{21}$ They showed that only possession importance (negative influence) and trend and convenience orientations (positive influence) had significant effects on the adoption of nonownership services. In a subsequent study, they focused on the B2B sector due to the increasing service infusion trend of firms outsourcing, leasing, or renting to each other (Wittkowski, Moeller, and Wirtz 2013). They found that using corporate nonownership services reduces the burdens of ownership. Thereafter, in other papers, nonownership services referred solely to corporate and B2B services and new business model opportunities (e.g., acquiring and/or sub-leasing cars to Uber drivers) in the “sharing economy" ecosystem (Ehret, and Wirtz 2018; Ndubisi, Ehret, and Wirtz 2016).

In other words, the term nonownership focuses on the B2B markets of the rental or access paradigm in the service literature (Lovelock and Gummesson 2004; Moeller and Wittkowski 2010), whereas the terms commercial sharing systems or access-based services became the preferred synonyms for consumer markets. As mentioned in the introduction, I refer to these terms as communal access-based services.

\section{Commercial access-based services}

Lamberton and Rose (2012) conceptualized commercial sharing programs as marketmediated systems that offer consumers a sustainable and profitable alternative to ownership, in which participation is largely driven by cost savings, self-interest, and utilitarianism. Commercial sharing systems like Zipcar are B2C business models (i.e. market-mediated) that provide access to unique product benefits without ownership (see Figure 1 in Introduction). Such alternatives are "[...] characterized by between-consumer rivalry for a limited supply of the shared product" (Lamberton and Rose 2012, p. 109). In line with Bardhi and Eckhardt (2012) among others, they found that participation in commercial access-based services was 
largely driven by cost savings, self-interest, and utilitarianism. Moreover, possessiveness and materialist values have a negative impact on participation (Lamberton and Rose 2012).

Service research eventually adopted the term access-based services, which was defined as "market-mediated transactions that provide customers with temporally limited access to goods in return for an access fee, while the legal ownership remains with the service provider. At the core of an access-based service is thus an asset that is successively used by multiple individuals (i.e. shared) over time" (Schaefers et al. 2016a, p. 571; see also Schaefers et al. 2016b, 2018). ${ }^{22}$ The term first appeared in Schaefers' (2013a) work on the motives behind commercial carsharing participation (i.e. Car2Go). He showed that not only utilitarian motives (cost-saving and convenience) but also affective motives (environmentalism and lifestyle trends) were driving the acceptance and usage of carsharing (Schaefers 2013b). In line with this, Hazée et al. (2017) recently defined access-based services to emphasize the "unique technology-based service innovations" as characterized by (1) high customer involvement with minimal supervision from the service provider, (2) substantial interpersonal anonymity, and (3) temporal access to goods without ownership transfer. This is similar to Lamberton and Rose's (2012) conceptualization of commercial sharing systems.

Schaefers et al. (2016a) ${ }^{23}$ argued that the usage of access-based services is positively influenced by the service's utilitarian value (e.g., Car2Go) as well as financial and social risk perceptions. In another study, Schaefers et al. (2016b) showed that customer misbehavior in the context of access-based services is contagious but not if people feel part of a community. Importantly, communal identification actually reversed the contagious effect. Hazée et al. (2017) also argued that the participation motive in access-based services is to alleviate the burdens of ownership (Berry and Maricle 1973; Moeller and Wittkowski 2010), but they further showed that customers encounter the burdens of access constituted by the barriers themselves (i.e. complexity, reliability, contamination, responsibility, compatibility, and image barriers), as well as the practices that customers engage in to attenuate those barriers. That is, firms commercializing access-based services where multiple customers sequentially share usage of the same goods encounter different challenges than traditional firms selling goods on B2C markets or traditional rental business models (due to the short duration of rental period, cf. Lovelock and Gummesson 2004; Moeller and Wittkowski 2010).

\subsection{Research on collaborative consumption}

To summarize the state of research, the years 2007-2012 were critical for the development of research concepts related to the "sharing economy" and collaborative consumption in particular. Most importantly, Belk $(2007,2010)$ conceptualized sharing in consumer research as different from acquisition-based consumption and market-mediated exchanges based on a 
transfer of ownership. Sharing is a pro-social behavior, non-market mediated, and based on shared ownership. The sharing logic is the opposite of the market logic embedded in economic exchanges mediated by market relationships between buyers and sellers (i.e. independent and impersonal) who trade ownership rights to possessions (Bagozzi 1975; Belk 2010; Eckhardt and Bardhi 2016; Houston and Gassenheimer 1987; Scaraboto 2015). Moreover, several empirical papers have shown that grassroots communities and cooperatives leveraged the Internet to organize the distributed production and recirculation of diverse resources without any monetary involvement (Albinson and Perera 2012; Giesler 2006; Hennig-Thurau et al. 2007; Nelson et al. 2007; Ozanne and Ballantine 2010; Plouffe 2008), contrary to the market logic driven by self-interest, utilitarian, and profit-seeking motives. However, regardless of its origins in anti-capitalistic piracy, file sharing is for example a form of pseudo-sharing (cf. Belk 2014a), as music and video files are not owned in common by the network, but, rather, they are still individually owned - it is a case of consumer gift systems (cf. Giesler 2006). Furthermore, online secondhand markets, such as craigslist.com (launched in 1995) or LeBonCoin.fr (2006), that facilitate the recirculation of goods between people (e.g., Fernando et al. 2018; Lindblom et al. 2018; Parguel et al. 2017) differ from the anti-consumption ideology of the non-monetary practices of swapping and donating. In summary, there are a variety of distinct consumer behaviors related to diverse aspects of sharing and market exchange in the "sharing economy."

To further investigate the new paradigm of access-based consumption, Bardhi and Eckhardt (2009, 2010), Lawson (2010), ${ }^{24}$ and Lamberton and Rose (2012), among others, studied commercial carsharing in the US, whereas Moeller and Wittkowski (2010) studied a German online network for people to rent each other's clothes. The difference in the mode of exchange between these two research streams (consumer behavior and service research) can be denoted as B2C relationships based on rental business models or P2P exchanges based on platform business models. Lawson et al. (2016) further argued for four consumer segments of access-based consumption. However, their empirical data were collected in the context of Uber and Airbnb. That is, the authors' findings relate to the specific context of collaborative consumption based on $\mathrm{P} 2 \mathrm{P}$ exchanges, although their discussion focused on the commercial provision of access-based consumption (i.e. in which "legal ownership remains with the service provider"; Schaefers et al. 2016a, p. 571). Notably, Bardhi and Eckhardt $(2009,2010)$ called Zipcar a case of collective consumption in 2009 and market-mediated collaborative consumption in 2010 - which might have misinformed readers that the case study concerned consumers sharing consumption at the same time, as a group, which was the contemporary definition of the term (cf. Belk 2007). Indeed, Felson and Spaeth's (1978) earlier work on acts of collaborative consumption - regarded as the origin of the term - referred to two or more people consuming goods or services simultaneously, such as "drinking beer with 
friends, eating meals with relatives" (p. 614). In other words, collaborative consumption was defined as no shared ownership and no market mediation.

Indeed, collaborative consumption was most often used to emphasize the $\mathrm{P} 2 \mathrm{P}$ dimension but not the access dimension of the phenomenon (Belk 2014b; de Rivera et al. 2017; Ertz et al. 2018a, 2018b; Hamari et al. 2016; Herbert and Collin-Lachaud 2017; Lindblom et al. 2018; Perren and Grauerholz 2015; Roos and Hahn 2017). For example, Perren and Grauerholz (2015) referred to the term as a new version of e-commerce for all sorts of monetary exchanges between private people mediated by the Internet (i.e. Uber, Airbnb, TaskRabbit, eBay, and LendingClub); this refers to both tangible and intangible exchanges and is not only about the shared usage of underutilized resources. ${ }^{25}$ This illustrates the lack of consensus regarding the definition and usage of the term collaborative consumption, which impedes the conceptualization of the different business activities and consumer behaviors within the access paradigm (i.e. not based on ownership or acquisition) but entails a different role for the firm between facilitator of $\mathrm{P} 2 \mathrm{P}$ exchanges and provider of goods for rental. While 20 years ago, "product sharing [was] quite simply, a means of transforming a physical product into a service" (Johnson et al. 1998, p. 167), service research on the "sharing economy" has simply focused on the commercial provision of access-based services and has overlooked the paradigm shift towards P2P exchanges. There needs to be more theoretical and empirical work to advance the conceptualization of collaborative consumption as $\mathrm{P} 2 \mathrm{P}$ exchanges on a continuum between sharing and market exchange that is embedded in the access paradigm but differs from both commercial access-based services characterized by $\mathrm{B} 2 \mathrm{C}$ relationships and nonownership services characterized by $\mathrm{B} 2 \mathrm{~B}$ relationships (see Figure 4).

To summarize, the concept of sharing enables us to understand the heart of collaborative consumption as the social benefits of sharing within a community of likeminded people in a period of increasing digitalization, urbanization, and individualization in society. Collaborative consumption participants want to meet new people, establish new friendships, and extend their social network (both online and offline), but they do so through P2P exchanges that are market-mediated. Considering the market logic of these exchanges enables us to understand the wallet of collaborative consumption as the economic incentive of compensating for the underutilization of private resources, where online platforms aim to disrupt existing processes and businesses. 


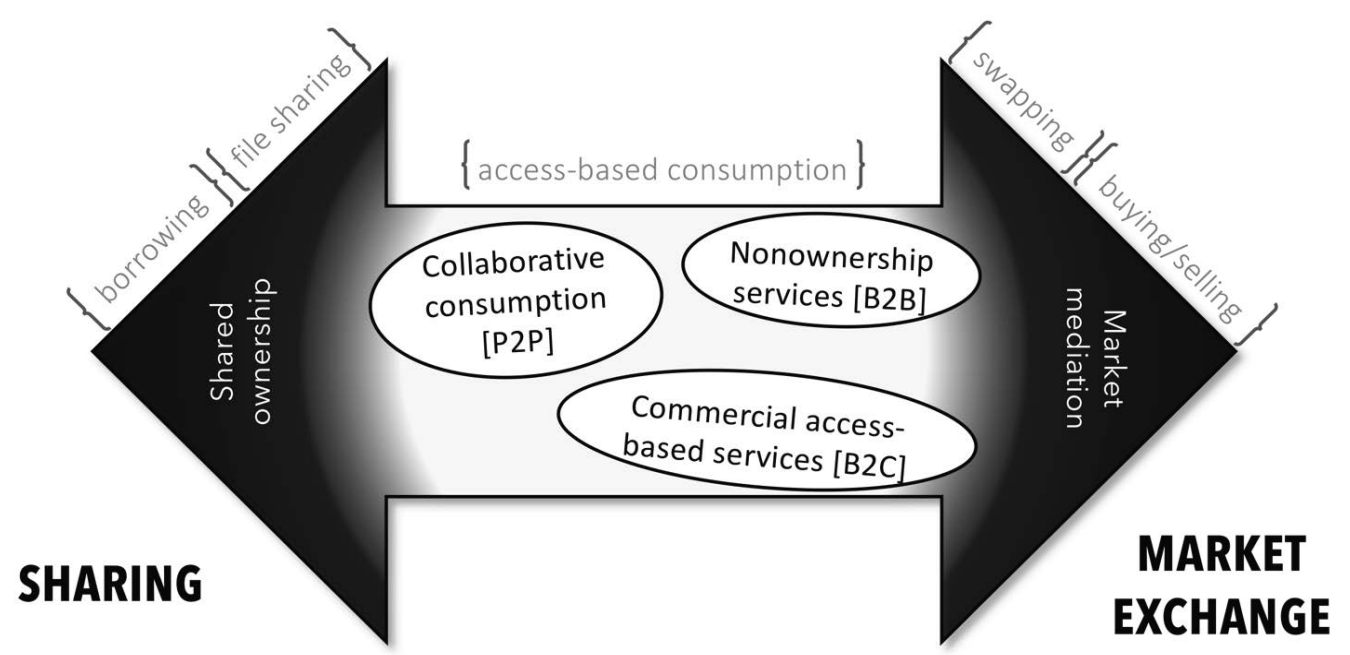

Figure 4. Collaborative consumption and related concepts.

\subsection{Alternative theoretical framework}

Since making a fundamental distinction between services and goods, service research has strengthened into its own academic field and has focused on the diverse processes that firms and customers engage in to create value. In recent years, service researchers have developed competing frameworks: for example, service science that has its roots in information systems research and operation management; relationship marketing that is focused on acquisition and retention of customers through service processes; transformative service research that aims at improving consumer well-being through service research (see also Appendix 3). However, the most prevalent meta-theory in marketing encompassing all these concepts and approaches is referred to as the service-dominant logic (or S-D logic, in opposition to a gooddominant logic), which was developed by Vargo and Lusch (2004, 2008, 2016). The S-D logic builds largely on the previous conceptualization of value co-creation in the Nordic school of service management (i.e. the service logic) developed by Grönroos (2006, 2011, 2012). This meta-theory, which integrates marketing and economic theories, further legitimizes service research as its own discipline.

The "sharing economy" phenomenon could well be depicted in light of the S-D logic, but that would mean defining and adapting a plethora of concepts. The fundamental premises of the S-D logic are a set of theoretical propositions that are valid in all marketing contexts, but their high level of abstraction makes them too distanced from empirical work to be comprehensible. For example, the S-D logic's actor-to-actor proposition aims to transcend 
the $\mathrm{B} 2 \mathrm{~B} / \mathrm{B} 2 \mathrm{C}$ distinction, as all social and economic actors engaged in exchange (e.g., firms and customers) "are fundamentally doing the same things, co-creating value through resource integration and service provision" (Vargo and Lusch 2011, p. 182). However, the distinction between B2B, B2C, and particularly consumer-to-consumer (C2C) relationships (referred to as P2P exchanges in this thesis) in the "sharing economy" is essential to better understand the diverse new forms of consumption or the changing role of firms. Alternatively, I decided to adopt concepts that were developed from the empirical phenomenon itself (e.g., accessbased consumption and P2P platforms), which are more precise than the more general concepts (e.g., value co-creation and service ecosystem). Although the theoretical concepts that are used as frame of reference do not all emanate from service research (e.g., sharing), they are inherently most relevant to contribute to the conceptualization of collaborative consumption in service research. 


\section{CHAPTER 3}

METHODOLOGY

It is not necessary to know everything in order to know something.

- C. Geertz (1973)

This chapter outlines my view of research in marketing, my perspectives on ontology and epistemology, the overall process of my doctoral research, the different methods used in the appended papers, and reflections on data collection. 


\subsection{Marketing research on services}

At the beginning of my $\mathrm{PhD}$ program, I had the opportunity to attend the Shopper Marketing and Pricing Conference at the Stockholm School of Economics (May 2014), where the incoming editor-in-chief of the Journal of Marketing was an invited speaker. ${ }^{26}$ I met some of the best marketing scholars from the Nordic community and a few AMA members, who all nodded in agreement with V. Kumar's vision for the journal: precision, rigor, and relevance (Kumar 2015). This allowed me not only to get acquainted with marketing scholarship, but also to realize that such conferences are frequented by practitioners, and that my future research should follow the new thinking in marketing theories as well as ongoing developments in society and business activities. This translates into advancing the conceptual knowledge in marketing, and rigorous yet actionable insights based on empirical investigations (Kumar 2015). Another influence early on in my research process was the realization of the omnipresence of services in the world's economy (e.g., 80\% GDP in the US, France, and the UK), and that there was an entire community of scholars dedicated to establishing a discipline since the 1970s (see also Appendix 3), which makes it "a wonderful time to be a service researcher!" (Bitner 2014, p. 3).

In the founding editorial of the Journal of Service Research, Rust (1998) argued that service research is academically rigorous (i.e. detailed, well-crafted, clever, sophisticated research), and focused on real managerial issues to present useful and applicable findings. Service research has become highly relevant since it is grounded in existing theories, while developing new models and theories when needed as the result of scholars inquiring about business challenges and changes in society, for example, in light of technological developments and ever-changing environments in business and society (Bitner 2017; Gustafsson et al. 2015; Kumar 2018; Rust 2006). As such, service research offers an appropriate and relevant framework to investigate the "sharing economy" phenomenon, develop new concepts (e.g., collaborative consumption, access-based services) and inform both managers and policy makers (e.g., Benoit et al. 2017; Hazée et al. 2017).

The commitment to rigor (i.e. high academic standards) and managerial relevance is also supported by the methodological diversity (e.g., quantitative and qualitative), international (not only North American, or European), and multidisciplinary (e.g., marketing, human resource management, economics) characteristics of service research (Bitner 2014; Gustafsson and Bowen 2017; Lemon 2013; Rust 2005). In particular, Bitner (2014) argued that to advance theory and provide managerially meaningful and generalizable empirical findings, researchers must rely on up-to-date and appropriate data collection and analysis techniques. That is, service researchers do not have to choose a quantitative design so their study is more likely to be published in top journals. Instead, "the method must fit the research 
problem" (Bitner 2017, p. 103)—researchers should be "using appropriate methods appropriately" (p. 104).

The requirements to graduate with a $\mathrm{PhD}$ include collecting and analyzing data - at least in Sweden. It makes complete sense to me. None of the appended papers to this thesis are conceptual. I argue that research needs be both theoretically and empirically grounded. Academics are often criticized for pursuing knowledge from an ivory tower that is disconnected with the practical reality-real business problems and societal challenges. Service researchers too have focused on studying the past rather than the future and winning academic debates (cf. Berry, in Fisk et al. 2000). Moreover, as the marketing practice is changing, reflecting technological advancements and increased data-processing capabilities, as well as the changing landscape of consumer preferences, competition, or government regulations (cf. Baron and Russel-Bennett 2016; Kumar 2018), researchers can and should leverage this explosion of data to provide guidance to managers that is evidence-based. In sum, I am among those who believe that for research to be relevant and rigorous, not only conceptual adequacy and methodological rigor are needed, but also accumulated empirical evidence (Gustafsson et al. 2015). Ultimately, I also believe that research can and should aim at improving lives — not only growing corporate interests (Gustafsson et al. 2015; Kumar 2018; Mick 2006; Ostrom et al. 2010, 2015).

In summary, my view of service research is one that aims at theoretical and methodological rigor, managerial relevance, and that is concerned with consumers' wellbeing.

\subsection{Research approach: Mixed-method as research paradigm}

Empirical research is often divided between the quantitative and qualitative paradigms (cf. Kuhn 1962[2012]) forming opposing interpretive frameworks (Denzin and Lincoln 2000). The quantitative paradigm relies on numbers, measurements, and statistical analyses, and a deductive approach to theory testing and knowledge creation, while the qualitative paradigm focuses on understanding and interpretation, and an inductive approach from the phenomenon to new theory (Denzin and Lincoln 2000). The paradigms are different in terms of their ontology (i.e. set of ideas, nature of reality), epistemology (i.e. set of questions, relationships between the researcher and the known), and of course methodology (i.e. set of procedures; cf. Lincoln and Guba 1985). For example, quantitative research is based on assumptions commonly called positivist or postpositivist, whereas qualitative research is based on assumptions called constructionist and interpretivist. In an attempt to reconcile the incompatibility thesis between qualitative and quantitative paradigms (cf. Howe 1988), Tashakkori and Teddlie (1998) and Johnson and Onwuegbuzie (2004) argued for a mixed- 
methods research paradigm using both quantitative and qualitative approaches within the same research program (i.e. across studies, or within the same study) — which is different than a multi-method approach within a single paradigm (e.g., different qualitative methods for the same study).

Mixed-methods research proposes to yield a richer understanding of a phenomenon, more meaningful and confident answers to research questions, and more comprehensive, consistent, and valid findings than research conducted within a unique paradigm (Creswell and Plano Clark 2017; Johnson and Onwuegbuzie 2004; Johnson et al. 2007). It is defined as "the type of research in which a researcher or team of researchers combines elements of qualitative and quantitative research approaches (e.g., use of qualitative and quantitative viewpoints, data collection, analysis, inference techniques) for the broad purposes of breadth and depth of understanding and corroboration" (Johnson et al. 2007, p. 123). The rationale of mixed-method research is that in most situations, researchers can gain further insights by using both quantitative and qualitative methods. In a nutshell, "mixed method research provides strengths that offset weaknesses in both qualitative and quantitative research" (Harrison and Reilly 2011, p. 20). In particular, there are five main benefits to opting for mixed-methods research (Greene 2006; Johnson and Onwuegbuzie 2004; Johnson et al. 2007):

1) Triangulation: by triangulating the measurement process (Webb et al. 1966), also called multi-operationalism (Campbell and Fiske 1959), the researcher studies the same phenomenon with different methodologies - i.e. between-method triangulation (Denzin 1978). This seeks to converge and corporate the results from different methods and designs.

2) Complementarity: using different methods enables us to provide different facets of the same phenomenon, by enhancing, illustrating or clarifying the results of one method with another.

3) Initiation: opposing results enable researchers to discover paradoxes, contradictions and new research questions.

4) Development: using one method to develop the other method.

5) Expansion: expanding the scope and focus of a study with additional analyses.

The mixed-method research paradigm is neither postpositivist (i.e. research is not objective, but intersubjective due to the many decisions made throughout the process) nor interpretivist (i.e. all multiple realities, aka perspectives on a phenomenon, are not equally valid). It is based on pragmatism. This essentially means that the choice of methodology is guided by the research question, for example in some situations the qualitative-dominant approach is more appropriate and vice versa (Creswell and Plano Clark 2017; Johnson and Onwuegbuzie 2004; Johnson et al. 2007). That is in line with the methodological adequacy 
evoked in service research, depending on the problem at hand (e.g., Bitner 2017; Gustafsson et al. 2015).

Understanding both the advantages and the weaknesses of qualitative and quantitative approaches and methods is thus necessary to inform the research design and the best understanding of a phenomenon (Johnson et al. 2007). In practice, most mixed-method research designs involve using qualitative and qualitative methods sequentially — only a few employ mixed-models using both simultaneously (Creswell and Plano Clark 2017; Harrison and Reilly 2011; Johnson and Onwuegbuzie 2004). That is, mixed-method research includes a quantitative phase and a qualitative phase: exploratory research designs are based on qualitative before quantitative (e.g., in order to generalize the findings), while explanatory research designs are based on quantitative before qualitative (e.g., in order to better understand results). Harrison and Reilly (2011) showed that most mixed-method research in marketing (i.e. 2003-2009) is designed for exploratory purposes.

\subsection{Research design}

Throughout the research process (see Figure 5), a variety of research methods were adopted to better understand the new phenomenon of collaborative consumption from different perspectives (firms, users), different organizations (for-profit, non-profit), and different practices (ridesharing, $\mathrm{P} 2 \mathrm{P}$ car rental). This pluralism of perspectives and empirical settings go hand-in-hand with interpretivism. Importantly, I began my focus on the "sharing economy" while academia was still very much lagging behind - not that it is not any longerwhich also called for a qualitative-dominant approach to research to understand and appreciate the particular groups and individual stakeholders, and generate empirical descriptions.

In this thesis, the first and second research questions from the firm perspective are concerned with how private resources are monetized and the sharing logic stimulated in collaborative consumption. The qualitative approach is appropriate to this exploratory aim. Furthermore, from the platform users' perspective, the next research question is also explorative of the effects of the monetary compensation (e.g., compared with non-monetary practices). To gain a deeper understanding of collaborative consumption, I decided to employ an exploratory sequential design (cf. Creswell and Plano Clark 2017) primarily based on qualitative research methods. The results of this first qualitative phase in the research process are found in Paper I, II, and III.

The qualitative approach was better for exploring the practice of collaborative consumption and obtaining in-depth descriptions of the phenomenon; while further on into the research process, the quantitative approach was better for confirming the preliminary 
understanding from the exploratory phase and measuring relationships between constructs of interest. As such, the second phase of the research appended to this thesis (e.g., the last research questions from the platform users' perspective) was concerned with testing a theoretical model explaining the relationships between key concepts (e.g., communal belonging, customer satisfaction). The results of the quantitative phase are found in Paper IV measuring the importance of communal belonging for collaborative consumption participants.

Eventually, I focused on the shared mobility context due to the large body of existing research on carsharing and the disrupting changes in the industry. This led me to focus on three main cases: GoMore (founded in Denmark), BlaBlaCar (founded in France), and Skjutsgruppen (founded in Sweden).

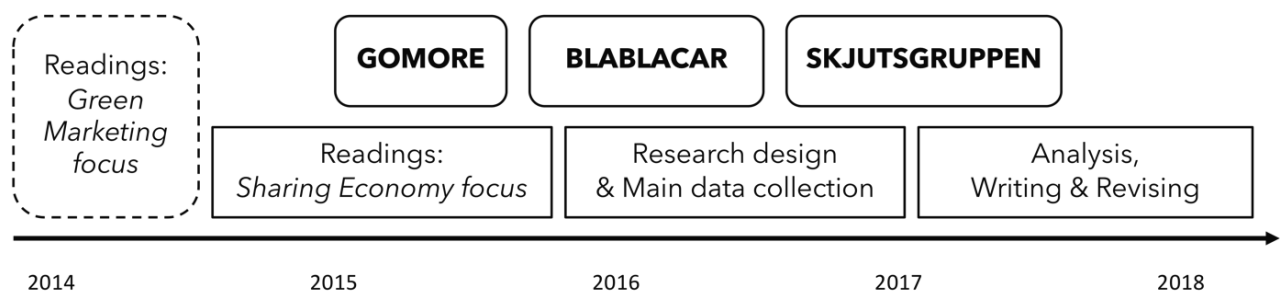

Figure 5. Research process.

Note: grosso-modo.

\section{Qualitative approach}

Qualitative research emphasizes the qualities of entities and their processes and meaningsnot in terms of amount, intensity or frequency (Denzin and Lincoln 2000). This approach is used when the research aims at exploring a phenomenon, discovering new ideas, describing observations, and interpreting things (e.g., Stake 2010). This is in line with the exploratory aim of this thesis and the phenomenon in question: to advance the understanding of collaborative consumption. As the phenomenon is new, it is currently ill-understood in academia, such as qualitative research is initially appropriate to provide the "rich descriptions of the social world" necessary to illuminate what is unexplored (Denzin and Lincoln 2000, p. 10) — with the methodological rigor of scholars rather than anecdotal evidence found in the popular press (e.g., Botsman and Rogers 2010a). The qualitative approach also enables young researchers to join a field (e.g., consumer-centric service research) and be curious and explore what seems worthy of interest (Tracy 2012), for example for a PhD. Almost all marketing research using the lens of paradox theory adopted a qualitative approach — although "paradox is an embryonic notion in marketing" (O’Driscoll 2008, p. 101). 
Qualitative researchers adopt an inductive approach to knowledge, and theories are generated from studied phenomena. As such, qualitative research relies on human perception and understanding — so all divisions of science have a qualitative approach to some extentto show how things work in particular situations (Stake 2010). For example, I particularly focus on the ridesharing context of collaborative consumption, where some findings would not generalize to accommodation rentals. Furthermore, the lived experiences of drivers are not the same as those of passengers. Furthermore, each passenger participating in the same ride has a unique experience. The qualitative approach to research is valuable to grasp this plurality of perspectives. Qualitative research concerns different practices that aim to get a better understanding of the subject at hand (e.g., the monetary incentive of ridesharing) by getting "closer to the actor's perspective" (p. 10), adopting the "view of the 'other' who is studied" (Denzin and Lincoln 2000, p. 18). This is valuable since this thesis is concerned with the tensions between the Heart \& Wallet, which requires understanding collaborative consumption from the firms' point of view, as well as those of consumers and peer providers. Furthermore, qualitative data and analysis techniques (e.g., interviews, case studies, hermeneutics, participant observations, and ethnographies) have been central to in-depth investigations of the meanings of consumer experiences and culture (Arnould and Thompson 2005; Belk et al. 1988, 1989; Sherry 1990).

The qualitative research approach was adopted for the first three papers. First, the case study methodology was used for GoMore and Skjutsgruppen (Papers I and II). In particular, the cases are based on semi-structured interviews conducted with online platform managers, and supplemented with a document analysis. Second, participant observation in ridesharing and ethnographic interviews with users of BlaBlaCar were conducted (Paper III). Third, netnographic study supplemented the dataset on BlaBlaCar (Paper III).

\section{Interviews}

I have interviewed the two types of actors of collaborative consumption: the online platform providers, and the platform users (cf. Benoit et al. 2017; Kumar et al. 2018), in line with the two perspectives adopted in this thesis. I mostly used interviews with platform managers for the firm's perspective (i.e. GoMore, Skjutsgruppen), and interviews with ridesharing participants for the platform users' perspective (i.e. BlaBlaCar).

For GoMore (Papers I and II), semi-structured interviews were conducted with six key informants from the platform management team. GoMore was selected as a case study because of its uniqueness in that it operates several shared mobility business models at once and, having been founded more than a decade ago, it also accounts for start-up survival whereas other "sharing economy" startups have failed. I conducted a first round of elaborated 
case study interviews (i.e. focused on events and processes, broad scope; Rubin and Rubin 2005) shortly after GoMore launched its car rental and leasing services in early 2015, as well as follow-up interviews in 2017-2018 when GoMore entered the French market. Moreover, the market manager for Scandinavia was replaced in 2017 , which allowed to gain a new perspective on similar topics. The interviews lasted about $60 \mathrm{~min}$.

The detailed case study of GoMore (Paper II) was further elaborated with corporate documents provided by the management team (i.e. survey reports, Facebook fan-page data, founding history, case study), and I collected additional secondary data (e.g., investment and buyouts reports, corporate announcements, startup pitches and company presentations, press articles, blogposts, email campaigns, Q\&A website section, press releases) that were publicly available online or to registered platform members. This methodological approach combined with the interviews provide an historical overview of GoMore's activities.

For Skjutsgruppen (Paper I), three semi-structured interviews were conducted with the founder, followed-up with personal communication, and document analysis (e.g., board meetings minutes, blogposts and Facebook communication) between 2015 and 2017. As with GoMore's study, the interviews were prepared according to a question guide and follow-up questions were further asked to clarify the interviewees' statements and correctly interpret what was said, and to obtain additional information related to the question or specific examples to illustrate the interviewees' statements (Fontana and Frey 2000; Kvale 1996). Skjutsgruppen was selected as a case because it is the oldest ridesharing actor in Sweden, but it remained (and survived as) a grassroots non-profit organization-whereas other shared mobility actors became for-profit ventures (e.g., BlaBlaCar, GoMore).

For BlaBlaCar (Paper III), the participant observation included ethnographic interviews (Spradley 1979, 1980), two techniques that go hand-in-hand in characterizing the phenomenological approach that allows for a better understanding of the lived experience by the informants and the researcher (van Maanen 1980). The ethnographic interview questions asked to passengers and discussions in the car were directed towards their perspective as consumers of a mobility service, their perception of the professionalization of ridesharing, the influence of reputation system (and its trustworthiness), the coordination of itineraries before the rides, the importance of the ridesharing community and culture, their expectations regarding interactions with others, their best/worst ridesharing experiences and why (cf. Critical Incident Technique), ${ }^{27}$ their understanding of BlaBlaCar's cost sharing and reservation system (i.e. its business model), their participation motives, and more, depending on the conversations. The ethnographic interviews were thought of as "[...] a series of friendly conversations into which the researcher slowly introduces new elements to assist informants to respond as informants" (Spradley 1979, p. 58). In ridesharing, my role was that of the driver, but my identity as a researcher was always revealed. Sometimes, the other car 
occupants would talk among themselves while I was just listening. Hence, the researcher acted as an expert on the questions, but absolutely not on the content of the answers.

\section{Participant observation}

As evoked earlier, the ethnographic interviews were collected in conjunction with participant observation in ridesharing (Paper III). This data collection was inspired by Belk's (1989) Consumer Odyssey and other ethnographic work (e.g., Scaraboto 2015; Sherry 1990), and Rudmin's (2016) call for consumer researchers to investigate the new sharing phenomenon by making more "naive phenomenological observations" and descriptions of consumer behaviors. To participate in this explorative quest, I posted rides on BlaBlaCar's platform, offering the empty seats from my old Renault Scenic to passengers throughout Germany, Belgium, France and Sweden (see Appendix 4). ${ }^{28}$ BlaBlaCar was used as it is the market leader. ${ }^{29}$ The first trip (16 May 2015) was from Rostock, Germany (where the Swedish ferry dropped me off) to Paris, France, with a few strategic stopovers in between. ${ }^{30}$ The second trip (25 May 2015) was from Paris back to Sweden.

To record observations, field notes were taken during the coffee breaks via speech-totext recording, as well as while waiting for other passengers (see Appendix 5). These notes were both inscriptive - in the field, i.e. mental notes and jottings (scratch notes), including photos and audio recordings - and descriptive - full field notes, i.e. containing descriptions of observations, summaries or accounts of conversations, situation descriptions (Emerson et al. 2011; Lecompte and Schensul 1999). But however thorough the field notes, they can only represent a fraction of the fieldwork experience (cf. van Maanen 2011).

\section{Netnography}

The data collection related to BlaBlaCar also concerns netnography (Paper III). Netnography has gained popularity and recognition since Kozinets' (2002) landmark article because the technique is "faster, simpler and less expensive than traditional ethnography and more naturalistic and unobtrusive than focus groups or interviews" (p. 61). Considering the newness of collaborative consumption, it is important to unravel information related to the relationship between platform actors, community-based interactions, how platforms create trust between strangers, understanding what users actually share, what their choice determinants are, what characteristics of the exchange bring satisfaction, and other characteristics that an in-depth research approach can reveal. Netnography is an appropriate method for doing so, especially considering how the consumer cyborgs engage in diverse practices, both online and offline, as part of the new networked society (Kozinets and Arnould 2017). 
Netnography is a research method "positioned somewhere between the vast searchlights of big data analysis and the close readings of discourse analysis" (Kozinets 2015, p. 4) that aims to provide insights on online social experience and interactions (i.e. communal exchanges, online rules, practices, innovative forms of collaboration and organization, and manifestations of creativity; Kozinets 2015, 2017). The netnographic approach to ridesharing offers an alternative window onto the ways participants make meaning of their online interactions with other participants. It also allows researchers to look at the past through digital archives. That is, the Internet is like an open book.

One benefit of netnography was also to familiarize myself with the vocabulary at play in ridesharing. The concept of consocial relationships evolving "around incidents, events, activities, places, rituals, acts, circumstances, and people", about "what we share" rather than the "what we are" tightly-bonded community, allows us to enrich our understanding of networks and communities (Kozinets 2015, p. 11). Another advantage of the netnographic approach was that it makes it possible to visit online archive (e.g., old blogposts), for example, to see how BlaBlaCar's organized ridesharing has changed since it started in 2004 (and particularly during its change of business model in the 2011-2013 period of contestation/communication; as well as during the funding rounds in 2014-2015), from the perspectives of platform users and platform owners/managers. Moreover, the netnographic approach was used in the "sharing economy" context by Gollnhofer (2017a) for foodsharing.de, Scaraboto (2015) for geocaching communities, Nelson and Rademacher (2009) and Martin et al. (2015) for online swapping platforms, McArthur (2015) for landshare.co.uk, and Corciolani and Dalli (2014) for bookcrossing.com, among others.

\section{Quantitative approach}

Broadly, quantitative research can be described as collecting numerical data and analyzing the dataset to show relationships. That is, the quantitative research approach is used to test theoretical hypotheses and measure relationships, with the aim of explaining - rather than exploring - a phenomenon by assigning numbers in a meaningful way (Zikmund et al. 2013). With its roots in natural science (i.e. positivism), the quantitative research approach adopts an objective view of reality (Bryman 1984; Denzin and Lincoln 2000). Quantitative researchers isolate causes and effects, operationalize theoretical constructs, and aim to generalize their findings - a deductive approach between theory and research (Denzin and Lincoln 2000). However, quantitative research is not incompatible with qualitative research. For example, developing consumer surveys requires a deep understanding of the concept to be measured (Zikmund et al. 2013). Using the rich description from qualitative research allows these concepts to be expressed in everyday language. 
To quantify the relationships between various concepts of interests (e.g., communal belonging, customer satisfaction) and empirically test a theoretical model of participation in collaborative consumption, I designed a cross-sectional survey for members of Skjutsgruppen's platform (Paper IV). Surveys are used to collect primary data from a representative sample of people, that is, active ridesharing participants. Compared with case studies, for example, surveys provide a snapshot at a given point in time. This is also a quick, inexpensive, accurate, and flexible method.

\section{Survey}

The survey sent to Skjutsgruppen members was set up online to measure respondents' replies to certain questions of interest, but there are is a risk that answers will be incomplete or incorrect, which can be deliberate (i.e. response bias). For example, respondents could forget to respond or even lie about how much they participate in ridesharing. To strengthen the validity of the study, the survey data (i.e. attitudinal measures) is supplemented with behavioral data (i.e. interactions with other members on the platform). ${ }^{31}$ In particular, participation in ridesharing was evaluated based on platform usage through the member's platform activity (i.e. posts on ride listings) and the number of logins (while controlling for the platform membership length since the signup date).

The survey was hosted on Linköping University's server and distributed in April 2017 to 5,836 registered members of Skjutsgruppen's platform. ${ }^{32}$ They received a short introduction by email explaining the scope of the survey (i.e. the participants' ridesharing experience, platform usage habits, and interactions with other users), the research purpose (i.e. understanding collaborative consumption), the incentive (i.e. a lottery with 25 lots of two cinema tickets), and the instructions (e.g., no forced response, $15 \mathrm{~min}$. response time). Three reminders were sent (following the design method by Dillman et al. 2014) and the survey was closed after one month: 980 participants started to complete up to $20 \%$ of the survey (but 391 quit) and 589 surveys were submitted (10\% response rate). The sample was reduced to 495 completed responses due to 67 respondents removed for missing values (i.e. more than $15 \%$, not at random), 22 outliers for being unfamiliar with Skjutsgruppen (i.e. respondents reporting 0 and 1 on $0-3$ Likert scale assessing familiarity), and 5 outliers for excessive mileage (i.e. uncompleted cross-country trips). Based on previous survey measures (all on a Likert scale from 1 to 7 ), the answers to the survey questions enable relationships between constructs to be statistically investigated (Paper IV).

Partial-Least Square (PLS) Structural Equation Modeling (SEM) was used in Paper IV. SEM is a method based on OLS regressions and on making no assumptions regarding the distribution of the data. Compared to CB-SEM (co-variance based), PLS-SEM is more 
prediction oriented, aiming to maximize the explained variance in the dependent outcomes or constructs (i.e. rather than explaining co-variances). PLS-SEM is appropriate when the model is complex (as in Paper IV), and PLS-SEM also considers formative indicators with fewer constraints (Hair et al. 2011, 2012, 2016; Sarstedt et al. 2016). Moreover, the method's limitations (e.g., overestimating factor loadings, and underestimating path coefficients and R-squares (i.e. structural relationships) actually suggest that it offers a conservative test of the hypotheses. Concerns over data normality and higher order, complex constructs are commonly cited as justifications for using PLS-SEM in service research (e.g., Benoit et al. 2016; Moeller and Wittkowski 2010; Oyedele and Simpson 2018). PLS-SEM was run in SmartPLS v.3.2.8 (Ringle et al. 2015) following bootstrapping procedures (5,000 samples, mean replacement of missing values) to estimate the confidence intervals of the model path. Moreover, the findings from Paper IV can be considered reliable (i.e. composite reliability of constructs was above the cutoff value of 0.7 ) and valid (i.e. convergent validity was established based on the average variance extracted for each construct, as well as discriminant validity based on the HTMT criteria).

\subsection{Overview of data collection methods}

Mixed-methods researchers are required to consider the strengths and weaknesses of each method to draw on complementary advantages and avoid potential redundant problems (Johnson and Onwuegbuzie 2004; Johnson et al. 2007). Throughout the research process, I carefully reviewed the qualitative and quantitative tools and datasets used to constitute the research package appended in the papers (see Table 3).

\subsection{Methodological reflections}

During the research process, both quantitative and qualitative research methods were used to gain a more comprehensive understanding of collaborative consumption and better answer the research questions of this thesis. However enriching the multiple sources of data were, perfect research does not exist. In hindsight, several weaknesses in the data collection and analysis procedures have come to light. 
Table 3. Data collection methods used in the thesis.

\begin{tabular}{|c|c|c|}
\hline & Advantages & Disadvantages \\
\hline Interview & $\begin{array}{l}\text { Obtaining in-depth information from } \\
\text { interviewee's perspective (i.e. firm or user). } \\
\text { Allowing follow-up questions on relevant } \\
\text { topics. } \\
\text { Providing "thick" descriptions of complex } \\
\text { phenomena. }\end{array}$ & $\begin{array}{l}\text { Difficulty generalizing } \\
\text { findings. } \\
\text { Results depending on the } \\
\text { researcher's interpretation of } \\
\text { the interviewee's point of } \\
\text { view. } \\
\text { Expensive (e.g., time). }\end{array}$ \\
\hline $\begin{array}{l}\text { Secondary } \\
\text { data/document } \\
\text { analysis }\end{array}$ & $\begin{array}{l}\text { Accurate and reliable. } \\
\text { Providing background to "join the field of } \\
\text { research." } \\
\text { Preparing interview guide. } \\
\text { Confirming interview data. } \\
\text { Not focused on one firm but entire sector. } \\
\text { "Triangulation" of data sources. } \\
\text { Can be reviewed repeatedly. }\end{array}$ & $\begin{array}{l}\text { Not illustrating the entire } \\
\text { phenomenon (e.g., firms' } \\
\text { biased selectivity). } \\
\text { Can be difficult to access. } \\
\text { Can be difficult to understand. }\end{array}$ \\
\hline $\begin{array}{l}\text { Participant } \\
\text { observation }\end{array}$ & $\begin{array}{l}\text { Different types of naturally occurring and } \\
\text { contextualized data (e.g., field notes). } \\
\text { Closest to the lived experience, the "native's } \\
\text { point of view." } \\
\text { Specific information is obtainable from study } \\
\text { subjects. }\end{array}$ & $\begin{array}{l}\text { Dependent on the researcher's } \\
\text { manipulation of events. } \\
\text { Expensive (e.g., time). }\end{array}$ \\
\hline Netnography & $\begin{array}{l}\text { Focus on online interactions, and platform } \\
\text { design and functionalities. } \\
\text { Combines qualitative and quantitative tools to } \\
\text { collect and analyze a variety of data (e.g., text, } \\
\text { media), both primary and secondary (e.g., } \\
\text { interviews, observations). } \\
\text { Allows the researcher to travel back in time by } \\
\text { consulting old webpages and archives. }\end{array}$ & $\begin{array}{l}\text { Easily lost in data. } \\
\text { Gives too much importance to } \\
\text { the digital world. }\end{array}$ \\
\hline Survey & $\begin{array}{l}\text { Replicable study design. } \\
\text { Generalizability of quantitative findings. } \\
\text { Quick. } \\
\text { Cheap. }\end{array}$ & No room for discovery. \\
\hline
\end{tabular}

Note: Case study is not listed here as a method, as it is considered a research design involving multiple data collection methods such as interviews and document analysis (Eisenhardt and Graebner 2007; Järvensivu and Törnroos 2010; Stake 2010; Yin 2018). 
First, the number of informants from the management teams of GoMore (i.e. six interviewees) and Skjutsgruppen (one interviewee) as well as the overall number of interviews conducted is rather low to represent the full spectrum of the firm's perspective. Additional interviews with other firms could have been collected to increase the generalizability and representativeness of the studies. Second, the participant observation as a ridesharing driver and ethnographic interviews of BlaBlaCar passengers (eleven interviewees) should have been replicated in the opposite role (i.e. as a passenger) to further apprehend both users' perspectives. Third, the netnography approach has been highly valuable as a complementary source of data supporting the explorative study with BlaBlaCar, although it would have been beneficial to broaden the scope of the netnography to other ridesharing platforms or collaborative consumption practices to advance the transfer of the study findings to other contexts. Fourth, the measurement of the latent constructs through the online questionnaire (although valid and reliable) should have relied more on established scales, and been further pre-tested before collecting the data from Skjutsgruppen members. Moreover, although the sample of respondents is large, it could have been more representative of non-participants in ridesharing (e.g., online platform members who have yet to participate as a driver or passenger). Ultimately, the participation measures are based on platform metrics (i.e. number of logins and the number of comments on ridesharing offers), which are proxy to Skjutsgruppen members' actual participation in ridesharing, and result in a more challenging interpretation than having, for example the shared distance. 


\section{CHAPTER 4 SUMMARY OF PAPERS}

A writer should have the precision of a poet and the imagination of a scientist.

- V. Nobokov

The appended papers in this thesis are all different in their theoretical background (e.g., sustainability marketing, platform business model, service marketing), or their empirical approach (qualitative or quantitative), or their perspective (firm or platform users), which illustrate various facets of the same phenomenon. Three of the appended papers are accepted for journal publication, ${ }^{33}$ while the last one is a work-in-progress. In the following, each paper is summarized with regard to the purpose of this thesis and their individual contributions (see Table 6). 


\subsection{Identifying the resource integration processes of Green Service}

This paper is situated in the transformative research paradigm called for by marketing, consumer behavior and service researchers (Gustafsson et al. 2015; Kumar 2018; Mick 2006; Ostrom et al. 2010, 2015). It concerns a topic of utmost importance for business and society: environmental resources. Firms in the service sector have already been implementing ecoefficient technologies into existing processes or asking their customers to "walk the talk" and change their consumption habits. However, practices such as reducing, reusing, or recycling (i.e. the $3 R$ framework of waste management) have so far been insufficient in solving the challenges of natural resource depletion-on $1^{\text {st }}$ August 2018, humanity's environmental resource consumption exceeded what the Earth ecosystem can generate in a year. Moreover, service research on sustainability is scarce - only a few peer-reviewed publications in scholarly journals - and much of the academic debate has taken place at conferences. In other words, the economic profitability of service provision and more recently the service firms' social responsibility have received considerably more attention than environmental sustainability from service researchers.

The paper aims at revisiting the conceptualization of green service for transformative service research (TSR) that creates "uplifting changes" in the lives of consumers, society, and the natural ecosystem (Ostrom et al. 2010). As such, green service should be concerned not only with service provision minimizing the socio-ecological negative consequences of consumption, but also with improving positive effects for the environment. Therefore, we defined green service as service provision aimed at improving the well-being of the natural ecosystem - not only satisfying customer needs eco-efficiently, but relying on the TSR concept of well-being, i.e. "to better the quality of life of present and future generations" (Ostrom et al. 2010, p. 9). TSR is integrated with theory on resource integration to better understand the nuances in firms' activities and services processes that aim at not only doing the same with less, but also doing more with less. In particular, the two processes of homopathic and heteropathic resource integration (Peters 2016), enable researchers to examine how resources are consumed, acted on, transformed, depleted and integrated. This theory of resource integration allows us to differentiate summative and emergent processes, where green service delivered with the former can only reduce environmental impact (homopathic resource integration) while the latter can create a unique outcome (heteropathic resource integration).

Based on a multiple case study, the paper demonstrates six processes of resource integration based on their characteristics (e.g., summative or emergent) and their effects (i.e. reducing consumption impact or improving environmental resourceness). While we revisit the existing $3 R$ framework, we also identify new ones (see Table 4). Reducing, recirculating (a revision of reusing), recycling, and redistributing resources (a new process particularly 
relevant to understanding collaborative consumption) are homopathic processes, which have also been the focus of previous service research on sustainability. Reframing and renewing resources (both new processes) are heteropathic processes, which are consistent with TSR and the view that service firms can create uplifting changes for the environment and, by extension, the well-being of humanity. Ultimately, the paper improves the conceptual clarity of green service.

Table 4. Summary of findings from Paper I.

\begin{tabular}{ll}
\hline Processes & Descriptions \\
\hline Reducing & $\begin{array}{l}\text { To alter the manufacturing of tangible goods and redesign service processes to } \\
\text { conserve resources (e.g., with technology). }\end{array}$ \\
Recirculating & $\begin{array}{l}\text { To use existing tangible resources (e.g., goods that are no longer utilized) again } \\
\text { by changing their ownership and extending their utilization. }\end{array}$ \\
Recycling & $\begin{array}{l}\text { To collect, reclaim, sort, and demanufacture waste (e.g., food scraps, organic } \\
\text { left-overs from industrial manufacturing) back into raw material (i.e. thanks to } \\
\text { technology) for industrial remanufacturing instead of virgin resources (e.g., }\end{array}$ \\
& $\begin{array}{l}\text { biogas). } \\
\text { Redistributing }\end{array}$ \\
& $\begin{array}{l}\text { (i.e. no permanent change in ownership), thanks to technology (e.g., online } \\
\text { platforms). }\end{array}$ \\
Reframing & To give waste a new purpose (e.g., creative "upcycling" activities). \\
Renewing & $\begin{array}{l}\text { To create new natural ecosystems (e.g., lakes), restore or replant, and improve or } \\
\text { expand existing natural resources (e.g., water, nutrient soil). }\end{array}$ \\
\hline
\end{tabular}

Taking the perspective of the firm, this paper contributes to answering the first research question related to mechanisms to leverage and monetize resources outside of the firm's boundaries. Moreover, it shows that online platforms that facilitate ridesharing (i.e. Skjutsgruppen) and P2P car rental (GoMore) demonstrate a resource integration process of temporarily redistributing resources. Hence, the focus is on the role of the firm to facilitate the redistribution of private resources from people (peer providers), to serve the needs of other people (consumers) who want a temporal access to their resources without buying them (e.g., a car). On the other hand, secondhand markets (e.g., Red Cross stores) demonstrate a resource integration process of permanently recirculating resources. That is, the role of the organization is to facilitate the change of ownership of private resources. Similar to redistributing, recirculating is a process where resources are considered underutilized, but are also unwanted. In other words, secondhand markets concern people donating (i.e. sharing 
logic) or selling their possessions to others (i.e. market logic) who can use them as such. To be clear, another newly identified resource integration process, reframing, is similar to recirculating as resources also change hands, but they also change purpose - so it is a different process.

In a nutshell, the paper contributes to better conceptualizing collaborative consumption as based on a different resource integration process (i.e. redistributing) than other market-mediated (e.g., selling) and non-monetary (e.g., gifting) practices where ownership changes (i.e. recirculating, reframing). Moreover, the comparative case study analysis reveals noteworthy differences between the two shared mobility platforms: one platform is for-profit, the other one non-profit. Ultimately, this thorough understanding of resource integration processes situated in service research pinpoints the lack of emphasis on the access dimension (i.e. no change of ownership) from circular economy researchers in the sustainability literature baited by the trendier popularity of the "sharing economy", but misusing the term collaborative consumption.

\section{Contribution to Paper I}

The project on green service was initiated by the senior researchers of the marketing group when I started at the Business Administration Division in the fall of 2013-Lars Witell, Per Frankelius, and Mikael Ottosson. Their idea resulted in a coauthored extended abstract and the structure for a short paper. I contributed by reviewing the service research literature on sustainability for the front-end of the paper, while case studies were provided from other research projects (e.g., Grönovation). Per and I presented the manuscript at $8^{\text {th }}$ SERVSIG International Research Conference (held bi-annually by the AMA's Special Interest Group on Services Marketing established in 1993), after which the project became somewhat dormant for two years. In late 2016 and early 2017, I took the lead in writing a new manuscript, by changing the theoretical framework-less green marketing and innovation (e.g., eco-efficient services, product-service systems) - towards service research and theories on resource integration, by adding my two cases from the shared mobility sector, and by subsequently conducting a new analysis. The author team discussed and iteratively revised the manuscript, which I presented at the $15^{\text {th }}$ QUIS conference in 2017 (QUIS stands for the bi-annual International Research Symposium on Service Excellence in Management, originally called the Quality in Service Symposium, and established in Sweden in 1988). The conference organizers invited us to submit to the Special Issue on Service Interactions and Well-Being of the Journal of Service Management in December 2017 and the paper was accepted in January 2019. 


\subsection{Business model diversification in the sharing economy: The case of GoMore}

Similar to the "sharing economy" phenomenon that relies extensively on recent technological developments, the vaguely defined term business model is born out of the Internet boom and its seemingly unlimited new opportunities for e-commerce (cf. Muzellec et al. 2015). Business models describe the value creation, delivery and capture value (Baden-Fuller et al. 2017). Whereas previous research has differentiated diverse business models based on offering access-based consumption through rental and online platforms (Andreassen et al. 2018; Baden-Fuller et al. 2017; Breidbach and Brodie 2017; Dreyer et al. 2017; Ehret and Wirtz 2018; Field et al. 2018; Kumar et al. 2018; Piscicelli et al. 2018), there has not been any significant empirical investigation of firms operating several business models simultaneously in the "sharing economy." However, firms such as Uber and Airbnb have long diversified their activities. For example, Uber not only matches professional drivers and passengers on-demand (i.e. ride-hailing), but the firm also tried P2P car rental (which failed), bikesharing, and recently scooter sharing (among a plethora of other shared mobility services). As such, this paper focuses on the shared mobility sector to study a case of a business model portfolio to contribute to the understanding of such diversification strategy.

By using the strategy literature on platform business models, the paper illustrates what could be called a Car-as-a-Service portfolio of business models complementing each other that GoMore established in the shared mobility sector. We identified the six key resources (i.e. member community, platform technology, user data, customer support, local management teams, partners), three key capabilities (leverage of a community's assets, technological improvement, user engagement) and five key performances (size of user community, brand visibility, matchmaking quality, reservations, commissions) which are shared across mobility services to take advantage of synergies through multiple business models (see Figure 6). The case study shows how GoMore sequentially develops ridesharing, P2P rental, and car leasing services (i.e. their business model diversification strategy), which enables it to fuel the supply side of its P2P markets and benefit from business model synergies.

This paper contributes to the first and second research questions by exploring how a firm operates several business models simultaneously to maximize benefits. The case study shows how GoMore manages to retain its existing users on the platform by offering complementary shared mobility services through access-based provision. Each service fulfills the needs of a specific customer segment (e.g., ridesharing best suits users with low mobility needs, while P2P car rental best suits those with moderate mobility needs, and leasing suits those with high mobility needs), and each has its own business model based on a commission for each service provided. In other words, GoMore profits from facilitating P2P exchanges between private people (ridesharing and P2P car rental), but also from brokering the leasing 
contract for the fleet management firms, and the all-in-one solution platform promotes the combination of several mobility services (e.g., financing the leasing service with P2P car rental). Eventually, it becomes evident that GoMore largely emphasizes the economic incentives offered by its platform in its marketing communication, rather than promoting the feelings of communal belonging.

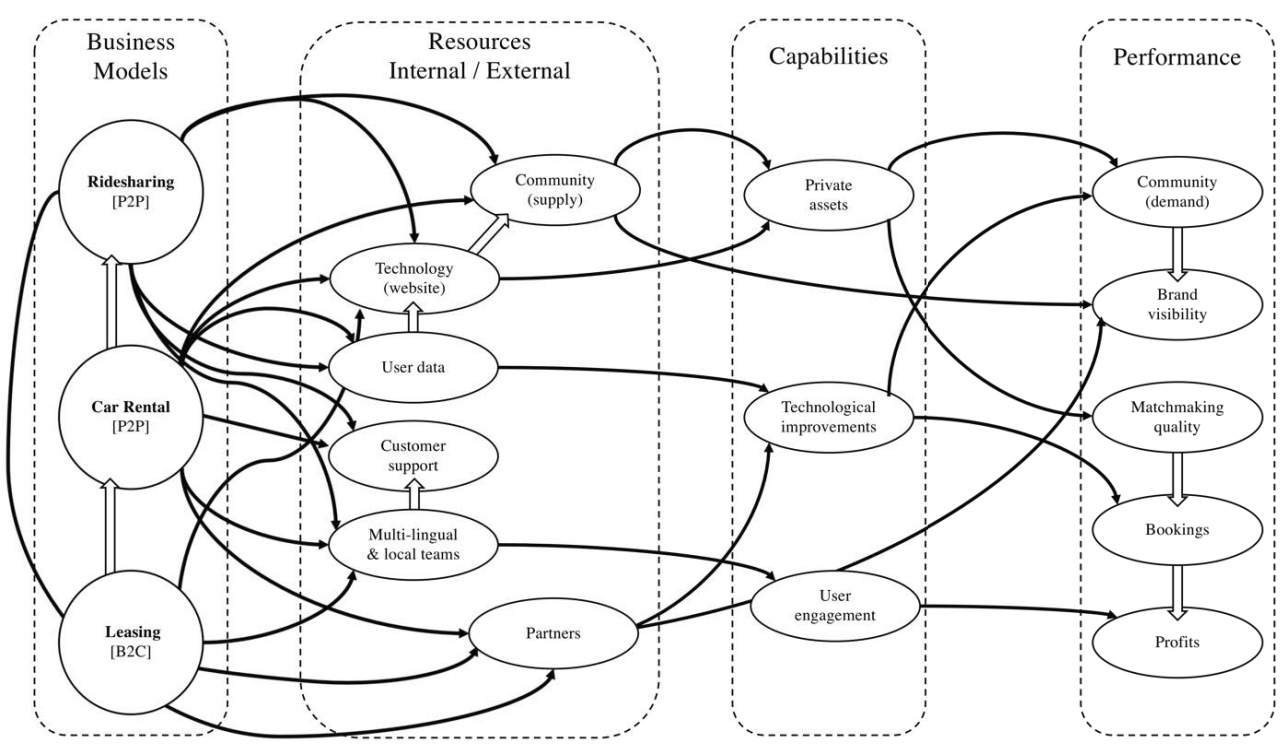

Figure 6. Summary of findings from Paper II.

\section{Contribution to Paper II}

This paper was born out of an interest in the shared mobility sector, and a potential collaboration with GoMore (which was put on hold for a year and a half until they gave up interest for a large survey of their users). Based on an initial round of interviews with management conducted together with Victor Aichagui in early 2015 (I prepared the question guide and transcripts), we coauthored an extended paper for QUIS 2015 using the servicedominant logic to present the case study of the shared mobility platform. Then, I supplemented the dataset with a document analysis, refocused the theoretical framework on service research on access-based consumption and platform business models, and submitted a new single-authored short paper to the 2017 International Workshop on the Sharing Economy (IWSE is a series of conferences organized by a scientific committee of European researchers since 2015). I invited Laura Piscicelli to join me in revising the manuscript and submit to the Special Volume on the Sharing Economy of the Journal of Cleaner Production, co-edited by the IWSE-2017 organizers. We further discussed the emerging literature on the 
"sharing economy" business models, I conducted an additional round of interviews to complement the case study and extended the theoretical framework and contribution of the paper, which was accepted in January 2019.

\subsection{No one rides for free! Three styles of collaborative consumption}

In light of the Heart \& Wallet paradox which platform users have to navigate, this paper set out to explore what people actually do when they participate in collaborative consumption. As mentioned in the previous chapter, the newness of the phenomenon calls for first-hand observations (and participation), in particular to capture the participants' perspective on the tensions between sharing and market logics and how they integrate the conflicting facets of collaborative consumption. In doing so, the application of practice theory enables the procedures, understandings, and engagements that compose a practice of collaborative consumption (e.g., ridesharing) to be disentangled. Practice Theory is a popular framework in service research, and it has been used to investigate the "sharing economy" (e.g., Hazée et al. 2017; Herbert and Collin-Lachaud 2017; Schor et al. 2016). Moreover, previous studies on collaborative consumption showed that various practices can be united by a practice style (cf. Herbert and Collin-Lachaud 2017). As a result, participants in collaborative consumption enact three differ styles: communal, consumerist, and opportunistic (see Table 5). The paper shows that there is no unique way to perform collaborative consumption but different styles, which enable a more granular understanding of the phenomenon. Moreover, I argued that collaborative consumption is not the same as sharing, and nor is it the same as commercial access-based services, although participants adopting the communal style embrace the sharing logic and those adopting the consumerist and opportunistic styles embrace the market logic.

Table 5. Summary of findings from Paper III.

\begin{tabular}{lll}
\hline Communal style & Consumerist style & Opportunistic style \\
\hline Participants seek pro-social & Participants seek status and & Participants seek to achieve \\
relationships in belonging to a & convenience, following an & monetary gain or personal \\
community with values of & access lifestyle trend, and with & benefits from abusive \\
sharing, altruism, and & a commercial orientation. & activities, regardless of the \\
generalized reciprocity. & & $\begin{array}{l}\text { authentic sharing culture and } \\
\text { original communal norms. }\end{array}$ \\
& &
\end{tabular}

This paper contributes to answering the second, third, and fourth research questions by diving deeper into the influence of both sharing and market logics in collaborative consumption 
simultaneously. It shows that ridesharing is a popular practice (e.g., exponential adoption), as the digitalization of the older practice of hitchhiking. From the firm's perspective, BlaBlaCar has been instrumental in leveraging the existing community of riders while implementing a platform business model (i.e. from free to fee). Taking the user's perspective, the original ridesharing community is likely to perform the communal style of collaborative consumption, influenced by collectivism, grassroots/cooperative orientation, sharing and altruism values - the pro-social sharing logic dominates. The more recent community members are more likely to engage in the consumerist style, influenced by the new lifestyle trend based on access, cost-efficiency, and service convenience, or the opportunistic style, influenced by individualism and profit maximization - the utilitarian market logic dominates.

\section{Contribution to Paper III}

This is a single-authored paper, but I will briefly describe the research and publication process like the other papers. In early 2015, I set out to explore and experience first-hand the phenomenon under investigation by participating in ridesharing - with the initial idea to pretest a survey for a study collaboration with GoMore, which was abandoned. Using BlaBlaCar, I shared rides and collected ethnographic data (i.e. field notes, interviews) about this collaborative consumption practice. I used the data for a course paper using the service marketing literature with Lars Witell in the spring of 2016. Meanwhile, I began online searches for news articles and document analysis to supplement the manuscript with quotations, which eventually transformed into a netnography. I subsequently revised the manuscript to submit it to the Journal of Services Marketing in the fall of 2016 and it was accepted for publication in spring 2018. Alongside the beneficial discussions with the review team, I also received feedback from friends and faculty at various stages of the process, as well as at conference presentations (i.e. IWSE 2016 and SERVSIG 2018).

\subsection{User retention in collaborative consumption: The Heart $\&$ Wallet paradox}

This paper contributes to the service marketing literature by presenting a framework (see Figure 7) integrating both logics of collaborative consumption (i.e. the Heart \& Wallet paradox) linking peers' involvement (i.e. perception of cooperation, feelings of communal belonging, authenticity of the sharing ethos) with traditional business metrics (i.e. service convenience, customer satisfaction, loyalty). The study is among the first to link survey measures (attitudes) with platform activity data (actual behaviors) for collaborative consumption. 


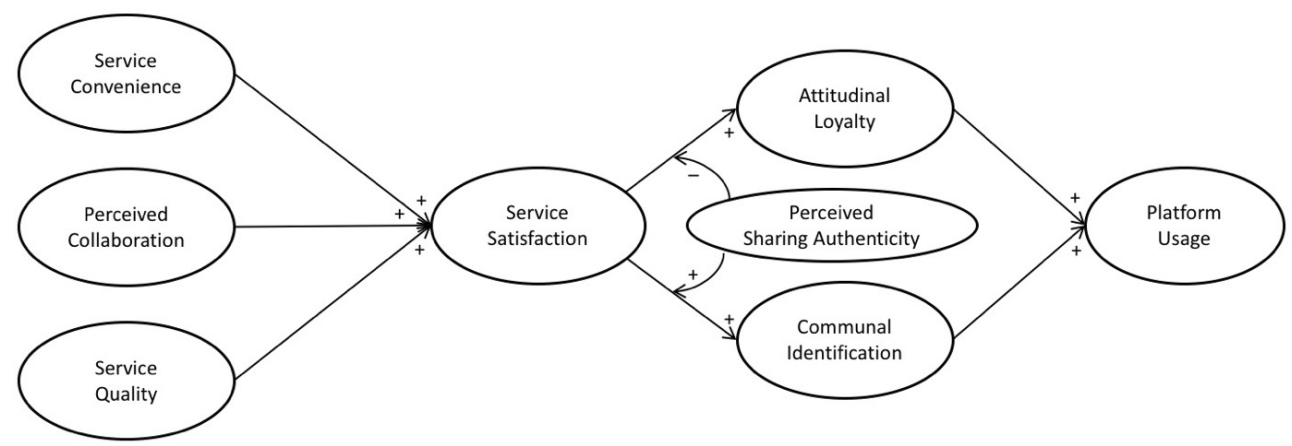

Figure 7. Summary of findings from Paper IV.

Note: Skjutsgruppen ("the lift group" in Swedish) is referred to as "The Ridesharing Group" in Paper IV.

This paper contributes to the fourth research question by taking the user's perspective on collaborative consumption and in particular inquiring about the role of communal belonging for P2P platforms. The results show that collaborative consumption exhibits a different set of factors driving satisfaction, loyalty intentions, and actual platform usage compared with access-based service firms. In particular, service convenience and perceived collaboration efforts from other peers positively influence satisfaction with collaborative consumptionwhile controlling for service quality. Moreover, communal belonging mediates the relationship between satisfaction and platform usage. Participants who are satisfied with their collaborative consumption experience are more likely to continue using the P2P platform if they sense the feeling of belonging to a community. Eventually, we find that perceived sharing authenticity (i.e. true sharing vs. sharewashing) strengthens this mediating effect of communal belonging.

\section{Contribution to Paper IV}

In early 2015, I began to think about collecting quantitative data on collaborative consumption platform users' attitudes. Negotiating access to platform usage metrics (i.e. user behavior) and collaborating with Skjutsgruppen - instead of GoMore or BlaBlaCar-I designed the survey (with feedback from Lars Witell) that was launched in the spring of 2017. Preliminary statistical analyses and theoretical model tests led me to present an extended abstract at the $26^{\text {th }}$ Frontiers of Service Conference (nicknamed FRONTIERS 2017 and held annually by the AMA since 1992). The fall of 2017 was dedicated to revising the model (with Lars' assistance) and writing the front-end of the manuscript (i.e. hypothesis development). I presented a draft at Florida State University for a seminar on Consumer Behavior (organized by Martin Mende), and I discussed the writing process with Charles Hofacker. Later in the 
summer of 2018, Sabine Benoit (who discussed the project with us at FRONTIERS 2017) was invited to join Lars and me to prepare the manuscript for journal submission. I reworked the front-end and methodology while Lars focused on the discussion and conclusion, and Sabine provided detailed suggestions.

\subsection{Summary}

Together, these papers contribute to a better understanding of the Heart \& Wallet paradox of collaborative consumption through answering the four research questions (see Table 6). 
Table 6. Summary of papers.

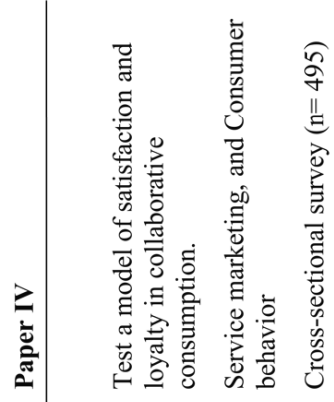

4

离.

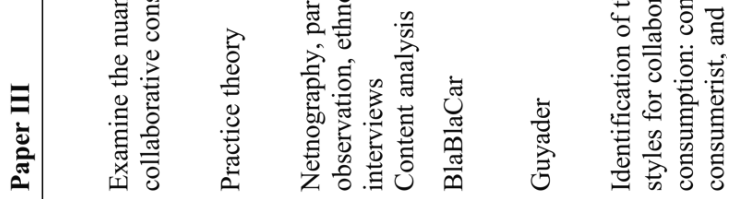

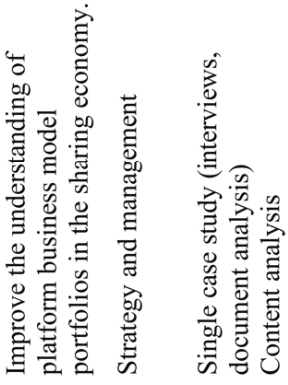

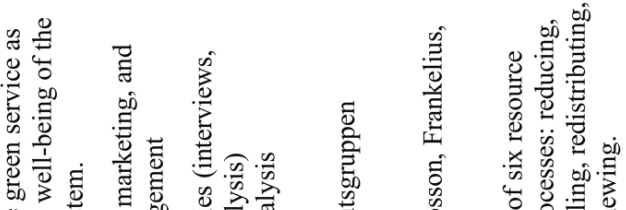

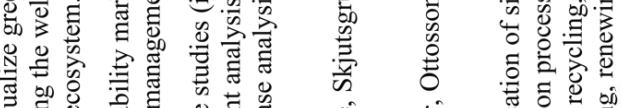

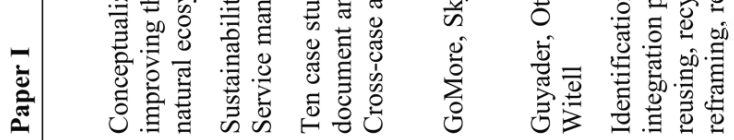

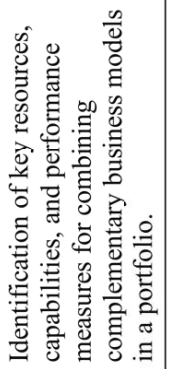

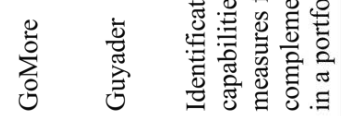

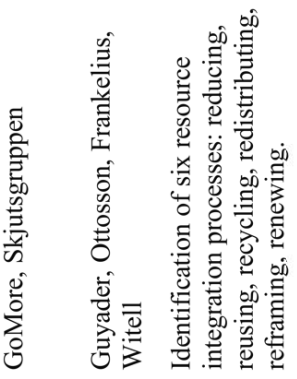

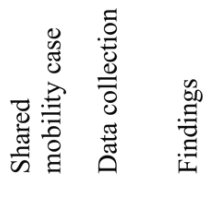

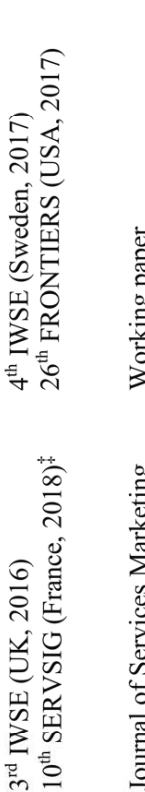

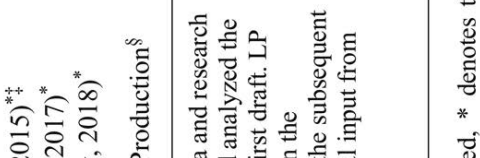

유ำ

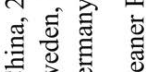

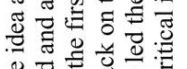

焉

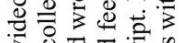

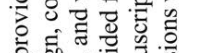

덴데 눙

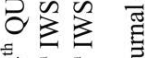

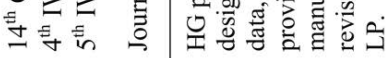

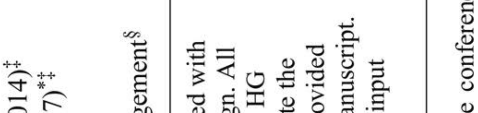

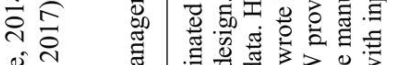

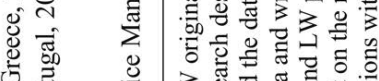

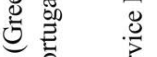

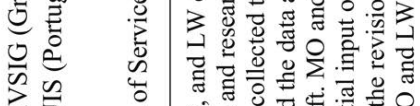

舀宫 焉

离言

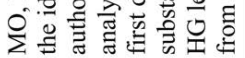

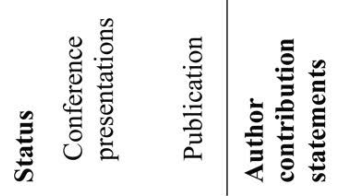

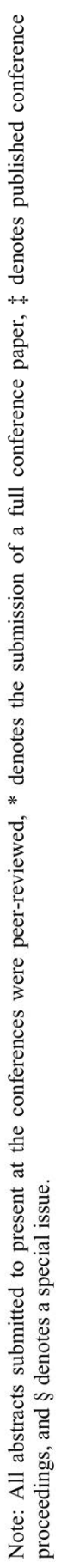





\section{CHAPTER 5 DISCUSSION}

Only the paradox comes anywhere near to comprehending the fullness of life.

- C. Jung (1968)

This chapter proposes to reposition and conceptualize collaborative consumption to better understand the phenomenon through the Heart \& Wallet paradox according to the logics of sharing and market exchange. This is followed by a discussion of the appended papers' findings from two perspectives: the firm's (RQs 1 and 2) and the platform user's (RQs 3 and 4). The discussion ends with a section on the tensions that constitute the Heart \& Wallet paradox, which are embedded in collaborative consumption and persist over time. 


\subsection{Positioning collaborative consumption}

Perhaps because Sharing is Caring had been trademarked by the Salvation Army in 1950, Botsman and Rogers (2010a) opted for What's Mine is Yours as their book title. ${ }^{34}$ Although Botsman and Rogers' (2010a, 2010b) classification was empirical rather than theoretical, it has been widely used in academia to understand the paradigm shift in consumer behavior (e.g., de Rivera et al. 2017; Habibi et al. 2016; Hamari et al. 2016; Roos and Hahn 2017). Based on the diverse concepts presented as theoretical background and in the appended research papers, it is possible to position and differentiate collaborative consumption from other paradigms (see Figure 8). The definition of collaborative consumption given in the introduction can be used to inform discussions of the following: (1) no ownership transfer, only temporal access to privately-owned and underutilized resources; (2) the triadic relationship between a platform provider (firm), peer service providers, and consumers using the platform as private individuals (not employees); and (3) market mediation (i.e. monetary exchanges).

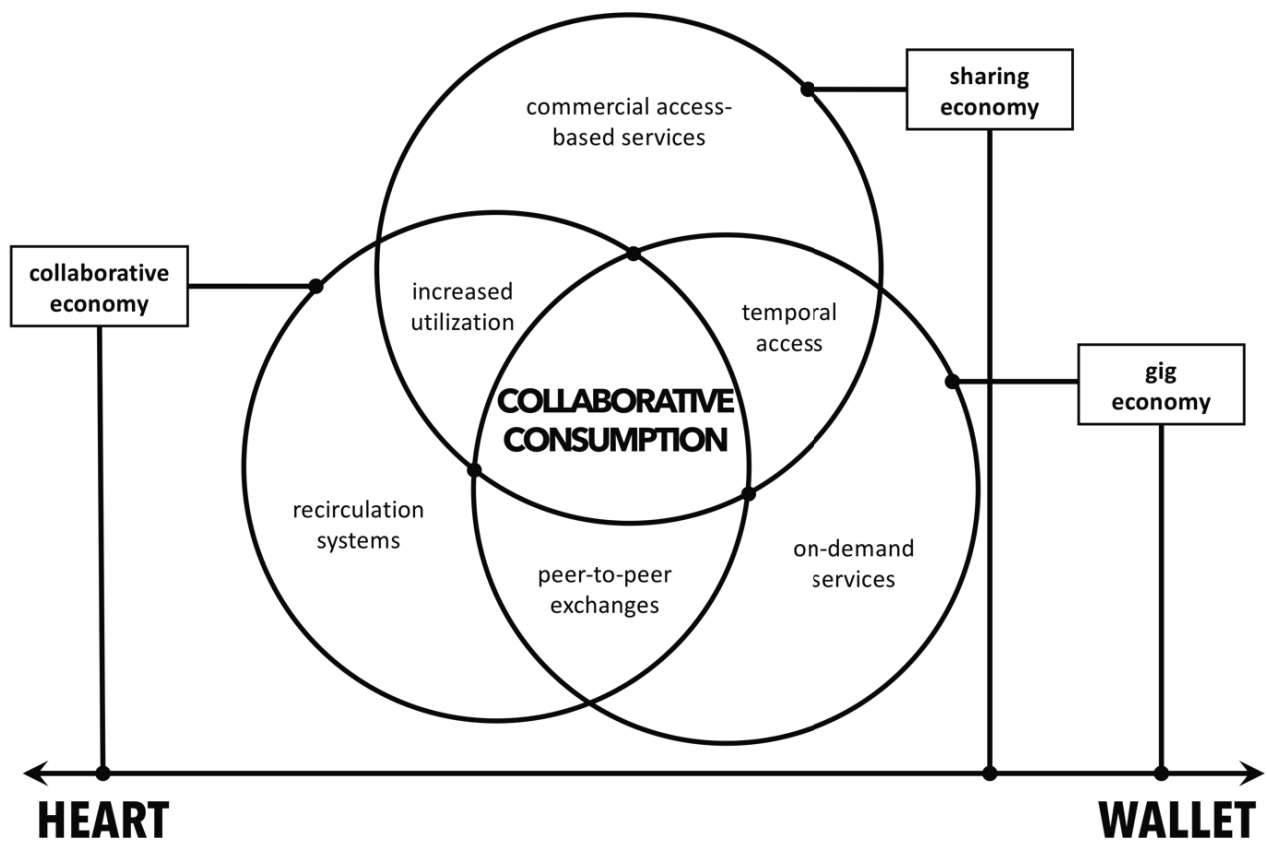

Figure 8. Differentiating collaborative consumption. 


\section{Collaborative consumption is not like commercial access-based services}

The terms "collaborative consumption," "access-based consumption," and "sharing economy" were referred to as synonyms to emphasize the increased utilization of existing resources and the nonownership consumption trend without differentiating between commercial access-based services characterized by B2C relationships and platform-based P2P exchanges (Eckhardt and Bardhi 2016; Habibi et al. 2016; Hartl et al. 2016; Hwang and Griffith 2017; Lawson et al. 2016; Oyedele and Simpson 2018). For example, Hwang and Griffith (2017) used the commercial carsharing context in their vignette studies (e.g., Zipcar) but they misused the term collaborative consumption services in their conceptualization. Fundamentally, collaborative consumption is situated within the access paradigm (Bardhi and Eckhardt 2017; Benoit et al. 2017; Böcker and Meelen 2017; Davidson et al. 2018; Eckhardt and Bardhi 2016; Fritze et al. 2018; Habibi et al. 2016; Hartl et al. 2016; Hofmann et al. 2017; Lamberton 2015, 2016; Möhlmann 2015; Piscicelli et al. 2015, 2018; Wilhelms et al. 2017a, 2017b), but it differs from commercial access-based services provided with a firm's own resources (i.e. the "sharing economy" paradigm) due to the platform business model leveraging private resources (see Papers I and II). For example, GoMore offers diverse shared mobility services without owning any cars or driving anyone themselves, and there is no central garage for customers to go to and meet employees - platform users only ever meet their fellow peers to exchange car keys or share a ride. Although firms offering commercial access-based services and facilitating collaborative consumption increase the utilization of physical resources (compared with individual ownership), only collaborative consumption can relate to the simultaneous shared usage of a private good (e.g., ridesharing participants occupy the car at the same time) rather than the sequential utilization of the same good where customers do not meet each other (i.e. no direct interactions). In other words, collaborative consumption differs from commercial access-based services that are characterized by the sequential usage of commercial goods and not by private resources. Whereas access-based service customers are involved to a certain degree (i.e. self-service), they do not directly interact with one another (Bardhi and Eckhardt 2012; Johnson et al. 1998; Koppenhafer 2014; Lovelock and Gumesson 2004). Moreover, collaborative consumption requires greater consumer cooperation, which leads to greater individual engagement towards the online community formed around the online platform (see Papers III and IV).

\section{Collaborative consumption is not like on-demand services}

Collaborative consumption further differs from the on-demand services offered in the gig economy paradigm — sometimes called the platform economy - as collaborative consumption participants not only meet each other offline but also share the usage of a physical good 
contrary to intangible service offerings, such as consulting services offered by freelancers and independent contractors. The potential for monetization through the $\mathrm{P} 2 \mathrm{P}$ exchange of goods and services is greatly emphasized in the more recent gig economy discourse (see also Appendix 2). On-demand services are based on traditional selling/buying behaviors, but they are mediated online (or via an app). Although both on-demand services and collaborative consumption are facilitated by online platforms, the latter requires direct interactions between peer providers and consumers, such as meeting to exchange car rental keys (see Paper II). Moreover, collaborative consumption is pro-social, for example feelings of communal belonging are highly significant for participants in P2P exchanges (see Papers III and IV) contrary to on-demand services, which are characterized by impersonal exchanges.

Thus, Uber is not a good example of collaborative consumption. Such on-demand services are provided by trained professionals and freelancers who actually add capacity and resources to the market (e.g., more cars are added in the streets). On the contrary, peer providers of BlaBlaCar-the prototypical example of collaborative consumption-are occasional amateurs, who participate in ridesharing to compensate their costs by increasing the efficiency of what they were already doing: i.e. driving to their destination with more people. While Uber has claimed to facilitate ridesharing - an instance of sharewashing - their drivers do not increase the utilization of existing assets (e.g., empty seats) but drive on purpose (i.e. adding seats or traffic congestion) to make a profit, so the firm provides a taxi or ride-hailing service with a simple app (Legros 2015; Meelen and Frenken 2015; Rayle et al. 2016). Ultimately, ridesharing and ride-hailing are two different shared mobility services (see also Appendix 6).

\section{Collaborative consumption is not like recirculation systems}

The concept of collaborative consumption is entangled with the lack of differentiation between consumer practices that impede a change in ownership and those that do not. Moreover, several key papers on the various contexts have been confusingly interchanged as references to diverse "new" modes of consumption embedded in the "sharing economy" (e.g., Albinson and Perera 2012; Bardhi and Eckhardt 2012; Belk 2010, Moeller and Wittkowski 2010; Ozanne and Ballantine 2010). Therefore, subsequent studies may have misguiding research findings on actual collaborative consumption due to the newness of the phenomenon and the inconsistent use of terminology.

Ultimately, collaborative consumption differs from recirculation systems that facilitate a change of ownership (see Paper I). Although both increase the utilization of goods, collaborative consumption does so through temporal access, while donation platforms (i.e. online intermediaries) and secondhand stores (i.e. offline intermediaries) that are framed as 
the collaborative economy or circular economy relate more to gift giving, swapping (i.e. nonmonetary practices), and traditional buying/selling behaviors (i.e. market exchanges). That is, recirculation systems facilitating a permanent change in private individual ownership are not collaborative consumption practices - the utilization of goods is shared over time between several people (i.e. extending the lifetime of a good), which lacks the temporal dimension of the access paradigm. Nevertheless, collaborative consumption participants can evoke similar anti-consumption values as grassroots movements engaging in non-monetary practices (see Paper III).

\section{Collaborative consumption and the Heart $\varepsilon$ Wallet paradox}

In summary, collaborative consumption is embedded in the Heart \& Wallet paradox. The collaborative economy discourse tends to emphasize the heart, while the sharing economy and gig economy discourses tend to emphasize the wallet (see Figure 8). Others have attempted to encapsulate the diverse consumption trends in a Venn diagram. Acquier et al. (2017) argued that the "sharing economy" is an umbrella construct with three interrelated foundational cores: access-based consumption to increase the utilization of existing resources (goods/services), the online platform mediating P2P exchanges, and the grassroots communities practicing non-contractual and non-monetary practices. However, Acquier et al. (2017) do not further delineate nuances within these core trends - it is inherently an incomplete diagram - despite their argumentation that the "sharing economy" phenomenon has fuzzy boundaries (cf. Belk 2014b; Frenken and Shor 2017).

Frenken (Frenken and Schor 2017; Frenken 2017) (35 $^{35}$ argued that the key characteristics of the "sharing economy" reflect broader economic trends: P2P exchanges (platform economy), temporary access (access economy), and underutilized goods (circular economy). Inversely, these characteristics also distinguish the new phenomenon from older economic trends (i.e. before the Internet): the secondhand economy (change of ownership, both for free or compensated), the product-service system economy (the rental paradigm where firms sell services instead of goods), and the on-demand economy (intangible services such as a handyman). Frenken's representation basically refers to collaborative consumption as the "sharing economy," although it emphasizes differences between diverse business activities and consumer behaviors that are similar to those in this thesis.

\subsection{The firm's perspective}

From the firm's perspective, Papers I and II provide relevant findings to answer the first research question regarding the mechanisms, business processes, and pitfalls of online 
platforms facilitating the $\mathrm{P} 2 \mathrm{P}$ exchange of private resources for a fee. There are two key takeaways from investigating the firm's perspective on collaborative consumption. Firms such as GoMore and BlaBlaCar have developed online platforms that replicate the functionalities of e-commerce websites (e.g., reputation system, booking system, and online payment) and leverage social media networks to make collaborative consumption as personal as previously existing sharing practices with friends and family - that is, firms have digitalized sharing practices that were limited to family, friends, and grassroots movements. The firm's role as an enabler of P2P exchanges is embedded in platform business models that charge a fee for each transaction facilitated between people with their private resources. In summary, the firms monetize private resources through collaborative consumption.

Concerning the second research question on how firms stimulate the sharing logic of collaborative consumption, it is interesting to further compare the different cases of shared mobility_GoMore (Papers I and II), BlaBlaCar (Paper III), and Skjutsgruppen (Papers I and IV). Firms engage their platform users to take an active role and promote a communal image of collaborative consumption that benefits from the personal nature of the $\mathrm{P} 2 \mathrm{P}$ exchanges between people and with their own possessions.

\section{E-commerce onto sharing practices}

Carsharing was nothing new for grassroots movements when firms institutionalized the old non-monetary practice (Belk 2010). ${ }^{36}$ It took until the early 1990s for organizations to become legitimized and carsharing systems to spread worldwide (Shaheen et al. 1999; Shaheen et al. 2015). From cooperative carsharing (e.g., Vivalla bil or Majorna in Sweden), in which a few households organized the shared ownership and utilization of vehicles locally (Belk 2014a), carsharing evolved with organizations (non-profit and for-profit) taking on fleet management responsibility (see also Appendix 1). Carsharing is in fact the most studied context for access-based consumption (Bardhi and Eckhardt 2012; Gruen 2017; Johnson et al. 1998; Lamberton and Rose 2012; Lawson et al. 2016; Schaefers et al. 2016a, 2016b). Shortly after Zipcar was launched in 2000 as the first commercial access-based service for carsharing, the first P2P car rental platforms were launched by eGO CarShare (Boulder, Colorado) and RentMyCar (Germany) in 2001 (Shaheen et al. 2012, 2018) and by GoMore in 2014. Similar to the way in which Zipcar commercialized the previously existing practice of cooperative carsharing, these firms adapted the practice of borrowing a car between friends and family and began to facilitate $\mathrm{P} 2 \mathrm{P}$ car rental-also called personal carsharing - by developing online platforms for owners (peer providers) to rent their car directly to other people (consumers). 
Firms facilitating P2P car rental replicated e-commerce website functionalities, such as reputation system based on peer reviews, booking (order) system, and online payment in their online platforms, to make it efficient and attractive to organize P2P exchanges (see Paper II). Before P2P car rental, people used to share their car for free if a friend asked. That is, it was a case of borrowing - a "borderline case of sharing" (Belk 2010, p. 717). Borrowing cars also happened between acquaintances, such as colleagues or friends of friends, but it was difficult to arrange outside of these relationships due to a lack of demand/awareness of a potential match between owner and driver as a result of a too small number of people one knows or a lack of trust. GoMore's platform functionalities include an ID verification process that requires a license number and driving experience for new users, which helps participants take the necessary leap of trust associated with sharing their underutilized but personal things with strangers, on a global scale. GoMore also partnered with an insurance firm to cover the rental period (see Paper II). Borrowing became rental. Such online platforms for P2P car rental facilitate monetary exchanges between people taking on market roles, which assimilates to the logic of market exchanges (Bagozzi 1975; Belk 2010; Eckhardt and Bardhi 2016; Houston and Gassenheimer 1987; Hunt 1976; Scaraboto 2015). Previous research has shown that inconvenience is a barrier to access-based consumption (Hazée et al. 2017) — it can be complicated to understand and use the diverse services offered in the "sharing economy." Thanks to technology, GoMore as well as BlaBlaCar make it easy and convenient for people to increase the utilization of existing resources. As such, they reduce both the burdens of ownership (Berry and Maricle 1973; Moeller and Wittkowski 2010) and the burdens of access (Hazée et al. 2017). This is in line with Kumar et al. (2018), who argue that practicality is key to success for online platforms.

In the same way, BlaBlaCar considerably improved the former notice board websitewhich was without interactive functions - by leveraging some of the rules of e-commerce and integrating functionalities replicating social media networks onto a new online platform that was comparatively more efficient at helping ridesharing participants organize their P2P exchanges (see Paper III). Drivers and passengers could interact in more ways and with greater ease - rather than being limited by the static and archaic notice boards and online forums. For example, BlaBlaCar developed a website with search functions similar to other transportation services, such as the date, the itinerary (i.e. point of origin and destination, as well as time flexibility, possible detours, and luggage size, etc.), the number of seats requested, and of course the price of the rides (see Appendix 4).

Importantly, BlaBlaCar and GoMore facilitate online payment, which is among the reasons that collaborative consumption is associated with e-commerce websites (e.g., Perren and Grauerholz 2015). That is, P2P exchanges in collaborative consumption are set in a market logic due to the agreed terms of exchange (e.g., price), such as a contract (Houston 
and Gassenheimer 1987). It is the payment function of online platforms that tilts collaborative consumption towards the wallet by emphasizing the market logic.

Furthermore, GoMore is an interesting case to differentiate between platform business models and rental business models based on B2C relationships (see Paper II). Whereas ridesharing and $\mathrm{P} 2 \mathrm{P}$ car rental are typical examples of collaborative consumption services taking place between people with their private resources, the leasing service offered by GoMore is basically a long-term rental service provided by a firm to its customers (Berry and Maricle 1973; Lovelock and Gummesson 2004). GoMore's partnership with a leasing firm is a strategy to unlock value co-creation (i.e. P2P car rental) by increasing (car) ownership in the first place (Ehret and Wirtz 2018; Ndubisi et al. 2016). Car leasing customers acquire permanent usage for a long time period (e.g., up to several years), such that they perceive the car as their own property (i.e. psychological ownership; Peck and Shu 2018). Schaefers et al. (2018) also showed that long-term access (vs. short-term) was perceived as too similar to ownership by consumers. Moreover, unlike P2P exchanges, leasing services do not involve direct interactions between multiple consumers. In sum, leasing services are closer to traditional ownership-based consumption than commercial access-based services (Bardhi and Eckhardt 2012), let alone collaborative consumption. Ultimately, the leasing service targets a different customer segment (i.e. people who need the benefits of car ownership without the burdens of ownership; cf. Berry and Maricle 1973; Moeller and Wittkowski 2010). However, leasing increases the number of cars available for rental on the platform, as it enables customers to reduce their leasing costs. GoMore launched its services consecutively so that leasing boosted the P2P car rental business, which in turn boosted the ridesharing business model.

\section{Platform-based business model}

GoMore puts it this way: "People get the experience of renting a friend's car, instead of hiring a car. It's a business transaction, but they talk about it as if they do each other a favor [...] we're doing the same thing as Avis or Hertz, just cheaper" (Personal communication 2015). In other words, P2P car rental is like traditional carsharing (or commercial access-based services) but provided by private people (cf. Wilhelms et al. 2017a). In its role as facilitator, the firm assists platform users in pre-arranging an exchange of services online before conducting the exchange offline, i.e. directly from peer providers to consumers. Redistributing underutilized resources (e.g., seats and cars) is potentially beneficial from an environmental resource perspective (see Paper I), but it is all the more interesting for firms if a fee can be charged for doing so (see Paper II). For example, BlaBlaCar, GoMore, and 
Skjutsgruppen started as non-profit organizations in 2004, 2005, and 2007, respectively. ${ }^{37}$ Contrary to Skjutsgruppen, which has thus far remained a non-profit organization, BlaBlaCar and GoMore have since adopted a for-profit orientation. Previous research has shown that grassroots movements tend to become commercially-oriented, particularly in the "sharing economy" (e.g., Casprini et al. 2018; Martin et al. 2015). ${ }^{38}$ In 2011, BlaBlaCar deployed a platform business model based on a commission (10-12\%) and a fixed fee on each seat reserved by passengers (see Paper III). ${ }^{39}$ The same year, GoMore's founders realized the business opportunity of their project and developed similar functionalities to BlaBlaCar on their platform (while keeping it free for users). In 2013, GoMore also adopted a platform business model based on a $9 \%$ commission for each ride. The commission was raised to $12.5 \%$ in 2018 , which is standard for ridesharing platforms. For P2P car rentals, GoMore operates the same platform business model on a different P2P exchange: the commission is $20.5 \%$ per transaction - which is a competitive pricing strategy compared to other car rental platforms averaging 30\% commission. This commission varies based on the extent of value added by GoMore (e.g., the insurance coverage needs be more extensive for P2P car rental than ridesharing). Benoit et al. (2017) argued that the role of the firm as a service enabler is different in collaborative consumption, but they did not mention such provision of insurance despite its significant influence on the matchmaking commission.

GoMore can be considered to operate multiple platforms on the same website/app: one ridesharing platform for drivers/passengers and one carsharing platform for renters/owners (see Paper II). In short, GoMore's portfolio of shared mobility services is supported by a portfolio of platform business models that leverage the technological capabilities developed for one service onto another (e.g., matchmaking algorithms and localization services) as well as the existing partners' relationships (e.g., insurance and online payment) and the existing platform user base (e.g., a growing community with existing peer reviews). In doing so, GoMore has leveraged and monetized private resources that belong to the same platform user: the car can be rented on its own, or it can be used to deliver a ridesharing service. This is likely to reinforce the exploitative processes referred to by critics of capitalism (e.g., Bourdieu 1986), as it emphasizes the self-interest and utility maximization of the market logic (Bagozzi 1975; Houston and Gassenheimer 1987).

Much of GoMore's message is based on the economic aspect of collaborative consumption (see Paper II). For example, one of their recent email campaigns offered platform users a car photoshoot to increase rentals, which illustrated a certain professionalization of the wallet of collaborative consumption-Airbnb was the precursor of such cooperation with professional photographers. Another GoMore campaign (see Figure 8) had the subject line Four reasons why you should rent your car and went on to convince car owners by listing the economic incentive first. It also listed the arguments that borrowers 
obtain a $4.5 / 5$ peer review on average and that car owners help others by offering their carswhich emphasizes that P2P car rental is safe and can be perceived as a form of altruism, although it is framed as a way to enhance one's own personal benefits (i.e. karma). In other words, this involves helping others in a way that first and foremost helps oneself. This is in line with the market logic of utility maximization and profit-seeking behavior rather than the sharing logic (Belk 2010; Scaraboto 2015). Platform users are informed of the commercial potential of ownership to make money rather than increasing resource utilization or reducing consumption in general.

GoMore's landing page for car rental provides guidelines for owners to increase the number of reservations, such as highlighting the rental offer in the search results or printing ready-made flyers (see Figure 9). This focus on self-interest evokes the logic of market exchanges (Bagozzi 1975; Houston and Gassenheimer 1987; Hunt 1976). The emphasis on increasing monetary benefits corroborates the tendency towards profit-making motives among collaborative consumption participants engaging in an opportunistic style (see Paper III).

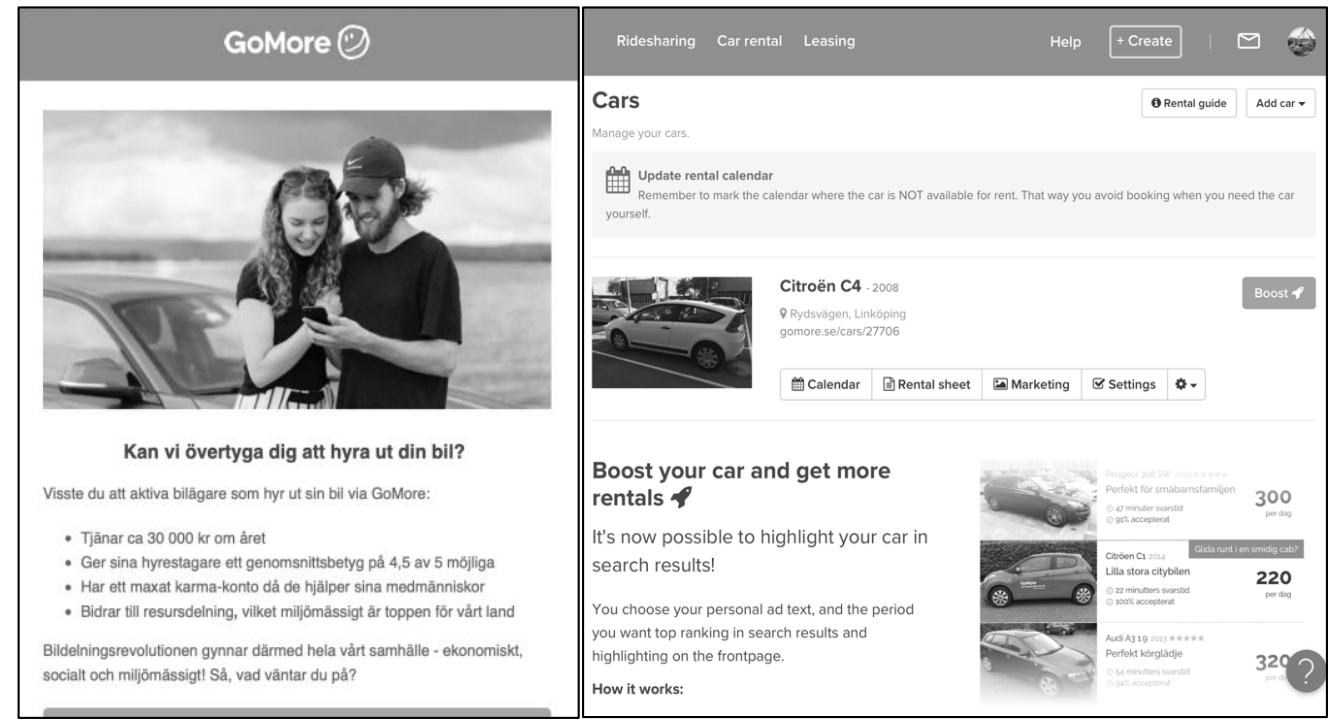

Figure 9. Examples of GoMore's marketing communications.

Note: To the left, screenshot of an email campaign [in Swedish] (12 September, 2017). To the right, screenshot of the online platform (9 August, 2016).

As mentioned earlier, Skjutsgruppen has no revenue model — it has no commission or paid advertising. It is a non-profit organization that is financed by public funding from local governments, small grants, and crowd-financing campaigns - i.e. it is a community-backed 
initiative. However, Skjutsgruppen participants exchange money when compensating for fuel, tolls, etc., so it differs from other grassroots movements that support non-monetary practices of trading and redistributing goods outside of markets (Albinsson and Perera 2012; Corciolani and Dalli 2014; Gollnhofer et al. 2016, 2017a, 2017b; Kim 2017; Krush et al. 2015; Martin and Upham 2016; McArthur 2015; Nelson et al. 2007; Ozanne and Ballantine 2010). The online platform does not facilitate credit card transactions or contractual seat reservations, and money is exchanged in cash in the car or through Swish (a free smartphone app for making payments in Sweden). In other words, Skjutsgruppen has facilitated collaborative consumption without a platform business model—although platform users still compensate each other monetarily.

\section{Community engagement}

Contrary to access-based consumption, which is characterized by self-service (i.e. low customer involvement), between-customer rivalry for a limited supply of the good, and low customer identification with the firm's other customers (Bardhi and Eckhardt 2012; Lamberton and Rose 2012; Schaefers et al. 2016b), collaborative consumption is characterized by a higher individual engagement towards the community. This is a fundamental difference between the B2C relationships of commercial access-based services and the P2P exchanges of collaborative consumption.

Skjutsgruppen started as a simple Facebook group in 2007 to attenuate the necessary leap of trust required to participate in ridesharing with strangers. Participants in the movement could check each other's personal page, social network connections, and other personal aspects of their life. ${ }^{40}$ As a grassroots movement, the Skjutsgruppen community relied exclusively on social media networks until 2012, when the movement crowd-funded the development of a platform with more functionality than Facebook groups. Interestingly, the online platform has no reputation system; only the degrees of separation (cf. Milgram 1967) between users are displayed to show how many other relationships separate them (see Appendix 7). This emphasizes communal sharing relationships (cf. Clark and Mills 1979) and the sharing logic of a cooperative group of people with social interactions and a sense of commonality who self-organize and redistribute resources (Belk 2010).

BlaBlaCar argued that its trusted community members rate their level of trust in each other (88\%) almost as much as friends (92\%) or family (94\%) (Mazzella and Sundararajan 2016). This is interesting, as it relates to communal relationships involving kindness, cooperation, and shared identity taking place between friends and family members (Clark and Mills 1979; Fiske 1992). Schor (2014, p. 7) also argued that collaborative consumption is a kind of stranger sharing, as it involves personal relationships similar to the prototype of 
sharing (Belk 2010). As such, collaborative consumption concerns practices between friends of friends - a form of sharing (out $)^{2}$ where the circle of people who can be trusted is further extended to form a large family. In other words, online platforms are designed to remove the impersonal characteristics of market exchanges (Belk 2010; Scaraboto 2015), thus emphasizing the heart of collaborative consumption embedded in the sharing logic.

Jägerskog, the founder of the Facebook group, describes the participatory culture of Skjutsgruppen that engages its community by calling its members to be "actors within the ridesharing movement" (e.g., through crowd-financing and crowdsourcing the platform): "We call ourselves a civil society movement. None of our users are customers, we are all participants." The board of the non-profit organization argued that anybody could take over the development and support of the movement: "We, as an organization, we are not the movement. We are helping the movement. The movement is the users" (Personal communication 2015). ${ }^{41}$ This is the sharing ethos found in the open-source software movement, embedded in values of transparency, social justice, autonomy, open production, and distribution (cf. Tapscott and Williams 2006). In other words, Skjutsgruppen promotes a genuine idea of ridesharing to its members based on sharing the costs of driving among car occupants - with a strong environmental orientation. BlaBlaCar also organizes events for its community to meet up, and it promotes a shared idea of what ridesharing is about (see Paper III). BlaBlaCar and Skjutsgruppen have involved and engaged their (core) community members to be actors in the shared mobility revolution, which emphasizes the sharing logic of collaborative consumption.

GoMore often communicates the likelihood of making new friends among strangers and belonging to a trustworthy and caring community. It employs images of people engaging in a seemingly friendly conversation or laughing out loud while sharing a ride, which strongly emphasizes the social interactions of collaborative consumption (see Figure 8). Moreover, a campaign offered a $€ 10$ voucher for describing a GoMore story to the marketing team. These personal anecdotes are collected and used to communicate to the existing community and potential new customers through blogposts and on social media networks (similar to BlaBlaCar). These customer experiences are not only authentic but also invariably positive. Kumar et al. (2018) argued that firms should engage their platform users to share their experiences on social media networks to increase word-of-mouth.

However, GoMore attempts to leverage and stimulate the sharing logic while at the same time extensively communicating the economic benefits of using the platform. This could be considered a case of community washing or plain sharewashing (Hawlitschek et al. 2018; Price and Belk 2016). Sharewashing was defined as "a platform operator's efforts of misleading consumers by purposely portraying an image of social and ecological principles while the platform's business model is actually centered around delivering utilitarian value" 
(Hawlitschek et al. 2018, p. 2). In reality, interactions between car owners and borrowers in P2P car rental are often characterized as "sterile," "anonymous," and "nothing" (cf. Fenton 2015). Hawlitschek et al. (2018) also argued that sharewashing perceptions are caused by marketing communications, which should "be redirected away from notions of community, sociability, and sustainability, towards other concepts such as functionality, cost savings, ease of use, or individual benefits" (p.11). In other words, quit the sharing and community language to focus on consumer wallets or risk deceiving platform users with fake promises and corrupting their trust.

Previous research has pointed out that cultural differences influence sharing practices (Belk 2010; Belk and Llamas 2012) and collaborative consumption practices (Davidson et al. 2018), such as the way in which the individualistic orientation of Scandinavian people differs from the more collectivist orientation of other European cultures. In other words, when GoMore imported ridesharing from Germany ${ }^{42}$ and intended to replicate the growth strategy of BlaBlaCar in France (see Appendix 9), the firm did not consider that "it might also be OK to show pictures where people don't talk"- to quote one of my Swedish informants - to reflect the usual discretion adopted by Swedes when meeting strangers. Ridesharing participants perceive GoMore as facilitating commercial transactions rather than pro-social interactions. GoMore is embracing the Heart \& Wallet paradox of collaborative consumption by emphasizing the financial aspect of exchanges on P2P markets to motivate its participants, although it places commercial relationships in the sharing logic of socially-mediated exchanges between people.

To summarize the Heart \& Wallet of collaborative consumption from the firm's perspective, it is important to understand that the contemporary practices of ridesharing and $\mathrm{P} 2 \mathrm{P}$ car rental have their origins in older practices that used to take place outside of the market and within grassroots movements or non-profit cooperatives-i.e. without commercial orientation and sometimes even employing non-monetary practices. Firms have leveraged developments in technologies from e-commerce and social media networks to monetize private resources (i.e. not their own) through platform business models, although they emphasize the social aspects of $\mathrm{P} 2 \mathrm{P}$ exchanges so that participants associate their peers with friends rather than strangers and identify with their (online) community.

\subsection{The platform user's perspective}

To better understand the Heart \& Wallet paradox of collaborative consumption, it is relevant to take the perspective of the platform users participating in the multi-faceted phenomenon under investigation. 
Scaraboto (2015) showed that the geocaching community combines and reconciles opposing logics in hybrid economies where economic and social values coexist in continuous tensions - which is in line with how markets are entangled with society, and supports employing paradox theory to further understand collaborative consumption. Similarly, Corciolani and Dalli (2014) showed that participant members of bookcrossing.com combine different anti-consumption practices to facilitate the recirculation of books (in contrast with buying and owning books). Such practices (e.g., foodsharing.de, freecycle.org, landshare.co.uk, and timerepublik.com) connote anti-capitalist or anti-consumption values (Arcidiacono 2018; Gollnhofer et al. 2016; Kim 2017; Krush et al. 2015; Martin and Upham 2016; McArthur 2015; Nelson et al. 2007; Nelson and Rademacher 2009; Ozanne and Ozanne 2016; Papoikonomou and Valor 2016; Schor et al. 2016), although they are also embedded in the market logic due to the change of ownership and claims of direct reciprocity.

The third research question investigates the effects of monetary compensation. Previous research showed that the cases of Airbnb and Uber were closer to the market logic than CouchSurfing (i.e. an accommodation sharing platform rather than a rental platform like Airbnb, its more recent cousin) and KangaRide (i.e. a ridesharing platform similar to BlaBlaCar) are to the sharing logic, although all these organizations are facilitating exchanges between people (i.e. P2P and not B2C) and access-based consumption (Bucher et al. 2016; Davidson et al. 2018; Habibi et al. 2016). While the findings from Paper III are derived from a single context (i.e. ridesharing), they are in line with the conceptualization of collaborative consumption as involving different degrees of true sharing and market exchange. In particular, Paper III conceptualizes three styles of collaborative consumption according to how ridesharing participants perform the practice, i.e. the procedures, understandings, and engagements involved in ridesharing. The consumerist and opportunistic styles of collaborative consumption are situated closer to the market exchange side of the continuum (see Figure 10). The two styles emphasize the commercial orientation that paying for collaborative consumption entails - i.e. collaborative consumption participants can embrace the market logic of collaborative consumption to varying extents.

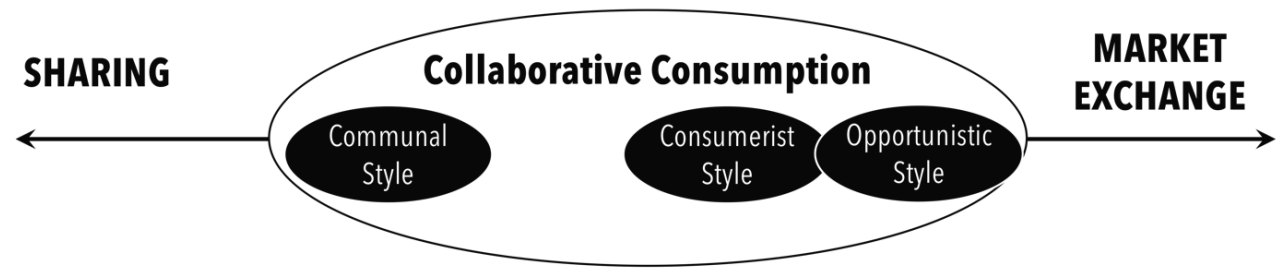

Figure 10. Positioning the collaborative consumption styles. 
The fourth research question regards the role of communal belonging in collaborative consumption, to which Papers III and IV yielded relevant findings. In particular, Paper III conceptualizes the communal style of collaborative consumption, and Paper IV shows that communal belonging is a necessary component for peer providers and consumers to actually be active platform users - i.e. ridesharing participants.

\section{Consumerist collaborative consumption}

The consumerist style of collaborative consumption is closer to the sharing logic than the opportunistic style. As such, consumerist collaborative consumption represents the middleground between the three styles. Participants are commercially oriented-they consider collaborative consumption as a transaction between peer providers and consumers of services - but they also acknowledge that all participants are socially interested (see Paper III). They value the economic utility of sharing the usage of resources, which also allows them to interact with new people. For example, passengers (i.e. not car owners) in the consumerist style consider ridesharing as a cheaper alternative to public transportation rather than as a pro-social opportunity. Drivers (i.e. car owners) consider ridesharing as an opportunity to reduce their travel costs. Collaborative consumption between consumerist participants is based on the mutual maximization of their self-interests - i.e. cost-savings (Belk 2010; Houston and Gassenheimer 1987; Scaraboto 2015). In a sense, the consumerist style is the P2P equivalent of commercial access-based services (cf. Wilhelms et al. 2017a): participants expect professionalism from their peers (rather than courtesy). This is in line with practices referred to in the gig economy paradigm - the latest version of e-commerce.

\section{Opportunistic collaborative consumption}

The market logic is more salient in the opportunistic style than the consumerist style, and it is performed by participants motivated by resource exploitation and profit maximization and who are willing to forego communal norms (i.e. communitarian ideology and the original sharing ethos of ridesharing) — in this case, there is no desire for social interactions. Although peer providers and consumers have a name, it does not matter to the opportunists, who associate collaborative consumption with commercial and impersonal transactions, which is a characteristic of the market logic (Belk 2010; Scaraboto 2010). The deceptive and abusive ridesharing activities illustrated in the opportunistic style (see Paper III) show that collaborative consumption can be much closer to the traditional market behaviors of selling and buying than it is to sharing.

Previous marketing research has pinpointed opportunistic behaviors performed by customers in $\mathrm{B} 2 \mathrm{C}$ relationshipssuch as service workers using their professional knowledge, 
rule breakers, or illegitimate complainers for example (c.f. Wirtz and McColl-Kennedy 2010). Paper III is the first to document such dysfunctional behaviors in the context of collaborative consumption where the firm's customers are on either or both sides of a P2P platform - so that they behave opportunistically to each other, and not only towards the firm. In other words, the opportunistic style of collaborative consumption represents the "dark side of the sharing economy" (cf. Malhotra and Van Alstyne 2014).

\section{Communal collaborative consumption}

The communal style of collaborative consumption is situated closer to the sharing side of the continuum than market exchange. As such, it shows that although collaborative consumption is market-mediated (i.e. there is an exchange of money), it is embedded in a sharing ethosthe heart aspect of the paradox. Participants performing a communal style of collaborative consumption have a pro-social orientation; they value the community to which they feel they belong (i.e. the grassroots movement), but they resent the capitalist ideology embedded in the technological improvements of the platform leading to a professionalization of the practice. There is a sort of "us versus them" (cf. McArthur 2015) situation, where "us" are experienced users (communal style) who were sharing rides before BlaBlaCar improved the overall organization of the ridesharing practice, and "them" are the newcomers (consumerist and opportunistic styles) who adopt collaborative consumption as the most fashionable and convenient alternative for an access lifestyle (cf. Rifkin 2000).

The feelings of communal belonging shared by the participants in collaborative consumption are one of the fundamental differences with commercial access-based services or traditional self-services: collaborative consumption is less institutionalized, as there are no trained employees but only heterogeneous private individuals (see Paper III). Previous research has shown that social interactions can be one of the driving motives for participating in collaborative consumption (Hamari et al. 2016; Herbert and Collin-Lachaud 2017; Koppenhafer 2014; Möhlmann 2015; Wilhelms et al. 2017a, 2017b). Compared with commercial access-based services, collaborative consumption participants meet each other. For example, ridesharing participants have the entire duration of their trip $(300 \mathrm{~km}$ on average) to chat and get to know each other (see Paper III). Moreover, feelings of belonging to a community seem to be a key differentiator between the communal style (i.e. sharing logic) and the consumerist and opportunistic styles (i.e. market logic) of collaborative consumption (see Paper III).

In summary, the Heart \& Wallet paradox for platform users translates into the enactment of several styles of collaborative consumption. There is not a single way to participate, but, rather, different nuances of the same practice (e.g., ridesharing) can be 
observed, which fall in different positions on the continuum of collaborative consumption between sharing and market exchange.

\section{The role of communal belonging}

Paper III shows the importance of the original ridesharing community for BlaBlaCar. Previous research on brand communities showed that participation in a "brandfest" (e.g., Harley-Davidson and Jeep) increased their communal engagement and repurchase intentions (McAlexander et al. 2002). Newcomers to BlaBlaCar or ridesharing (i.e. similar to novice owners of a Harley-Davidson motorcycle) also gradually feel part of the community on hearing personal stories, and they learn the tricks of the trade to yield greater benefits from their new community; while experienced participants (similar to long-time product owners) reaffirm their community ties by mentoring and performing. Moreover, communal belonging leads to greater engagement: people who identify as members of the brand community have an intrinsic motivation to interact and cooperate with other members, helping them if necessary and "acting volitionally in ways that the community endorses and that enhance its value for themselves and others" (Algesheimer et al. 2005, p. 21). Similarly, participation in online communities is associated with greater brand commitment (Casaló et al. 2008; Schau et al. 2009). Communal belonging and community engagement are very much constructs of interest to better understand not only the adoption of collaborative consumption but also why community members are actual users and not simply inactive online profiles. Perren and Kozinets (2018) emphasized that firms managing online platforms should infuse communal norms and increase consociality to avoid the negative consequences of software algorithms and value creation through networks of peer providers and consumers (e.g., the opportunistic style). However, firms should do so without falling into sharewashing (see Paper IV).

Some of the more experienced community members are strongly engaged with the authenticity of the original practice of ridesharing as a community of practice. A community of practice is a group of people who share the same concern or passion and exchange knowledge to get better at what they do (Wenger et al. 2002). Staying with a ridesharingbased community, Paper IV sheds light on the role of communal belonging for platform users by showing that it is a critical factor influencing participation in ridesharing. In traditional service settings (e.g., commercial access-based services), consumers who are happy with the firm providing the service will express intentions to repurchase. In the context of collaborative consumption, platform users who are satisfied with their experience will only continue to use the same platform (i.e. firm) when they feel like they belong to a community. Communal belonging offers an alternative explanation for the relationship between satisfaction and repurchase. As such, service research on collaborative consumption can 
benefit from exploring the role of communal belonging between participants - the heart of collaborative consumption. The literature indicated that in communal sharing relationships (cf. Clark and Mills 1979), the need for social interactions and the sense of commonality are characteristics of sharing (Belk 2010) and counter indicative of market exchange, but Papers III and IV show that collaborative consumption participants also attach considerable importance to these characteristics.

Moreover, Paper IV further demonstrates the pitfalls of sharewashing by showing that a higher sharing authenticity of the collaborative consumption experience (i.e. comprehending both the platform's and the P2P exchange's perceived authenticity) increases feelings of communal belonging. That is, if the collaborative consumption experience is perceived as close to sharing, platform users who identify with the community are more likely to use the platform. Inversely, when the collaborative consumption experience is associated with sharewashing and thus closer to the market logic, it actually reduces platform users' likelihood of expressing re-usage intentions (attitudinal loyalty). In summary, Paper IV offers an understanding of the role of communal belonging as well as the sharewashing pitfalls for collaborative consumption.

Previous marketing research has focused on communities where membership was based on product ownership and was often organized by firms with an explicit for-profit orientation (Algesheimer et al. 2005; Benoit et al. 2016; McAlexander et al. 2002; Muñiz and O'Guinn 2001; Muñiz and Schau 2005; Schau et al. 2009). Whereas brands used to be the driving factor behind communal belonging in the traditional paradigm, now it is the characteristics of the community itself that firms operating online platforms use to differentiate themselves and attract new users. For example, GoMore and BlaBlaCar provide stickers for users to promote the availability of their cars for rental or that they are ridesharing participants. Moreover, aggregating a critical mass of users (Evans and Schmalensee 2010), promoting communal norms (Perren and Kozinets 2018), and sustaining community engagement to increase loyalty (Algesheimer et al. 2005) are necessary for the survival (and growth) of collaborative consumption platforms facilitating P2P exchanges.

\subsection{The tensions within the Heart \& Wallet}

The lens of paradox theory is useful to further understand collaborative consumption and its apparent contradictions between the sharing logic and the market logic. In particular, the four categories of tensions established by management scholars (Lewis 2000; Smith and Lewis 2011) and recently employed in sustainability research (Ozanne et al. 2016; van Bommel 2018) and servitization (Kohtamäki et al. 2018) are used to outline the Heart \& Wallet paradox of collaborative consumption. 


\section{Belonging tensions}

First, the tensions of belonging appear when firms' or platform users' interpersonal relationships and identity are conflicted between their own self-expression and the group there are affiliated to (Lewis 2000; Ozanne et al. 2016; Schad et al. 2016; Smith and Lewis 2011). In other words, "identity fosters tensions between the individual and the collective and between competing values, roles, and memberships" because people and groups of people seek both homogeneity and distinction (Smith and Lewis 2011, p. 383). For example, firms can identify with the new Big Sharing startups that are disrupting industry incumbents with new technology (e.g., Uber) or with historically anti-capitalist communities formed around non-monetary practices, depending on their customer segmentation.

The three styles of collaborative consumption illustrate the tensions between the different ways people participate in the same practice (e.g., ridesharing). Platform users enacting a consumerist or opportunistic style of collaborative consumption would participate in an apparently contradictory way to platform users who enact a communal style (tensions between people). It is possible to extrapolate the practice styles to firms, where those closer to the sharing ethos and collaborating to advocate their vision would be in opposition to those closer to the market logic and advocating for market deregulation (tensions between firms). The participants' style can also be at odds with the firms that provide the platform they use. For example, participants in the original ridesharing practice (i.e. a communal style of collaborative consumption) felt betrayed by BlaBlaCar's change of business model and did not share the same vision than the firm had for them (i.e. a consumerist style of collaborative consumption).

Moreover, the tensions of belonging also pertain to the dichotomy of platform roles between consumers and peer providers. As unique individuals, consumers' motivations can vary between an economical way to obtain goods and services to an expectation of social benefits from P2P exchanges (tensions of performing within people), but as they belong to the group of consumers, their personal characteristics might be reduced and generalized as only economic (instead of both/and). These socio-economic motives and their respective importance are associated with diverse consumer segments (e.g., millennials or green consumers) that might not reflect such individual diversity.

On their side of the platform, peer providers of collaborative consumption can approach collaborative consumption as a way to compensate for their ownership costs (i.e. a utilitarian motive in line with the market logic) or as an altruistic way to offer their underutilized resources for others to use. Once again, due to their role as peer providers for a market-mediated mode of consumption their individual motives are often solely reduced to the economic aspect, with no regard for the social benefits of collaborative consumption. Eventually, each side of the platform perceives the other as a uniform group of people. 


\section{Performing tensions}

Second, the performing tensions "between the differing, and often conflicting, demands of varied internal and external stakeholders" (Smith and Lewis 2011, p. 384) that are substantively apparent in the triple bottom line of sustainability management (Ozanne et al. 2016; van Bommel 2018) appear in collaborative consumption when the diverse interests, goals, and strategies of firms or platform users are contradictory. Most importantly, the dichotomy of roles for collaborative consumption means that platform users have different objectives depending on which side they are on. For example, consumers want more choice, quality, and cheap offers. Peer providers want the most compensation for their underutilized possessions. The platform managers must balance each side of the platform (i.e. reach a critical mass of users) to provide a satisfactory service to both. Firms balance these performing tensions over time. Decisions such as which side to charge the highest commission are also influenced by the acquisition and retention strategy of the firm. For example, a firm that is late to the "sharing economy" (e.g., auto-manufacturers diversifying in shared mobility) and aims to build up the supply side of a platform will charge no commission on the price set by peer providers in markets where demand is abundant (e.g., BlaBlaCar for ridesharing); inversely, the platform will not charge consumers if it aims to attract them in markets where the supply of peer providers is abundant (e.g., Uber for ridehailing). Some firms split their revenue streams on each side of the platform (e.g., Airbnb for accommodation rental).

Moreover, a firm's goal to provide an efficient matchmaking service means that unreliable or low-quality peer providers and consumers should be removed from the platform, which is at odds with the inclusionary and communitarian values of the sharing ethos. Inversely, firms intending to facilitate meaningful interactions and social connections between people and to create feelings of communal belonging contradict the goal of globally extending their activities. Eventually, the tensions of performing also appear where organizations facilitate swapping or the recirculation of private goods through secondhand markets, which is embedded in the market logic, despite aiming to support the anti-capitalist movement. Moreover, organizations with the stated goal of local community building can also be at odds with the necessity to quickly acquire and maintain a critical mass of users for online platforms.

The tensions of performing in the Heart \& Wallet paradox also mean that collaborative consumption participants who aim to reduce overconsumption and become attached to the sharing logic and communitarian ethos (i.e. the communal style) can clash with the business model of the online platform they use to rent out goods and services-i.e. the firm making profits. Inversely, those who participate for economic rather than social reasons, such as the freeriders who benefit but do not contribute from generalized reciprocity (i.e. the 
opportunistic style), are also incongruent with organizations that promote shared ownership and non-monetary practices.

\section{Learning tensions}

Third, the tensions of learning that surface in the "sharing economy" phenomenon mean that the "efforts to adjust, renew, change and innovate foster tensions between building upon and destroying the past to create the future" (Smith and Lewis 2011, p. 383). These tensions between stability and change are perceptible for grassroots movements that adapted to the growing popularity of new consumption practices facilitated by digitalization while maintaining an authentic sharing ethos. Whereas the sharing logic from older non-monetary practices is maintained, contemporary practices of collaborative consumption are facilitated by online platforms and smartphone apps that pertain to the market logic. Moreover, popular on-demand services (the close cousins of collaborative consumption), such as Uber, sharewashing their core activity as the new sharing in their brand communication, and the media coverage of the uberization trend (i.e. yet another popular term referring for the "sharing economy") encourages a perception of platform technology and mechanisms as negative and thus to be avoided.

The tensions between radical innovation and incremental (or continuous) change in collaborative consumption are salient to the diversity of regulations adopted in European markets and the difference between their short-term or long-term perspective influencing firms and consumers. For instance, some countries have limited the maximum compensation per kilometer that one can obtain from ridesharing (to differentiate the practice of collaborative consumption from traditional taxi services), others have banned Uber or Airbnb from operating in certain cities, and others actually collaborate with these firms (on income tax issues). The question of whether to preserve the past or favor the future, or both, leads to tensions between slowing down the digital revolution that online platforms engage with, without missing out on opportunities, and promoting the evolutionary adaptation of existing infrastructures to recent technological developments.

Moreover, learning tensions for collaborative consumption participants translate into the necessity to overcome the barriers of access, such as learning to use new technologies (e.g., geo-localization and online payment). For example, whereas ridesharing participants used to put up their trips and phone numbers in local stores or post offices, online platforms have changed the process of ridesharing (e.g., participants need to create a profile and provide specific details), which mostly centralizes the coordination of drivers and passengers (e.g., BlaBlaCar's reservation system and the lack of contact information). In short, the tensions between the traditions of the old practice of hitchhiking or ad hoc ridesharing and the modern 
practice of ridesharing are concerned with how to organize the extant shared use of a car for efficient mobility.

Finally, the tensions of learning also exist for incumbent firms-for example, automotive manufacturers - but also startups such as GoMore that aimed to renew themselves and innovate by diversifying their service offerings and business models, dilute risk, and cannibalize their existing market share. In a fast-changing context of new consumer motives for access, firms strive to maintain and adapt their competitive advantage. Such learning tensions are inherent to the exploitation/exploration dilemma in management (Schad et al. 2016).

\section{Organizing tensions}

Finally, the tensions of organizing manifest between the conflicting demands of organizational processes and structures, particularly during periods of change (Lewis 2000; Ozanne et al. 2016; Schad et al. 2016; Smith and Lewis 2011). Firms adapting to the "sharing economy" can either acquire tangible resources to rent them out to consumers (i.e. commercial access-based services) or operate an online platform to facilitate exchanges between people and their private resources (i.e. collaborative consumption), or they can do both simultaneously (e.g., GoMore). As argued earlier, commercial access-based services and collaborative consumption entail different roles for firm managers (provider or enabler of access) and consumers (directly interacting with others or not). These different business models entail different challenges, such as how long should the maximum/minimum rental duration be set for consumers, whether prices are inflated when demand is higher, whether a membership price should be charged, how often goods need to be maintained and whether it is done in-house or outsourced, and the extant of the complimentary insurance coverage. Moreover, startups need to remain agile due to the influence of turbulent consumer demands and unstable financial markets on their geographical expansion and growth. For example, BlaBlaCar was able to raise funding and acquire competing ridesharing platforms in some countries, whereas it established local teams in other countries (see Appendix 9).

Finally, firms define the rules and guidelines for using the platform (e.g., capping monetary compensation), which institutionalizes the practice to a certain extent and determines the autonomy with which collaborative consumption participants can perform a practice. Firms negotiate the adaptation of non-monetary practices from those used by circles of friends and family (borrowing a friend's car) or those developed by grassroots movements by controlling online platforms and educating new participants, while they engage experienced participants to modify their practice and share their knowledge with newcomers. 


\section{Understanding the Heart $\&$ Wallet paradox of collaborative consumption}

Drawing from paradox theory to better understand collaborative consumption at both the individual and firm levels means to focus on the paradoxical tensions between the opposite logics of sharing and market exchange. As previous research argued that the phenomenon of collaborative consumption showcases elements of both concepts of sharing and market exchange (Belk 2014b; Habibi et al. 2016), the corollary is that collaborative consumption should not be conceptualized as either or. This is in line with practice theory: "existing on one continuum, these elements define one another, such that they can never be fully separated. The elements signify 'two sides of the same coin' (Lewis, 2000, p. 761)" (Schad et al. 2016, p. 16).

This section on the four tensions of the Heart \& Wallet paradox of collaborative consumption highlighted the specific elements of sharing and market exchange in isolation (e.g., the communal identification, or the monetary exchange, respectively). From the heart extremity, the tensions of belonging come from the communal relationships between participants (cf. Clark and Mills 1979) who relate to each other as friends (cf. Schor 2014), and expectations of generalized reciprocity (Bagozzi 1975). The performing tensions concern the pro-social goals for collaborative consumption, when participants want to meet and interact with new people, or when organizations adopt a grassroots model to develop local communities (Hamari et al. 2016; Herbert and Collin-Lachaud 2017; Möhlmann 2015; Wilhelms et al. 2017a). The learning tensions from a sharing logic result from the lack of adaptation to new technology, platform business models, and consumer demands, such as communities of practice that are stuck in the past. The organizing tensions emanate from the vision that everything could be shared, without any individual possessions and where shared goods are used by the community without underutilization.

On the other hand, from the wallet extremity, the belonging tensions emerge from the exchange relationships between participants (cf. Clark and Mills 1979) who relate to each other as impersonal strangers (e.g., Bagozzi 1975), and expectations of direct reciprocity so exchanges are balanced (Houston and Gassenheimer 1987; Sahlins 1972). The tensions of performing result from the utilitarian goal of market exchanges, where collaborative consumption participants and firms strive for economic utility, efficiency, and convenience (cf. Alderson 1958). The tensions of learning from the market logic mean that firms have been too quick to jump on the gig economy bandwagon powered by technological improvements and platform business models, while forgetting that humans are at the core of P2P exchanges. The organizing tensions extend from the potential economic benefits from rental, such as the acquisition of goods is encouraged in order to be further monetized.

While the sharing logic and the market logic make sense in isolation, they seem absurd when both are juxtaposed, which result in the contradictions and difficulties for the 
conceptualization of a phenomenon (Poole and van de Ven 1989; Smith and Lewis 2011). That is why the concept of collaborative consumption cannot be anchored to either the sharing concept or the market exchange concept, but it is better to appreciate them simultaneously to grasp the complexity of the phenomenon in its wholeness. It is these characteristics of contradictory but simultaneous logics, the diversity of stakeholders, and the interdependency of tensions that engender the persistence of collaborative consumption as a paradox. Moreover, paradoxes incorporate features of irony, as tensions create "incongruity between what is expected and what occurs or saying one thing and meaning the opposite" (Putnam et al. 2016, p. 67). As irony is a way to cope with absurd contradictions (Putnam et al. 2016), it is no surprise that the collaborative consumption phenomenon was dubbed with the oxymoron "sharing economy."

Although collaborative consumption is a specific phenomenon within the "sharing economy," it needs to be considered as a whole with persistent tensions that balance over time. Collaborative consumption practices are constantly shifting between the alternative poles of the sharing-exchange continuum. For example, BlaBlaCar, GoMore, or even CouchSurfing started as non-profit ventures that adopted the market logic. Platform users too can switch from a communal style to a more consumerist style of collaborative consumption. O'Driscoll (2008) also argued for a shift from viewing paradox as antithesis to regarding it as a means of synthesis. It is too simplistic to argue that collaborative consumption is not true sharing, while it is not quite market exchange either. The conceptual development of collaborative consumption demands for both/and approach on the logics of sharing and market exchange.

In summary, it is normal for the complex phenomenon of collaborative consumption to exhibit distinct contradictory logics. Contradictions lie at the foundations of paradoxical tensions. 


\section{CHAPTER 6}

CONCLUSION

What starts out here as a mass movement ends up as a racket, a cult, or a corporation.

- E. Hoffer (1967)

The purpose of this thesis is to advance the understanding of the tensions between the sharing and market logics in collaborative consumption by investigating what I have called the Heart \& Wallet paradox from the firm's and the user's perspectives. Besides technological developments (e.g., Internet availability, GPS, and smartphone apps), there are three main motives for collaborative consumption: the economic incentive of saving costs or compensating for underutilization, the social benefits of participating in joint activities within a community, and the environmental benefits of increasing the utilization of existing resources and reducing waste. Whereas the environmental benefits are merely a nice bonus, the socio-economic tensions of the Heart \& Wallet paradox are critical to the collaborative consumption phenomenon. This chapter pinpoints the contributions, implications, and limitations of this research, as well as suggestions for future research. 


\subsection{Thesis contributions}

By improving the understanding of collaborative consumption as a form of exchange that differs from traditional ownership and acquisition-based consumption, this thesis contributes to service research that focuses on the new access paradigm of consumption, which has provoked substantial changes in the consumer landscape and the adaptation of business activities (Andreassen et al. 2018; Benoit et al. 2017; Breidbach and Brodie 2017; Fehrer et al. 2018; Hazée et al. 2017; Lawson et al. 2016; Moeller and Wittkowski 2010; Schaefers et al. 2016b, 2018; Wittkowski et al. 2013). Most importantly, this stream of research has focused on commercial services provided by firms (i.e. B2C relationships) rather than services facilitated by firms but provided by peer providers (i.e. P2P exchanges). Despite the overall increase in academic publications on the "sharing economy" in general (Arcidiacono et al. 2018; Ertz and Leblanc-Proulx 2018; Fritze et al. 2018; Lamberton 2015), there is a lack of conceptual clarity regarding the phenomenon of collaborative consumption in service research.

Papers I and II shed light on the temporary redistribution process of collaborative consumption (no change in ownership) facilitated by platform business models (not B2C). Paper I enables collaborative consumption to be differentiated from recirculation systems (e.g., due to a permanent change in ownership or indirect exchange), while Paper II enables platform-based P2P exchanges to be differentiated from commercial access-based services (e.g., due to the mode of exchange and business models). From the firm's perspective, collaborative consumption is a new form of e-commerce that is based on recirculation and redistribution practices; these existed long before but can be improved thanks to recent developments in technology, and a fee can be charged to platform users for facilitating the P2P exchanges. Firms that aim to monetize private resources through platform business models reinforce the wallet aspect of collaborative consumption by emphasizing the economic benefits of P2P exchanges. However, they do so by developing trust systems based on social proof, leveraging social media networks, and engaging the community of peer providers and consumers to promote a pro-social orientation for P2P exchanges-i.e. they reinforce the heart aspect of collaborative consumption.

Papers III and IV concentrate on the platform user's perspective on collaborative consumption. In particular, the three styles enable a more granular understanding of the different ways of practicing collaborative consumption. The communal style puts a great emphasis on the values of community and the sharing ethos; it represents the heart aspect of collaborative consumption. In contrast, the consumerist and opportunistic styles emphasize the commercial aspect of $\mathrm{P} 2 \mathrm{P}$ exchanges and represent the wallet aspect of collaborative consumption. 
This thesis offers three contributions. First, the discussion of the findings of the appended papers enabled the conceptualization of collaborative consumption to be revisited. This thesis acknowledges the social aspect of collaborative consumption, that was not considered in current service research on the "sharing economy." Collaborative consumption is situated within the access paradigm and entails a $\mathrm{P} 2 \mathrm{P}$ activity, wherein participants interact online and exchange directly offline. This P2P exchange makes it possible to increase the utilization of private resources (not owned by the firm) and the compensation for ownership costs for peer providers - meanwhile, consumers are offered a temporary solution to their need based on access. In other words, there is no change of ownership. Collaborative consumption is a subset of access-based consumption (cf. Bardhi and Eckhardt 2012). As such, this thesis palliates the lack of conceptual clarity on collaborative consumption, and it attempts to reconcile and clarify previous research findings that use the term. Some research has been arguing that collaborative consumption can include a change of ownership (Belk 2014b; de Rivera et al. 2017; Ertz et al. 2018a, 2018b; Hamari et al. 2016; Herbert and CollinLachaud 2017; Lindblom et al. 2018; Perren and Grauerholz 2015; Roos and Hahn 2017), whereas this thesis emphasizes the access paradigm (e.g., rental) salient to service research.

Second, the thesis also contributes to bringing paradox theory into service research, which has been called for because "service scholars struggle to master paradoxical thinking" (Gustafsson and Bowen 2017, p. 213) due to the tendency to focus only on one approach (either/or) rather than in considering two opposites as coexisting (both/and approach) in service practice (e.g., both good and services) but also theory-building (e.g., academic rigor and managerial relevance). The thesis proposes an understanding of collaborative consumption that is situated on a continuum between true sharing and market exchange (in line with Belk 2014b and Habibi et al. 2016). In other words, there is a need for "paradoxical thinking" capabilities for collaborative consumption scholars - in line with the required capability for firm managers to accommodate and learn from multiple tensions (e.g., Hillebrand et al. 2015: Putnam et al. 2016; Smith and Lewis 2011; van Bommel 2018). For example, the discussion of the Heart \& Wallet paradox stressed the functionalities of ecommerce websites that are adapted and integrated into platform business models based on commission (the wallet) as well as participants' social networks, which are also leveraged to alleviate the fear of strangers and emphasize the large community of people centered on a practice of collaborative consumption (the heart). Particularly relevant are the three practice styles enacted by participants in collaborative consumption, which differ alongside the continuum and direct future research towards differentiating the nuances in new consumer practices.

Third, previous research on collaborative consumption has been led by conceptual papers that are based on illustrations and anecdotal experiences (e.g., Belk 2010). Despite the 
weight of conceptual papers that address this new phenomenon, it seems that collaborative consumption may be too novel a phenomenon for desk research alone. A more empirical investigation of new consumption practices is needed. Moreover, these practices change rapidly — startups are founded, firms are disrupted, and regulations are established—which demands a close follow-up in the real world rather than a broad overview from a distant ivory tower. As such, the four papers appended to this thesis provide empirics to the debate. Ultimately, the shared mobility sector is the most active of the "sharing economy," so this thesis relies on previous research on the central characteristics of the phenomenon, as well as on relevant contextual data.

\subsection{Managerial implications}

This thesis has several important managerial implications. First, the heart aspect of collaborative consumption emphasizes the importance of the original community that formed around an ad hoc practice with a common understanding of what it is about (e.g., ridesharing), and how firms developing online platforms to suit these people should sustain the genuine values of the community (e.g., a sharing ethos). Second, emphasizing the communal aspects of participation in collaborative consumption must not fall into sharewashing. Managers should avoid promoting the pro-social aspect of collaborative consumption when it is, in fact, not particularly likely to interact with and meet new people (e.g., P2P car rental). Third, the thesis highlights the platform business model and the role of the firm in developing an online website that is convenient to use and makes it efficient for collaborative consumption participants to self-organize. That is, a smoother collaborative consumption experience is better for firms. Fourth, industry incumbents (e.g., car manufacturers) can anticipate the shift towards nonownership — and alleviate the risk of "Uberization"-by increasing their accessbased offerings to consumers rather than concentrating on traditional sales based on ownership. As Belk (2018) put it, "in spite of its problems, the overall impact of the rise of the sharing economy and collaborative consumption has been positive" (p. x). In summary, this phenomenon is here to stay, and managers need to understand it.

\subsection{Societal implications}

By offering an in-depth understanding of a new socio-economic phenomenon, and in particular the tensions between sharing and market logics, I hope to better equip managers, policy makers, consumers, and other stakeholders to navigate the confusing and potentially disrupting mess that the "sharing economy" has been described as. My research on collaborative consumption offers several implications for society. In particular, the 
discussions on the positioning of collaborative consumption in light of previous research and theoretical conceptualization, as well as contemporary business activities and consumer behaviors, sheds light on the fundamental differences between various terms. For example, I highlighted the absence of a change in ownership in collaborative consumption, which is distinct from practices facilitated by secondhand platforms. Academics researching and producing governmental reports and policy makers proposing new regulations should be informed and accurate when it comes to addressing access-based services provided directly by a firm (e.g., carsharing), collaborative consumption between people (e.g., ridesharing), or more intangible and on-demand services provided by professional freelancers (e.g., ridehailing). This implies, for example, that peer providers of collaborative consumption should not be considered as professional freelancers for on-demand service apps in that they only compensate for underutilization without making their activities a source of income. However, when one acquires accommodation with the purpose of renting it out through Airbnb, it is first and foremost a rental business. This also implies that the users of online platforms should be protected by consumer laws (e.g., mandatory home safety protection for Airbnb hosts), and that firms should have the means and responsibility to verify that the P2P exchanges they facilitate are legal. In sum, this thesis offers a framework for naming what is to be discussed prior to actually discussing its details.

Other societal implications stem from the discussions of the firm's perspective as well as of the user's perspective. First, the firm's perspective highlights the e-commerce start-up mindset adopted by the Big Sharing unicorns (e.g., Uber and Airbnb), which attempt to disrupt the industry and aggregate the largest number of platform users to maximize their profits. However, online platforms also have the potential to bring people together by engaging their users to interact, meet, and share feelings of communal belonging and social cohesion rather than individualization. This implies that the firms' capabilities and infrastructure could be harnessed to deliver public good. For example, people living in remote locations could be offered ride-hailing services to close the gap between their home and the train or bus station rather than using a bus service that is costly for the city government. Another example is supporting neighborhood timebanks where people can trade without monetary involvement, such as exchanging healthcare or hairdressing services for help with laundry, fixing the car, or assembling IKEA furniture. Second, the user's perspective highlights that people are more likely to adopt the communal style of collaborative consumption when the sharing ethos is emphasized, and the consumerist and opportunistic style when the market logic is more salient. Like Skjutsgruppen's statement, "We are friends and friends of friends. Friends don't make money from friends," which its community is asked to agree to, this thesis implies that people can behave opportunistically for their own self-interest and personal benefit, but it is in their long-term interest to respect others as equal 
participants in collaborative consumption and create social ties within the larger community. Essentially, collaborative consumption is facilitated online - for example, a platform can be rolled out worldwide, but it is socially more impactful for an organization (e.g., a firm or governmental initiative) to concentrate on a local neighborhood to replicate what older sharing practices used to resemble.

\subsection{Limitations}

Some may say that there is no perfect paper-or PhD thesis—only publications and books that advance knowledge and understanding. All research endeavors have limitations. The limitations of this thesis pertain to its sole focus on collaborative consumption (i.e. P2P exchanges), whereas there are other practices within the broader "sharing economy" phenomenon that deserve further investigation and conceptualization (i.e. commercial access-based services or on-demand services). Moreover, this thesis is exclusively focused on the shared mobility sector (e.g., P2P car rental or ridesharing), whereas the tourism sector (e.g., accommodation rental) offers a similar empirical context as well as a bourgeoning interest from marketing scholars. Other limitations come from more traditional methodological constraints, such as a strong reliance on qualitative research to initially explore collaborative consumption. Finally, this thesis does not investigate the duality of the roles played by platform users, i.e. between peer providers and consumers, despite this being a key characteristic of collaborative consumption.

\subsection{Future research}

There are several opportunities to overcome the limitations of this thesis while further advancing the understanding of collaborative consumption. Future research could measure the three styles of collaborative consumption so as to investigate the influence of these styles (e.g., as clusters) on other diverse constructs and metrics (e.g., platform usage). These styles could also be explored in the B2C context of commercial access-based services, as it is unlikely that all customers will enact the practice in the same way-i.e. there are several ways in which to participate. The conceptualization of these styles could also lead to the study of the matches and mismatches between participants, such as when the communal style (the heart viewpoint) meets the opportunistic style (the wallet viewpoint).

Furthermore, there is a need to investigate contexts of collaborative consumption other than those of the shared mobility sector, such as the tourism industry (e.g., accommodation rental) and replicate the findings of this thesis. Further research should focus on the duality of the roles of platform users between peer providers and consumers, not only within a single 
practice but across practices (e.g., do professional hosts on Airbnb act more commercially when ridesharing as a passenger on BlaBlaCar?), as this is likely to influence their collaborative consumption experience. The difference in the service role that collaborative consumption platform users perform may well be that consumers are more likely to engage with the market logic while serving their role as consumers, while peer providers are more likely to engage with the sharing logic while looking for an altruistic experience by offering access to their resources. This also hints at the issue of compensation (amateurs) and remuneration (professionals), which deserves further research.

While this thesis focuses on active participants in collaborative consumption, new insights can be captured by investigating the reasons for not participating-which is in line with the foundations of consumer research that aims to understand both consumption and non-consumption. Finally, pricing research into the decisions made by peer providers would yield interesting findings, particularly regarding the professionalization of collaborative consumption and the value given to diverse private possessions (cf. the commoditization or financialization of private life).

To conclude this thesis, I again turn to Belk, who noted that "while there may be nothing new in the basic concept of sharing, the stir caused by the sharing economy is reshaping the way we live and the ways we think about production and consumption" (Belk 2018 , p. x). That is to say, there is still much to understand about the paradigm shift towards access-based and collaborative consumption in society. 

REFERENCES 
Acquier A., Daudigeos T., and Pinkse J. (2017), "Promises and paradoxes of the sharing economy: An organizing framework," Technological Forecasting and Social Change, 125: $1-10$.

Albinsson P.A. and Perera B.Y. (2012), "Alternative marketplaces in the 21st century: Building community through sharing events," Journal of Consumer Behavior, 11(4): $303-15$.

Albinsson P.A. and Perera B.Y. (2018), The rise of the sharing economy. Exploring the challenges and opportunities of collaborative consumption. ABC-CLIO, Santa Barbara, CA.

Alderson W. (1958), “The analytical framework for marketing," Proceedings of Marketing Teachers from Far Western States, UC Berkley, CA, pp. 15-28.

Algesheimer R., Dholakia U., and Herrmann A. (2005), "The social influence of brand community: Evidence from European car clubs," Journal of Marketing, 69(July): 1934

Andreassen T.W., Lervik-Olsen L, Snyder H., Van Riel A.C.R., Sweeney J., and Van Vaerenbergh Y. (2018), "Business model innovation and value-creation: The triadic way,” Journal of Service Management, 29(5): 883-906.

Arcidiacono D., Gandini A., and Pais I. (2018), "Sharing what? The 'sharing economy' in the sociological debate," The Sociological Review Monographs, 66(2): 275-288.

Arnould E.J. and Rose A.S. (2016), "Mutuality: Critique and substitute for Belk's 'sharing,," Marketing Theory, 16(1): 75-99.

Arnould E.J. and Thompson C.J. (2005), “Consumer Culture Theory (CCT): Twenty years of research," Journal of Consumer Research, 31(March): 868-882.

Baden-Fuller C., Giudici A., Haefliger S., and Morgan M.S. (2017), "Business models and value," Academy of Management Proceedings, 2017(1).

Bagozzi R.P. (1975), “Marketing as exchange,” Journal of Marketing, 39(10): 32-39.

Bardhi F. and Eckhardt G.M. (2009), “An examination of market-mediated collective consumption: The case of car sharing," American Marketing Association 2009 Summer Educators' Conference.

Bardhi F. and Eckhardt G.M. (2010), "Market-mediated collaborative consumption in the context of car sharing," Advances in Consumer Research, 37: 65-68.

Bardhi F. and Eckhardt G.M. (2012), "Access-based consumption: The case of car sharing," Journal of Consumer Research, 39(4): 881-898.

Bardhi F. and Eckhardt G.M. (2017), "Liquid consumption,” Journal of Consumer Research, 44(October): 582-597.

Baron S. and Russell-Bennett R. (2016), "Editorial: The changing nature of data," Journal of Services Marketing, 30(7): 673-675. 
Baron S., Warnaby G., and Hunter-Jones P. (2014), "Service(s) marketing research:

Developments and directions," International Journal of Management Reviews, 16(2): 150-171.

Bartels D.W. (1944), “Marketing principles,” Journal of Marketing, 9(2): 151-157.

Bartels D.W. (1951), "Influences on the development of marketing thought, 1900-1923," Journal of Marketing, 16(1): 1-17.

Bauwens M. (2018), "Everything for everyone: Michel Bauwens interviews Nathan Schneider," Commons Transition. Available at: http://commonstransition.org/ everything-for-everyone-michel-bauwens-interviews-nathan-schneider/ (accessed 12 September 2018).

Belk R.W. (2007), "Why not share rather than own?", Annals of the American Academy of Political and Social Science, 611(1): 126-140.

Belk R.W. (2010), "Sharing,” Journal of Consumer Research, 36(5): 715-734.

Belk R.W. (2014a), "Sharing versus pseudo-sharing in Web 2.0," Anthropologist, 18(1): 723.

Belk R.W. (2014b), "You are what you can access: Sharing and collaborative consumption online," Journal of Business Research, 67(8): 1595-1600.

Belk R.W. (2017), "Russ Belk, autobiographical reflections," Journal of Historical Research in Marketing, 9(2): 191-202.

Belk R.W. (2018), "Foreword: The sharing economy," in Albinsson \& Perera (eds.), The rise of the sharing economy. Exploring the challenges and opportunities of collaborative consumption, ABC-CLIO, Santa Barbara, CA, pp. ix-xii.

Belk R.W. and Llamas, R. (2012), "The nature and effects of sharing in consumer behavior," in Mick et al. (eds.), Transformative Consumer Research for Human and Earthly Welfare: Reviews and Frontiers, Routledge, London, UK, pp. 625-646.

Belk R.W., Sherry J.F., and Wallendorf M. (1988), “A naturalistic inquiry into buyer and seller behavior at a swap meet," Journal of Consumer Research, 14(4): 449-470.

Belk R.W, Wallendorf M., and Sherry J.F. (1989), "The sacred and profane in consumer behavior: Theodicy on the Odyssey," Journal of Consumer Research, 16(1): 1-38.

Benkenstein B.M., Bruhn M., Büttgen M., Hipp C., Matzner M., and Nerdinger F.W. (2017), "Topics for service management research - A European perspective," Journal of Service Management Research, 1(1): 4-21.

Benkler Y. (2004), "Sharing nicely: On shareable goods and the emergence of sharing as a modality of economic production," Yal Law Journal, 114: 273-358.

Benkler Y. (2006), The wealth of networks: How social production transforms markets and freedom. Yale University Press, New Haven, CT. 
Benoit S., Baker T.L., Bolton R.N. Gruber T., and Kandampully J. (2017), “A triadic framework for collaborative consumption: Motives, activities and resources \& capabilities of actors," Journal of Business Research, 79: 219-227.

Benoit S., Bilstein N., Hogreve J., and Sichtmann C., (2016) "Explaining social exchanges in information-based online communities (IBOCs)," Journal of Service Management, 27(4): 460-480.

Berry L.L. and Maricle K.E. (1973), “Consumption without ownership: Marketing opportunity for today and tomorrow," MSU Business Topics, 21(1): 33-41.

Berry L.L. and Parasuraman A. (1993), "Building a new academic field. The case of services marketing," Journal of Retailing, 69(1): 13-60.

Bishop M. (2016), Economics: An A-Z guide. Profile Books [E-Book].

Bitner M.J. (2014), "Editorial: A Vision for the future of the Journal of Service Research (JSR)," Journal of Service Research, 17(1): 3-4.

Bitner M.J. (2017), "Service research: Rigor, relevance, and community," Journal of Service Research, 20(2): 103-104.

Böcker L. and Meelen T. (2017), "Sharing for people, planet or profit? Analysing motivations for intended sharing economy participation," Environmental Innovation and Societal Transitions, 23(June): 28-39.

Botsman R. (2015), "Defining the sharing economy: What is collaborative consumptionand what isn't?", Fast Company. Available at: http://www.fastcoexist.com/3046119/ defining-the-sharing-economy-what-is-collaborative-consumption-and-what-isnt (accessed 1 June 2015).

* Botsman R. and Rogers R. (2010a), What's mine is yours: The rise of collaborative consumption. HarperCollins, New York, NY.

Botsman R. and Rogers R. (2010b), “Beyond Zipcar: Collaborative consumption”, Harvard Business Review, 88(10): 30.

Bourdieu P. (1986), "The forms of capital," in Richardson (ed.), Handbook of theory of research for the sociology of education, ABC-CLIO, Santa Barbara, CA, pp. 241-258.

Bradshaw A. and Brown S. (2008), "Scholars who stare at goats. The collaborative circle cycle in creative consumer research," European Journal of Marketing, 42(11/12): 1396-1414.

Breidbach C.F. and Brodie R.J. (2017), "Engagement platforms in the sharing economy: Conceptual foundations and research directions," Journal of Service Theory and Practice, 27(4): 761-77.

Breidbach C., Choi S., Ellway B., Keating B.W., Kormusheva K., Kowalkowski C., Lim C., and Maglio P. (2018), “Operating without operations: How is technology changing the role of the firm?", Journal of Service Management, 29(5): 809-833. 
Bryman A. (1984), "The debate about quantitative and qualitative research: A question of method or epistemology?”, British journal of Sociology, 35(1): 75-92.

Bucher E., Fieseler C., and Lutz C. (2016), "What's mine is yours (for a nominal fee): Exploring the spectrum of utilitarian to altruistic motives for Internet-mediated sharing," Computers in Human Behavior, 62(September): 316-326.

* Buczynski B. (2013), Sharing is good: How to save money, time and resources through collaborative consumption. New Society Publishers, Gabriola Island, BC Canada.

Campbell D.T. and Fiske D.W. (1959), "Convergent and discriminant validation by the multitrait-multimethod matrix," Psychological Bulletin, 56, 81-105.

Casaló, L. V., Flavián C., and Guinalíu M. (2008), "Promoting consumer's participation in virtual brand communities: A new paradigm in branding strategy," Journal of Marketing Communications, 14(1): 19-36.

Casprini E., Di Minin A., and Paraboschi A. (2018), "How do companies organize nascent markets? The BlaBlaCar case in the inter-city shared mobility market," Technological Forecasting \& Social Change (in press), DOI 10.1016/j.techfore.2018.01.012.

* Chase R. (2015), Peers Inc: How people and platforms are inventing the collaborative economy and reinventing capitalism. PublicAffairs, New York City, NY.

Clark M.S. and Mills J.R. (1979), “Interpersonal attraction in exchange and communal relationships," Journal of Personality and Social Psychology, 37(1): 12-24.

Corciolani M. and Dalli D. (2014), "Gift-giving, sharing and commodity exchange at Bookcrossing.com: New insights from a qualitative analysis," Management Decision, 52(4): 755-776.

Creswell J.W. and Plano Clark V.L. (2017), Designing and conducting mixed methods research. Sage, Thousand Oaks, CA.

Cruz I., Ganga R., and Wahlen S. (2018), Contemporary collaborative consumption: Trust and reciprocity revisited. Springer, Berlin, Germany.

Davidson A., Habibi M.R., and Laroche M. (2018), "Materialism and the sharing economy: A cross-cultural study of American and Indian consumers," Journal of Business Research, 82: 364-372.

de Malet C. (2015), “Après le «green washing», le «share washing»," Le Figaro. Available at: http://blog.lefigaro.fr/share-qui-peut/2015/12/apres-le-green-washing-voici-venu-leshare-washing.html (accessed 16 November 2017).

De Moor T. (2013), Homo cooperans: Institutions for collective action and the compassionate society. Universiteit Utrecht, Netherlands, Inaugural lecture, 30 August 2013. 
de Rivera J., Gordo Á., Cassidy P., and Apesteguía A. (2017), “A netnographic study of P2P collaborative consumption platforms' user interface and design," Environmental Innovation and Societal Transitions, 23(6): 11-27.

Deighton J. (2007), “The territory of consumer research: Walking the fences," Journal of Consumer Research, 34(3): 279-282.

Denzin N.K. (1978), The research act: A theoretical introduction to sociological methods. Praeger, New York, NY.

Denzin N.K. and Lincoln Y.S. (2000), "The discipline and practice of qualitative research," in Denzin \& Lincoln (eds.), Handbook of qualitative research, $2^{\text {nd }}$ ed. Sage, Thousand Oaks, CA, pp. 1-29.

Dillman D.A., Smyth J.D., and Christian L.M. (2014), Internet, phone, mail, and mixedmode surveys: The tailored design method, $4^{\text {th }}$ ed. Wiley, Hoboken, NJ.

Dreyer B., Lüdeke-Freund F., Hamann R., and Faccer K. (2017), "Upsides and downsides of the sharing economy: Collaborative consumption business models' stakeholder value impacts and their relationship to context," Technological Forecasting and Social Change, 125: 87-104.

Eckhardt G.M. and Bardhi F. (2015), “The sharing economy isn't about sharing at all," Harvard Business Review, 39(4): 881-98.

Eckhardt G.M. and Bardhi F. (2016), "The relationship between access practices and economic systems," Journal of the Association for Consumer Research, 1(2): 210-225.

Ehret M. and Wirtz J. (2018), “Ownership of cocreation assets driving B2B value propositions in the service economy," Journal of Creating Value, 4(1): 42-60.

Einav L., Farronato C., and Levin J. (2016), "Peer-to-peer markets," Annual Review of Economics, 8: 615-635.

Eisenhardt K.M. and Graebner M.E. (2007), “Theory building from cases: Opportunities and challenges," Academy of Management Journal, 50(1): 25-32.

Emerson R.M., Fretz R.I., and Shaw L.L. (2011), Writing ethnographic fieldnotes, $2^{\text {nd }}$ ed. University of Chicago Press, Chicago, IL.

Ertz M., Durif F., and François-Lecompte A., and Boivin C. (2018a), "Does 'sharing' mean 'socially responsible consuming'? Exploration of the relationship between collaborative consumption and socially responsible consumption," Journal of Consumer Marketing, 35(4): 392-402,

Ertz M., Durif F., and Arcand M. (2018b), “A conceptual perspective collaborative consumption," Academy of Marketing Science Review (in press), DOI 10.1007/s13162018-0121-3. 
Ertz M. and Leblanc-Proulx S. (2018), "Sustainability in the collaborative economy: A bibliometric analysis reveals emerging interest," Journal of Cleaner Production, 196(September): 1073-1085.

Evans D.S. and Schmalensee R. (2010), "Failure to launch: Critical mass in platform businesses," Review of Network Economics, 9(4).

Fehrer J.A., Benoit S., Aksoy L., Baker T.L., Bell S.J., Brodie R.J., and Marimuthu M. (2018), "Future scenarios of the collaborative economy: Centrally orchestrated, social bubbles or decentralized autonomous?", Journal of Service Management, 29(5): 859882.

Felson M. and Spaeth J. (1978), "Community structure and collaborative consumption: A routine activity approach," American Behavioral Scientist, 21(4): 614-624

Fenton A. (2015), The missing objects in relational work: comparing peer-to-peer and traditional rental car markets. Working paper [unpublished], Harvard University, Cambridge, MA.

Fernando A.G., Sivakumaran B., and Suganthi L. (2018), "Comparison of perceived acquisition value sought by online second-hand and new goods shoppers," European Journal of Marketing, 52(7/8): 1412-1438.

Field J., Victorino L., Buell R., Dixon M., Meyer Goldstein S., Menor L., Pullman M., Roth A., Secchi E., and Zhang J. (2018), “Service operations: What's next?”, Journal of Service Management, 29(1): 55-97.

* Filippova D., Berlingen F., Gauthey M.A., De Grave A., Guedira A., Léonard A., Mootoosamy E., Tincq B., and Tordo M. (2015), Société collaborative. La fin des hiérarchies. Rue de l'Échiquier, Paris, France.

Fisk R.P., Brown S.W., and Bitner M.J. (1993), "Tracking the evolution of the services marketing literature," Journal of Retailing, 69(1): 61-103.

Fisk R.P., Grove S.J., and John J. (2000), Services marketing self-portraits: Introspections, reflections, and glimpses from the experts. American Marketing Association, Chicago, IL.

Fisk R.P and Grove S.J. (2010), “The evolution and future of service: Building and broadening a multidisciplinary field," in Maglio et al. (eds.), Handbook of Service Science. Service science: Research and innovations in the service economy, Springer, Boston, MA, pp. 643-664.

Fiske A.P. (1992), "The four elementary forms of sociality: Framework for a unified theory of social relations," Psychological Review, 99(4): 689-723.

Folkes V. S. (2002), "Presidential address: Is consumer behavior different?”, Advances in Consumer Research, 29: 1-4. 
Fontana A. and Frey J.H. (2000), "The interview: From structured questions to negotiated text," in Denzin \& Lincoln (eds.), Handbook of qualitative research, $2^{\text {nd }}$ ed. Sage, Thousand Oaks, CA, pp. 645-672.

Fournier S., Eckhardt G.M., and Bardhi F. (2013), "Learning to play in the new 'share economy'," Harvard Business Review, 91(7): 125-129.

Frenken K. (2017), "Political economies and environmental futures for the sharing economy," Philosophical Transactions of the Royal Society A: Mathematical, Physical and Engineering Sciences, 375(2095), DOI 10.1098/rsta.2016.0367.

Frenken K. and Schor J. (2017), "Putting the sharing economy into perspective," Environmental Innovation and Societal Transitions, 23(June): 3-10.

Fritze M.P., Urmetzer F., Khan G.F., Sarstedt M., Neely A., and Schaefers T. (2018), "From goods to services consumption: A social network analysis on sharing economy and servitization research," Journal of Service Management Research, 2(3): 3-16.

* Gansky, L. (2010). The mesh: Why the future of business is sharing. Penguin, New York, NY.

Gansky L. (2014), "Collaborative economy companies need to start sharing more value with the people who make them valuable," Fast Company. Available at: https://www. fastcompany.com/3038476/collaborative-economy-companies-need-to-start-sharingmore-value-with-the-people-who-make-th (accessed 26 November 2015).

Gebauer H., Fleisch E., and Friedli T. (2005), “Overcoming the service paradox in manufacturing companies," European Management Journal, 23(1): 14-26.

Giesler M. (2006), “Consumer gift systems”, Journal of Consumer Research, 33(2): 283290.

Gölgeci I., Karakas,F., and Tatoglu E. (2019), "Understanding demand and supply paradoxes and their role in business-to-business firms," Industrial Marketing Management, 76: 169-180.

Gollnhofer J.F. (2017a), “The legitimation of a sustainable practice through dialectical adaptation in the marketplace," Journal of Public Policy \& Marketing, 36(1): 156-168.

Gollnhofer J.F. (2017b), "Normalising alternative practices: the recovery, distribution and consumption of food waste," Journal of Marketing Management, 33(7/8): 624-643.

Gollnhofer J.F., Hellwig K., and Morhart F. (2016), "Fair is good but what is fair? Negotiations of distributive justice in an emerging non-monetary sharing model," Journal of the Association for Consumer Research, 1(2): 226-245.

Gorenflo N. (2015), "How platform coops can beat death stars like Uber to create a real sharing economy", Shareable. Available at: http://www.shareable.net/blog/how-platform-coops-can-beat-death-stars-like-uber-to-create-a-real-sharing-economy (accessed 19 November 2015). 
Greene J. C. (2006), “Toward a methodology of mixed methods social inquiry,” Research in the Schools, 13(1): 93-98.

Grönroos C. (1978), “A service-orientated approach to marketing of services,” European Journal of Marketing, 12(8): 588-601.

Grönroos C. (2006), “On defining marketing: Finding a new roadmap for marketing," Marketing Theory, 6(4): 395-417.

Grönroos C. (2011), "Value co-creation in service logic: A critical analysis," Marketing Theory, 11(3): 279-301.

Grönroos C. (2012), "Conceptualising value co-creation: A journey to the 1970s and back to the future," Journal of Marketing Management, 28(13/14): 1520-1534.

Gruen A. (2017), "Design and the creation of meaningful consumption practices in accessbased consumption,” Journal of Marketing Management, 33(3/4): 226-243.

Gundlach G.T. (2007), "Introduction to the special section: The American Marketing Association's new definition of marketing: Perspectives on its implications for scholarship and the role and responsibility of marketing and society," Journal of Public Policy \& Marketing, 26(2): 243-250.

Gundlach G.T. and Wilkie W.L. (2009), “The American Marketing Association's new definition of marketing: Perspective and commentary on the 2007 revision," Journal of Public Policy \& Marketing, 28(2): 259-264.

Gustafsson A., Aksoy L., Brady M.K., McColl-Kennedy J.R., Sirianni N.J., Witell L., and Wünderlich N.V. (2015), "Conducting service research that matters," Journal of Services Marketing, 29(6/7): 425-429.

Gustafsson A. and Bowen D.E. (2017), “The curious case of interdisciplinary research deficiency: Cause or symptom of what truly ails us?", Journal of Business Research, 79: 212-218.

Habibi M.R., Kim A., and Laroche M. (2016), "From sharing to exchange: An extended framework of dual modes of collaborative nonownership consumption," Journal of the Association for Consumer Research, 1(2): 277-294.

Hair J.F., Hult G.T.M., Ringle C.M., and Sarstedt M. (2016), A primer on partial least squares structural equation modeling (PLS-SEM), $2^{\text {nd }}$ ed. Sage, Thousand Oaks, CA.

Hair J.F., Ringle C.M., and Sarstedt M. (2011), "PLS-SEM: Indeed a silver bullet," Journal of Marketing Theory and Practice, 19(2): 139-152.

Hair J.F., Sarstedt M., Ringle C.M., and Mena J.A. (2012), “An assessment of the use of partial least squares structural equation modeling in marketing research," Journal of the Academy of Marketing Science, 40(3): 414-433. 
Hamari J., Sjöklint M., and Ukkonen A. (2016), "The sharing economy: Why people participate in collaborative consumption," Journal of the Association for Information Science and Technology, 67(9): 2047-2059.

Harrison R.L. and Reilly T.M. (2011), "Mixed methods designs in marketing research," Qualitative Market Research: An International Journal, 14(1): 7-26.

Hartl B., Hoffman E., and Kirchler E. (2016), "Do we need rules for 'what's mine is yours'? Governance in collaborative consumption communities," Journal of Business Research, 69(8): 2756-2763.

Hartl B., Sabitzer T., Hofmann E., and Penz E. (2018), “'Sustainability is a nice bonus' the role of sustainability in carsharing from a consumer perspective," Journal of Cleaner Production, 202: 88-100.

Hawlitschek F., Stofberg N., Teubner T., Tu P., and Weinhardt C. (2018), "How corporate sharewashing practices undermine consumer trust," Sustainability, 10(8): 2638-2656.

Hazée S., Delcourt C., and Van Vaerenbergh Y. (2017), "Burdens of access: Understanding customer barriers and barrier-attenuating practices in access-based services," Journal of Service Research, 20(4): 441-456.

Hennig-Thurau T., Henning V., and Sattler H. (2007), "Consumer file sharing of motion pictures," Journal of Marketing, 71(4): 1-18.

Herbert M. and Collin-Lachaud I. (2017), "Collaborative practices and consumerist habitus: An analysis of the transformative mechanisms of collaborative consumption," Recherche et Applications en Marketing (English Edition), 32(1): 40-60.

Hillebrand B., Driessen P.H., and Koll O. (2015), "Stakeholder marketing: Theoretical foundations and required capabilities," Journal of the Academy of Marketing Science, 43(4): 411-428.

Hofmann E., Hartl B., and Penz E. (2017), "Power versus trust - what matters more in collaborative consumption?”, Journal of Services Marketing, 31(6): 589-603.

Holbrook M.B. (1987), "What is consumer research?”, Journal of Consumer Research, 14(1): 128-132.

Houston F.S. and Gassenheimer J.B. (1987), "Marketing and exchange,” Journal of Marketing, 51(4): 3-18.

Howe K.R. (1988), “Against the quantitative-qualitative incompatibility thesis or dogmas die hard," Educational Researcher, 17(8): 10-16.

Huang L.S. (2015), "\#WeWashing: When "sharing" is renting and "community" is a commodity," Huffington Post. Available at: http://www.huffingtonpost.com/leeseanhuang/wewashing-when-sharing-is b 6879018.html (accessed 7 May 2015).

Hunt S.D. (1976), “The nature and scope of marketing," Journal of Marketing, 40(3): 1728. 
Hwang J. and Griffiths M. (2017), "Share more, drive less: Millennials value perception and behavioral intent in using collaborative consumption services," Journal of Consumer Marketing, 34(2): 132-146.

Iaconesi S. (2017), “The financialization of life," Startups \& Venture Capital. Available at: https://startupsventurecapital.com/the-financialization-of-life-a90fe2cb839f (accessed 10 October 2017).

Jallat F. (2006), “Acheter ou louer les biens de consommation : une question de société. Compte rendu du séminaire international de l'Institut pour la Ville en Mouvement," Revue Française du Marketing, 208(2/5): 110.

Järvensivu T. and Törnroos J.A. (2010), "Case study research with moderate constructionism: Conceptualization and practical illustration," Industrial Marketing Management, 39(1): 100-108.

* John N.A. (2017), The age of sharing. Polity Press, Cambridge, UK.

Johnson E.M. (1969), Are goods and services different? An exercise in marketing theory. Doctoral dissertation, Business School, Washington University, St Louis, MO.

Johnson M., Herrmann A., and Huber F. (1998), "Growth through product-sharing services," Journal of Service Research, 2(1): 167-177.

Johnson R.B. and Onwuegbuzie A.J. (2004), "Mixed methods research: A research paradigm whose time has come," Educational Researcher, 33(7): 14-26.

Johnson R.B., Onwuegbuzie A.J., and Turner L.A. (2007), "Toward a definition of mixed methods research," Journal of Mixed Methods Research, 1(2): 112-133.

Judd R.C. (1964), “The case for redefining services," Journal of Marketing, 28(1), 58-59.

Kalamar A. (2013), "Sharewashing is the new greenwashing," OpEdNews. Available at: http://www.opednews.com/articles/Sharewashing-is-the-New-Gr-by-Anthony-Kalamar-130513- 834.html (accessed 8 November 2017).

Kim J. (2017), “The ownership distance effect: The impact of traces left by previous owners on the evaluation of used goods," Marketing Letters, 28(4): 591-605.

Kohtamäki M., Rabetino R., and Einola S. (2018) "Paradoxes in servitization," in Kohtamäki et al. (eds.) Practices and Tools for Servitization: Managing Service Transition, Springer, Cham, Switzerland, pp. 185-199.

Koppenhafer L.E. (2014), Accounting for the social element in access-based consumption. Doctoral dissertation, Department of Marketing, University of Oregon, Eugene, OR. Kotler P. (1972), “A generic concept of marketing,” Journal of Marketing, 36(2): 46-54. Kotler P. and Levy S.J. (1969), "Demarketing, yes, demarketing” Harvard Business Review, 49(11/12): 74-80.

Kotler P. and Zaltman G. (1971), "Social marketing: An approach to planned social change," Journal of Marketing, 35(3): 3-12. 
Kozinets R.V. (2002), “The field behind the screen: Using netnography for marketing research in online communities," Journal of Marketing Research, 39(1): 61-72.

Kozinets R.V. (2015), Netnography: Redefined. Sage, London, UK.

Kozinets R.V. (2017), "Netnography: Radical participative understanding for a networked communications society," in Willig \& Rogers (eds.), Handbook of qualitative research in psychology, Sage, London, UK, pp. 374-380.

Kozinets R.V. and Arnould E.J. (2017), "Ruminations on the current state of consumer ethnography," in Keller et al. (eds.), Handbook on consumption, Routledge, London, UK.

Krush MT., Pennington J.R., Fowler A.R., Mittelstaedt J.D. (2015), "Positive marketing: A new theoretical prototype of sharing in an online community," Journal of Business Research 68(12): 2503-2512.

Kuhn T.S. (1962[2012]), The structure of scientific revolutions. University of Chicago Press, Chicago, IL.

Kumar V. (2015), "Evolution of marketing as a discipline: What has happened and what to look out for," Journal of Marketing, 79(January): 1-9.

Kumar V. (2018), “Transformative marketing: The next 20 years," Journal of Marketing, 82(4): 1-12.

Kumar V., Lahiri A., and Dogan O.B. (2018), “A strategic framework for a profitable business model in the sharing economy," Industrial Marketing Management, 69: 147160.

Kvale S. (1996), Interviews: An introduction to qualitative research interviewing. Sage, Thousand Oaks, CA.

Lamberton C.P. (2015), “Consumer sharing: Collaborative consumption, from theoretical roots to new opportunities," in Norton et al. (eds.), The Cambridge handbook of consumer psychology, Cambridge University Press, Cambridge, MA, pp. 673-692.

Lamberton C.P. (2016), “Collaborative consumption: A goal-based framework," Current Opinion in Psychology, 10(August): 55-59.

Lamberton C.P. and Rose R.L. (2012), "When is ours better than mine? A framework for understanding and sharing systems," Journal of Marketing, 76(4): 109-125.

Lang C. and Joyner Armstrong C.M. (2018), "Collaborative consumption: The influence of fashion leadership, need for uniqueness, and materialism on female consumers' adoption of clothing renting and swapping," Sustainable Production and Consumption, 13: $37-47$.

Lawson S.J. (2010), "Transumers: Motivations of non-ownership consumption," Advances in Consumer Research, 37: 842-853. 
Lawson S.J., Gleim M.R., Perren R., and Hwang J. (2016), "Freedom from ownership: An exploration of access-based consumption," Journal of Business Research, 69(8): 26152623.

LeCompte M.D. and Schensul J.J. (2012), Analysis and interpretation of ethnographic data: A mixed methods approach, $2^{\text {nd }}$ ed. AltaMira Press, Lanham, Maryland.

LeGros C. (2015), “Michel Bauwens « Uber et Airbnb n’ont rien à voir avec l'économie de partage »," Le Monde. Available at: https://www.lemonde.fr/entreprises/article /2015/06/25/michel-bauwens-uber-et-airbnb-n-ont-rien-a-voir-avec-l-economie-departage 4661680 1656994.html (accessed 26 September 2016).

Lemon K.N. (2013), "Focus on the multidisciplinary nature of service research," Journal of Service Research, 16(2): 119-120.

Levitt T.H. (1960), “Marketing myopia,” Harvard Business Review, 38(7/8), 45-56.

Lewis M.W. (2000), "Exploring paradox: Toward a more comprehensive guide," The Academy of Management Review, 25(4): 760-776.

Libai B., Bolton R., Bügel M.S, de Ruyter K., Götz O., Risselada H., and Stephen A.T. (2010), "Customer-to-customer interactions: Broadening the scope of word of mouth research,” Journal of Service Research, 13(3): 267-282.

Lincoln, Y.S. and Guba E.G. (1985), "Postpositivism and the naturalist paradigm," in Lincoln \& Guba (eds.), Naturalistic Inquiry, Sage, Thousand Oaks, CA, pp. 14-46.

Lindblom A., Lindblom T., and Wechtler H. (2018), "Collaborative consumption as C2C trading: Analyzing the effects of materialism and price consciousness," Journal of Retailing and Consumer Services, 44: 244-252.

Lovelock C. and Gummesson E. (2004), "Whither services marketing? In search of a new paradigm and fresh perspectives," Journal of Service Research, 7(1): 20-41.

MacInnis D.J. and Folkes V.S. (2010), “The disciplinary status of consumer behavior: A sociology of science perspective on key controversies," Journal of Consumer Research, 36(6): 899-914.

Malhotra A. and Van Alstyne M. (2014), "The dark side of the sharing economy... and how to lighten it," Communications of the ACM-Association for Computing Machinery, 57(11): 24-27.

Martin C.J. and Upham P. (2016), "Grassroots social innovation and the mobilisation of values in collaborative consumption: A conceptual model," Journal of Cleaner Production, 134(Part A): 204-213.

Martin C.J., Upham P., and Budd L. (2015), “Commercial orientation in grassroots social innovation: Insights from the sharing economy," Ecological Economics, 118: 240- 251.

Mazzella F. and Sundararajan A. (2016), Entering the trust age. BlaBlaCar \& New York University Stern School of Business, New York, NY. 
McAlexander J.H., Schouten J.W., and Koenig H.F. (2002), "Building brand community," Journal of Marketing, 66(1): 38-54.

McArthur E. (2015), "Many-to-many exchange without money: Why people share their resources," Consumption Markets \& Culture, 18(3): 239-56.

* McLaren D. and Agyeman J. (2015), Sharing cities: A case for truly smart and sustainable cities. MIT Press, Cambridge, MA.

Meade J.E. (1972), "The theory of labour-managed firms and of profit sharing," The Economic Journal, 82(325): 402-428.

Meade J.E. (1986), Different forms of share economy. Public Policy Centre, University of Michigan, Ann Arbor, MI.

Meelen T. and Frenken K. (2015), "Stop saying Uber is part of the sharing economy. What is being shared besides your money?", Fast Company. Available at: http://www.fastcoexist.com/3040863/stop-saying-uber-is-part-of-the-sharing-economy (accessed 30 April 2015).

Mick D.G. (2006), "Presidential address: Meaning and mattering through transformative consumer research," Advances in Consumer Research, 33: 1-4.

Mick D.G. and Fournier S. (1998), "Paradoxes of technology: Consumer cognizance, emotions, and coping strategies," Journal of Consumer Research, 25(2): 123-143.

Milgram S. (1967), “The small world problem,” Psychology Today, 1(1): 61-67.

Mittendorf C. (2018), "Collaborative consumption: The role of familiarity and trust among millennials," Journal of Consumer Marketing, 35(4): 377-391.

Moeller S. and Wittkowski K. (2010), “The burdens of ownership: Reasons for preferring renting," Managing Service Quality, 20(2): 176-191.

Möhlmann M. (2015), “Collaborative consumption: Determinants of satisfaction and the likelihood of using a sharing economy option again," Journal of Consumer Behavior, 14(3): 193-207.

Morozov E. (2013), “The 'sharing economy' undermines workers' rights,” The Financial Times. Available at: https://www.ft.com/content/92c3021c-34c2-11e3-814800144feab7de (accessed 22 May 2015).

MSI (2018), Research Priorities 2018-2020. Marketing Science Institute, Cambridge, MA.

Muñiz A.M. and Guinn T.C.O. (2001), "Brand community," Journal of Consumer Research, 27(4): 412-432.

Muñiz A.M. and Schau H.J. (2005), "Religiosity in the abandoned Apple Newton brand community," Journal of Consumer Research, 31(4): 737-747.

* Munger M.C. (2018), Tomorrow 3.0: Transaction costs and the sharing economy. Cambridge University Press, Cambridge, MA. 
Muzellec L., Ronteau S., and Lambkin M. (2015), “Two-sided Internet platforms: A business model lifecycle perspective," Industrial Marketing Management, 45(1): 139150.

Ndubisi N.O., Ehret M., and Wirtz J. (2016), "Relational governance mechanisms and uncertainties in nonownership services," Psychology \& Marketing, 33(4): 250-266.

Nelson M.R. and Rademacher M.A. (2009), "From trash to treasure: Freecycle.org as a case of generalized reciprocity," Advances in Consumer Research, 36: 905-906

Nelson M.R., Rademacher M.A., and Paek H.J. (2007), "Downshifting consumer = upshifting citizen? An examination of a local freecycle community," Annals of the American Academy of Political and Social Science, 611(1): 141-156.

Nicholls R., (2010), "New directions for customer-to-customer interaction research," Journal of Services Marketing, 24(1): 87-97.

O’Driscoll A. (2008), “Exploring paradox in marketing: Managing ambiguity towards synthesis," Journal of Business \& Industrial Marketing, 23(2): 95-104.

Ostrom A.L., Bitner M.J., Brown S.W., Burkhard K.A., Goul M., Smith-Daniels V., Demirkan H., and Rabinovich E. (2010), "Moving forward and making a difference: Research priorities for the science of service," Journal of Service Research, 13(1): 436.

Ostrom A.L., Parasuraman A., Bowen D.E., Patricio L., and Voss, C.A. (2015), "Service research priorities in a rapidly changing context," Journal of Service Research, 18(2): 127-159.

Ouishare (2015), "Presentation Ouishare \& Collaborative Economy - Norway", Ouishare. Available at: http://www.slideshare.net/OuiShare/presentation-ouishare-collaborativeeconomy-norway/ (accessed 25 September 2015).

Owyang J. (2015), “The collaborative economy defined," Crowd Companies. Available at: http://www.web-strategist.com/blog/2015/08/27/the-collaborative-economy-defined/ (accessed 20 November 2015).

Oyedele A. and Simpson P. (2018), "Emerging adulthood, sharing utilities and intention to use sharing services," Journal of Services Marketing, 32(2): 161-174.

Ozanne L.K., and Ballantine P.W. (2010), "Sharing as a form of anti-consumption? An examination of toy library users," Journal of Consumer Behavior, 9(6): 485-98.

Ozanne L.K. and Ozanne J.L. (2016), "How alternative consumer markets can build community resiliency," European Journal of Marketing, 50(3/4): 330-57.

Ozanne L.K., Phipps M., Weaver T., Carrington M., Luchs M., Catlin J., Gupta S., Santos N., Scott K., and Williams J. (2016), "Managing the tensions at the intersection of the triple bottom line: A paradox theory approach to sustainability management," Journal of Public Policy \& Marketing, 35(2): 249-261. 
Papaoikonomou E. and Valor C. (2016), "Exploring commitment in peer-to-peer exchanges: The case of timebanks," Journal of Marketing Management, 32(13-14): $1333-58$.

Parguel B., Lunardo R., and Benoit-Moreau F. (2017), "Sustainability of the sharing economy in question: When second-hand peer-to-peer platforms stimulate indulgent consumption," Technological Forecasting and Social Change, 125: 48-57.

* Parker G.G., Van Alstyne M.W., and Choudary S.P. (2016), Platform revolution: How networked markets are transforming the economy and how to make them work for you. Norton \& Company, New York City, NY.

Peck J. and Shu S. (2018), Psychological ownership and consumer behavior. Springer, Cham, Switzerland.

Peters L.D. (2016), "Heteropathic versus homopathic resource integration and value cocreation in service ecosystems," Journal of Business Research, 69(8): 2999-3007.

Perren R. and Grauerholz L. (2015) "Collaborative consumption,” in Wright J. (ed.), International Encyclopedia of the Social \& Behavioral Sciences, Vol. 4, Elsevier, Palo Alto, CA, pp. 139-144.

Perren R. and Kozinets R. (2018), “Lateral exchange markets: How social platforms operate in a networked economy," Journal of Marketing, 82(1): 20-36.

Philip H.E., Ozanne L.K., and Ballantine P.W. (2015), "Examining temporary disposition and acquisition in peer-to-peer renting," Journal of Marketing Management, 31(11/12): 1310-1332.

Piscicelli L., Cooper T., and Fisher T. (2015), "The role of values in collaborative consumption: Insights from a product-service system for lending and borrowing in the UK," Journal of Cleaner Production, 97: 21-29.

Piscicelli L., Ludden G.D.S., and Cooper T. (2018), "What makes a sustainable business model successful? An empirical comparison of two peer-to-peer goods-sharing platforms," Journal of Cleaner Production, 172: 4580-4591.

Plouffe C.R. (2008), “Examining 'peer-to-peer' (P2P) systems as consumer-to-consumer (C2C) exchange," European Journal of Marketing, 42(11/12): 1179-1202.

Poole M.S. and van de Ven A.H. (1989), "Using paradox to build management and organization theories," The Academy of Management Review, 14(4): 562-578.

Prabhat D. (2018), “'Borrowmydoggy.com': Rethinking peer-to-peer exchange for genuine sharing," Journal of Law and Society, 45(1): 84-98.

Price L.L. and Belk R.W. (2016), "Consumer ownership and sharing: Introduction to the issue," Journal of the Association for Consumer Research, 1(2): 193-197. 
Putnam L.L., Fairhurst G.T., and Banghart S. (2016), "Contradictions, dialectics, and paradoxes in organizations: A constitutive approach," The Academy of Management Annals, 10(1): 65-171.

PwC (2015), “The sharing economy: Consumer intelligence series," BAV Consulting. Available at: https://www.pwc.fr/fr/assets/files/pdf/2015/05/pwc etude sharing economy.pdf (accessed 18 May 2018).

Ranaweera C., and Sigala M. (2015), "From service quality to service theory and practice," Journal of Service Theory and Practice, 25(1): 2-9.

Rayle L., Dai D., Chan N.D., Cervero R., and Shaheen S.A. (2016), "Just a better taxi? A survey-based comparison of taxis, transit, and ridesourcing services in San Francisco," Transport Policy 45: 168-178.

Richardson L. (2015), "Performing the sharing economy," Geoforum, 67: 121-129.

Rifkin J. (2000), The age of access: The new culture of hypercapitalism, where all of life is a paid-for experience. Tarcer/Putnam, New York, NY.

Ringle C.M., Wende S., and Becker J.M. (2015), SmartPLS 3. Bönningstedt: SmartPLS. Available at: http://www.smartpls.com.

Roberts J.J. (2015), "As sharing economy fades, these 2 phrases are likely to replace it," Fortune. Available at: http://fortune.com/2015/07/29/sharing-economy-chart/ (accessed 16 August 2015).

Rochet J. and Tirole J. (2006), "Two-sided markets: A progress report," RAND Journal of Economics, 37(3): 645-667.

Roos D. and Hahn R. (2017), "Does shared consumption affect consumers' values, attitudes, and norms? A panel study," Journal of Business Research, 77(August): 113-123.

Rubin H.J. and Rubin I. (2005), Qualitative interviewing: The art of hearing data. Sage, Thousand Oaks, CA.

Rudmin F. (2016), "The consumer science of sharing: A discussant's observations," Journal of the Association for Consumer Research, 1(2): 198-209.

Rust R.T. (1998), "What kind of journal is the Journal of Service Research?", Journal of Service Research, 1(1): 3-4.

Rust R.T. (2005), “The first seven years of JSR,” Journal of Service Research, 7(4): 311312.

Rust R.T. (2006), "From the editor: The maturation of marketing as an academic discipline," Journal of Marketing, 70(3): 1-2.

Sahlins M.D. (1972), Stone age economics. Aldine Atherton, Chicago, IL.

Sandel M.J. (2012), What money can't buy: The moral limits of markets. Farrar, Straus and Giroux (Macmillan), New York, NY. 
Sarstedt M., Hair J.F., Ringle C.M., Thiele K., and Gudergan S. (2016), "Estimation issues with PLS and CBSEM: Where the bias lies!", Journal of Business Research, 69(10): 3998-4010.

Sasser W.E. Jr., Olsen R.P., and Wyckoff D.D. (1978), Management of service operations: Text, cases, and readings. Allyn and Bacon, Boston, MA.

Scaraboto D. (2015), "Selling, sharing, and everything in between: The hybrid economies of collaborative networks," Journal of Consumer Research, 42(1): 152-176.

Schad J., Lewis M.W., Raisch S., and Smith W.K. (2016), "Paradox research in management science: Looking back to move forward," The Academy of Management Annals, 10(1): 5-64.

Schaefers T. (2013a), “Saving time, money, or the environment? Consumers' motives of access-based service use," in Kubacki (ed.), Ideas in marketing - Finding the new and polishing the old: Proceedings of the Academy of Marketing Science annual conference 2013, p. 652.

Schaefers T. (2013b), "Exploring carsharing usage motives: A hierarchical means-end chain analysis," Transportation Research Part A, 47: 69-77.

Schaefers T. and Lawson S.J. (2016), "Less risk, more fun? The role of ownership risk perception for access-based service value perception and usage," in Obal et al. (eds.), Let's get engaged! Crossing the threshold of marketing's engagement era, developments in marketing science: Proceedings of the Academy of Marketing Science annual conference 2014, pp. 455-456.

Schaefers T., Lawson S.J., and Kukar-Kinney M. (2016a), "How the burdens of ownership promote consumer usage of access-based services," Marketing Letters, 27(3): 569577.

Schaefers T., Roger M., and Narayanamurthy G. (2018), “Access-based services for the base of the pyramid," Journal of Service Research, 21(4): 421-437.

Schaefers T., Wittkowski K., Benoit S., and Ferraro R. (2016b), "Contagious effects of customer misbehavior in access-based services," Journal of Service Research, 19(1): 321.

Schau H.J., Muñiz A.M., and Arnould E.J. (2009), "How brand community practices create value," Journal of Marketing, 73(5): 30-51.

* Shareable (2017), Sharing cities: Activating the urban commons. Shareable, Palo Alto, CA. Schneider N. (2014), "Owning is the new sharing," Shareable. Available at: http://www. shareable.net/blog/owning-is-the-new-sharing (accessed 15 December 2015).

Schneider N. (2015), "The future of work: Owning what we share," Pacific Standard. Available at: http://www.psmag.com/business-economics/the-future-of-work-owningwhat-we-share (accessed 15 December 2015). 
Scholz (2014), "Platform cooperativism vs. the sharing economy," Digital Labor. Available at: https://medium.com/@trebors/platform-cooperativism-vs-the-sharing-economy2ea737f1b5ad (accessed 7 May 2015).

Scholz T. (2016a), Platform cooperativism: Challenging the corporate sharing economy. Rosa Luxemburg Stiftung, New York, NY.

Scholz T. (2016b), Uberworked and underpaid: How workers are disrupting the digital economy. Wiley, Hoboken, NJ.

Scholz T. and Schneider N. (2016), Ours to hack and to own: The rise of platform cooperativism, a new vision for the future of work and a fairer internet. OR Books, New York, NY.

Schor J.B. (2014), "Debating the sharing economy," Great Transition Initiative. Available at: http://www.greattransition.org/publication/debating-the-sharing-economy (accessed 28 Avril 2015).

Schor J.B., Fitzmaurice C., Carfagna L.B., Attwood-Charles W., and Dubois Poteat E. (2016), "Paradoxes of openness and distinction in the sharing economy," Poetics, 54: 66-81.

Shaheen S.A., Chan N.D., and Micheaux H. (2015), “One-way carsharing's evolution and operator perspectives from the Americas," Transportation, 42: 519-536

Shaheen S.A., Mallery M., and Kingsley K.J. (2012), "Personal vehicle sharing services in North America," Research in Transportation Business \& Management, 3: 71-81.

Shaheen S.A., Martin E., and Bansal A. (2018), Peer-To-Peer (P2P) carsharing: understanding early markets, social dynamics, and behavioral Impacts. Transportation Sustainability Research Center, UC Berkeley, CA.

Shaheen S.A., Sperling D., and Wagner C. (1999), "A short history of carsharing in the 90's," World Transport Policy and Practice, 5(3):16-37

Sherry J.F. (1990), "A sociocultural analysis of a midwestern American flea market," Journal of Consumer Research, 17(June): 13-30.

Sheth J.N. and Sisodia R.S. (2006), Does marketing need reform? Fresh perspectives on the future. Routledge, New York, NY.

Shostack G.L. (1977), "Breaking free from product marketing,” Journal of Marketing, 41(2): 73-80.

* Slee T. (2015), What's yours is mine: Against the sharing economy. OR Books, New York, NY.

Smith A. (1776[1976]), An inquiry into the nature and causes of the wealth of nations. Oxford University Press, The Glasgow Edition of the Works and Correspondence of Adam Smith, Oxford, UK. 
Smith, W.K. and Lewis M.W. (2011), "Toward a theory of paradox: A dynamic equilibrium model of organizing," Academy of Management Review, 36(2): 381-403.

Smith W.K. and Tracey P. (2016), "Institutional complexity and paradox theory:

Complementarities of competing demands," Strategic Organization, 14(4): 455-466.

Spradley J.P. (1979), The ethnographic interview. Harcourt, New York, NY.

Spradley J.P. (1980), Participant observation. The developmental research sequence:

Anthropology. Holt, Rinehart and Winston, New York, NY.

Stake R.E. (2010), Qualitative research: Studying how things work. Guilford Press, New York, NY.

* Stephany A. (2015), The business of sharing: Making it in the new sharing economy. Palgrave Macmillan, London, UK.

* Sundararajan A. (2016), The sharing economy: The end of employment and the rise of crowd-based capitalism. MIT Press, Cambridge, MA.

Tapscott D. and Williams A.D. (2006), Wikinomics: How mass collaboration changes everything. Portfolio, New York, NY.

Tashakkori A. and Teddlie C. (1998), Mixed methodology: Combining qualitative and quantitative approaches. Sage, Thousand Oaks, CA.

Täuscher K. and Kietzmann J. (2017), "Learning from failures in the sharing economy," MIS Quaterly Executive, 16(253): 253-264.

Tidström A., Ritala P., and Lainema K. (2018), "Interactional and procedural practices in managing coopetitive tensions," Journal of Business \& Industrial Marketing, 33(7): 945-957.

Tracy S.J. (2012), Qualitative research methods: Collecting evidence, crafting analysis, communicating impact. Wiley, Hoboken, NJ.

van Bommel K. (2018), "Managing tensions in sustainable business models: Exploring instrumental and integrative strategies," Journal of Cleaner Production, 196: 829-841.

van Maanen J. (1980), "Participant observation. The ethnographic interview," Administrative Science Quarterly, 25(3): 526-530.

van Maanen J. (2011), Tales of the field: On writing ethnography. University of Chicago Press, Chicago, IL.

Vargo S.L. and Lusch R.F. (2004), "Evolving to a new dominant logic for marketing," Journal of Marketing, 68(1): 1-17.

Vargo S.L. and Lusch R.F. (2008), "Service-dominant logic: Continuing the evolution," Journal of the Academy of Marketing Science, 36(1): 1-10.

Vargo S.L. and Lusch R.F. (2011), “It's all B2B...and beyond: Toward a systems perspective of the market," Industrial Marketing Management, 40(2): 181-187. 
Vargo S.L. and Lusch R.F. (2016), "Institutions and axioms: An extension and update of service-dominant logic," Journal of the Academy of Marketing Science, 44(1): 5-23.

Webb E.J., Campbell D.T., Schwartz R.D., and Sechrest L. (1966), Unobtrusive measures: Non-reactive research in the social sciences. Rand McNally, Chicago, IL.

Weitzman M. (1984), The share economy: Conquering stagflation. Harvard University Press, Cambridge, MA.

Wenger E., McDermott R.A., and Snyder W. (2002), Cultivating communities of practice: A guide to managing knowledge. Harvard Business Press, Cambridge, MA.

Widlok T. (2017), Anthropology and the economy of sharing. Routledge, Chicago, IL.

Wilhelms M.P., Henkel S., and Falk T. (2017a), "To earn is not enough: A means-end analysis to uncover peer-providers' participation motives in peer-to-peer carsharing," Technological Forecasting and Social Change, 125: 38-47.

Wilhelms M.P., Merfeld K., and Henkel S. (2017b), "Yours, mine, and ours: A user-centric analysis of opportunities and challenges in peer-to-peer asset sharing," Business Horizons, 60(6): 771-781.

Williams R. (1976), Keywords. A vocabulary of culture and society. Oxford University Press, New York, NY.

Wirtz J. and McColl-Kennedy J.R. (2010), “Opportunistic customer claiming during service recovery," Journal of the Academy of Marketing Science, 38(5): 654-675.

Wittkowski K., Moeller S., and Wirtz, J. (2013), "Firms' intentions to use nonownership services," Journal of Service Research, 16(2): 171-185.

Yin R.K. (2018), Case study research and applications: Design and methods, $6^{\text {th }}$ ed. Sage, London, UK.

Zervas G., Proserpio D., and Byers J.W. (2017), “The rise of the sharing economy:

Estimating the impact of Airbnb on the hotel industry," Journal of Marketing Research, 54(October): 687-705.

Zikmund W.G., Babin B. J., Carr J.C, and Griffin M. (2013), Business research methods. Cengage Learning South-Western, Mason, $\mathrm{OH}$. 

APPENDICES 


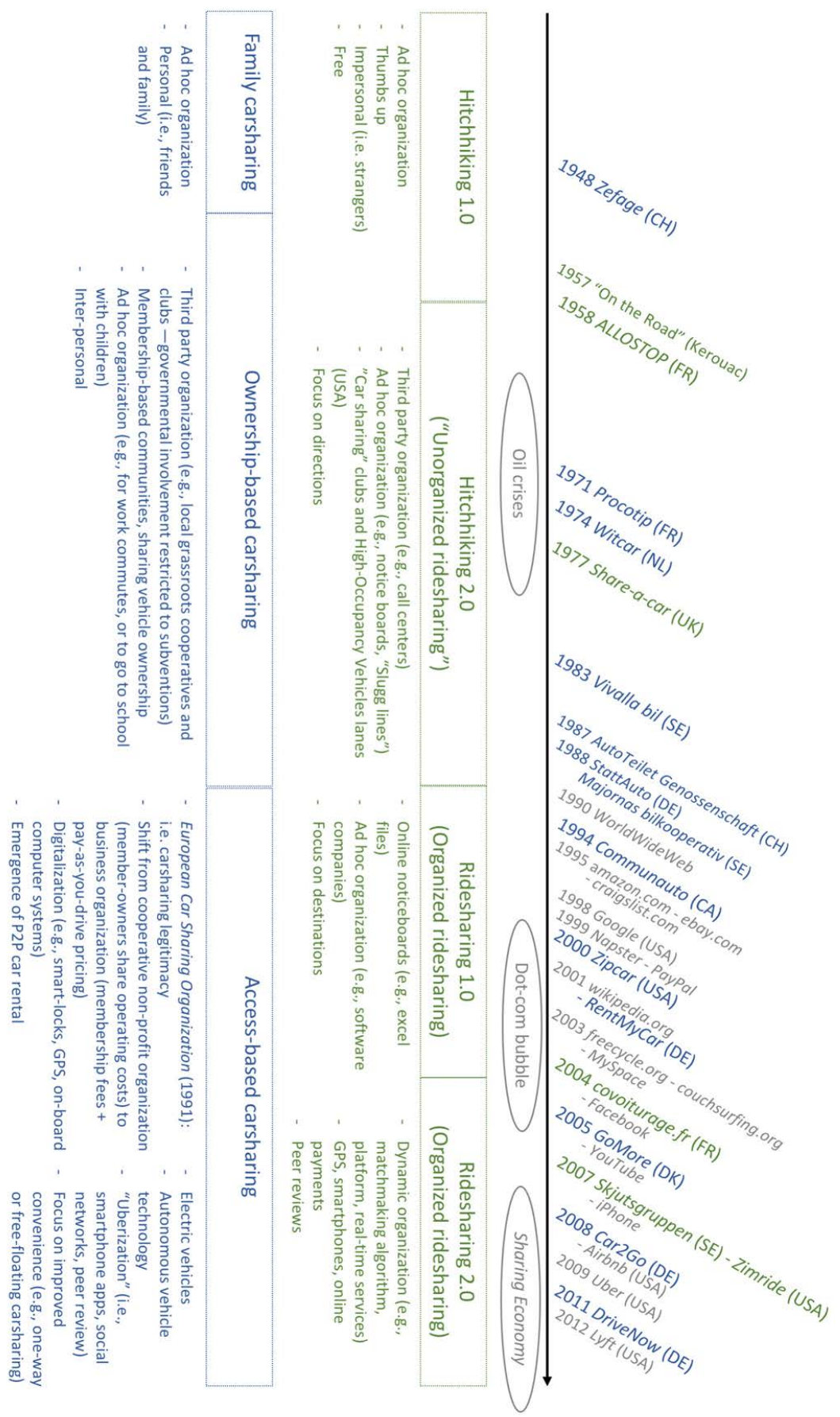

Appendix 1. A brief history of shared mobility. 
Note: Focus on ridesharing and carsharing. The use of 1.0 and 2.0 refers to the Internet culture: the "web 2.0" (i.e. the Dot-com bubble) refers to explosion of interactive websites in the early 2000 's enabling an increased amount of Internet users to generate content, interact, and collaborate with others (e.g., social media networks, blogs) - whereas the web 1.0 (1990's) would refer to the first generation of static websites that limited visitors to read content, passively. As such, ridesharing 2.0 is the improved version of ridesharing 1.0. However, the term hitchhiking 2.0 is sometimes used to refer to ridesharing in general (1.0 or 2.0) as an improved practice compared with basic hitchhiking (e.g., Casprini et al. 2018). 


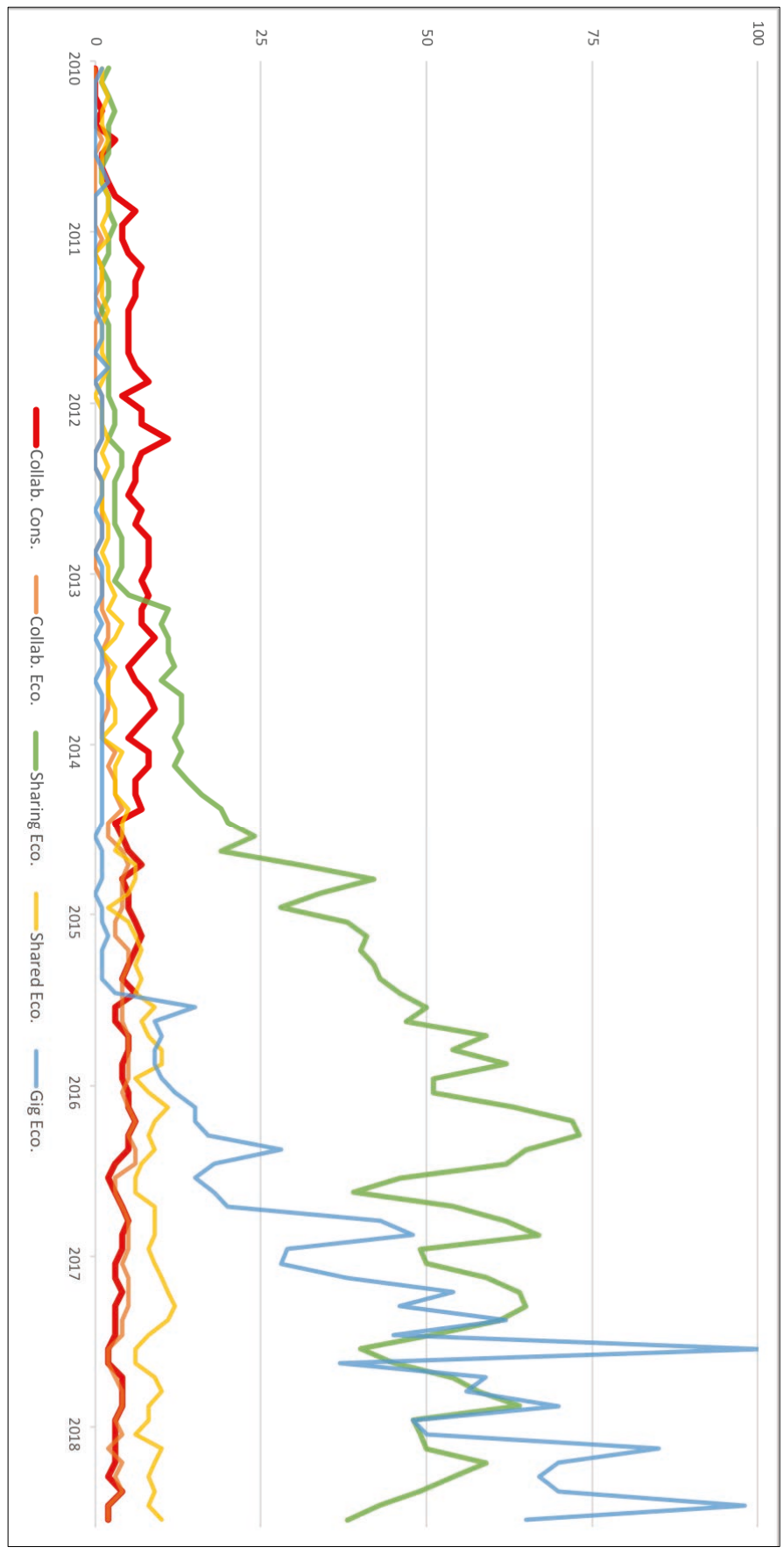

Appendix 2. From "collaborative consumption" to "gig economy".

Note: Worldwide Google search interests between January 2010 and July 2018 on the popular terms collaborative consumption, sharing economy, and gig economy (and a few derivatives). 


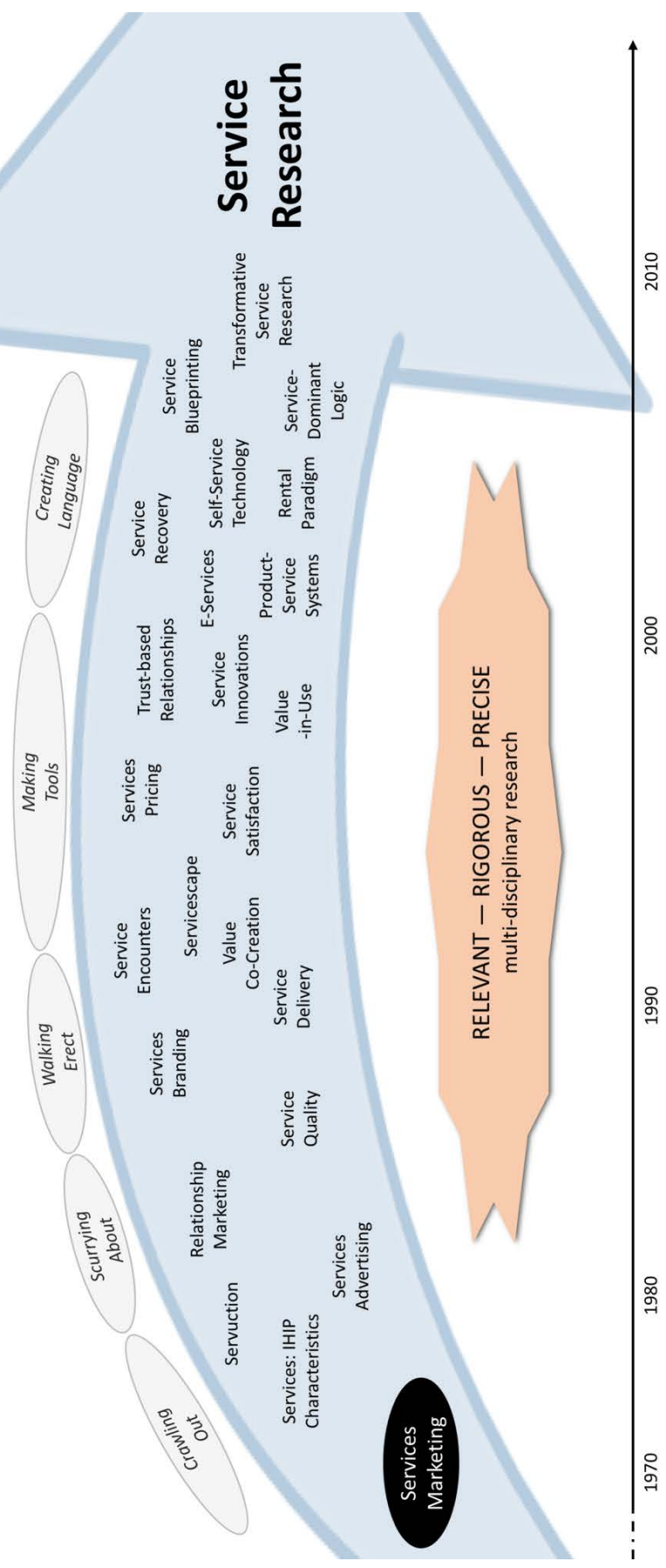

Appendix 3. A brief history of Service Research.

Note: Based on Berry and Parasuraman (1993); Fisk, Brown, and Bitner (1993); Berry's reflections in Fisk, Grove, and John (2000); Fisk and Grove (2010); and Baron et al. (2014). 

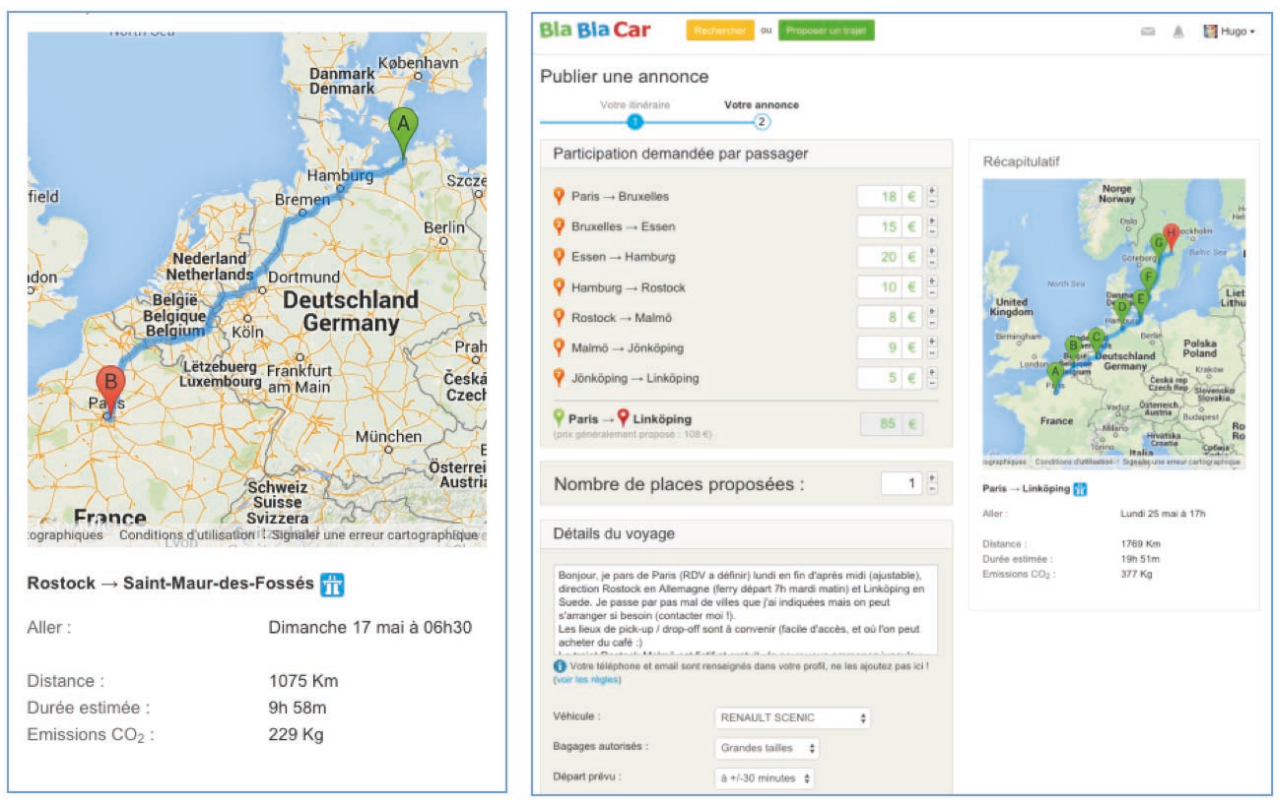

Appendix 4. Posting ridesharing offers on BlaBlaCar's platform.

Note: Screenshots of blablacar.fr [in French]: maps, stopovers, ride description, and suggested prices per seat for each portion of a ride - based on estimated fuel consumption, road tolls, but also the car's comfort and maintenance costs (14 May 2015). Prices can be adjusted within \pm 50 percent, and they are color-coded to help passengers differentiate between recommended-price rides and those more expensive: orange $(+25$ percent) to red (+ 50 percent). The platform's functionalities (i.e. stopovers, search engine) were improved, and the visual identity (i.e. logo) was recently changed (30 January 2018).

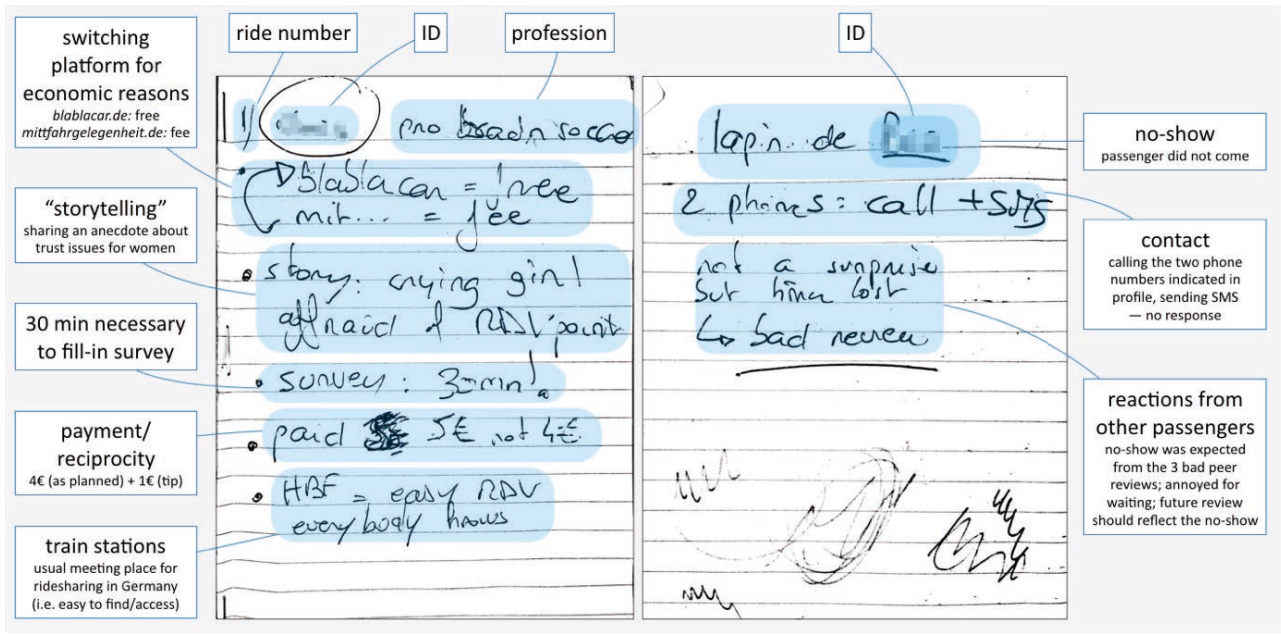

Appendix 5. Example of field notes.

Note: The participants' real names are hidden. They are anonymized when referred to (e.g., in quotes). 


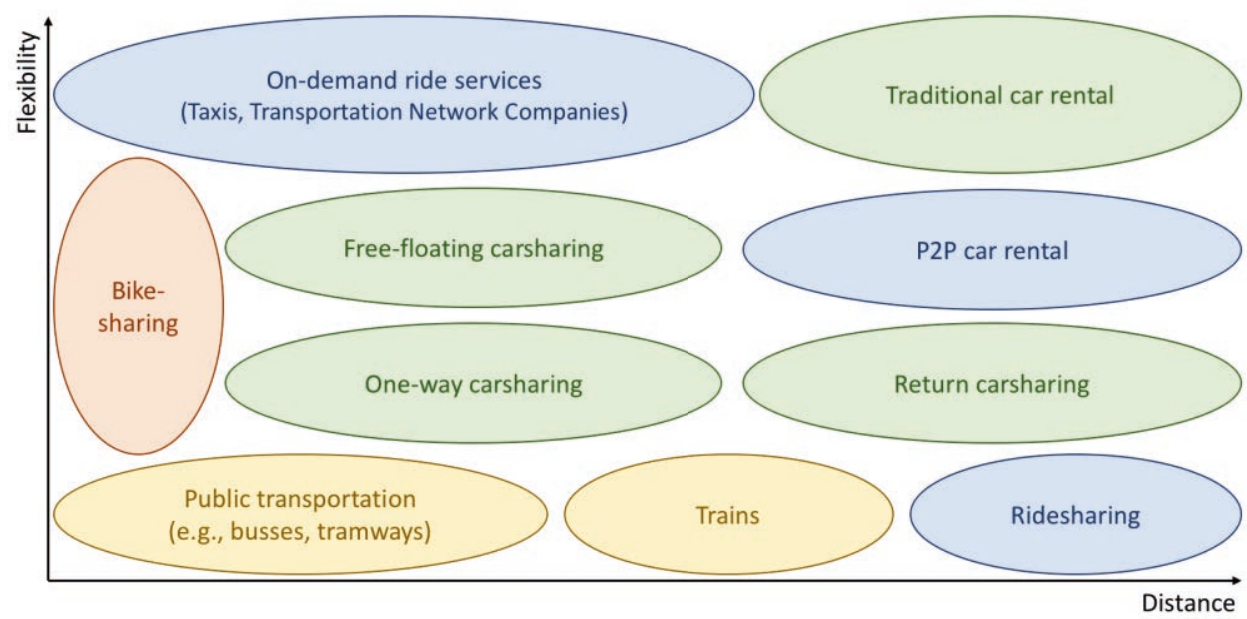

Appendix 6. The shared mobility sector.

Note: Distance and flexibility refer to mobility needs, which different providers fulfill through shared forms of transportation. This representation excludes walking, car ownership and leasing (assimilated to permanent ownership), Mobility-as-a-Service (MaaS) or Mobility-as-Network (MasN) systems and other "all-in-one" integrated solutions (as they combined different shared mobility modes into one single app), and scooter sharing (i.e. self-service, free-floating electric scooters very recently launched in the US). This also excludes shared delivery and transportation services (i.e. P2P packages, crowd-logistics, on-demand delivery, etc.).

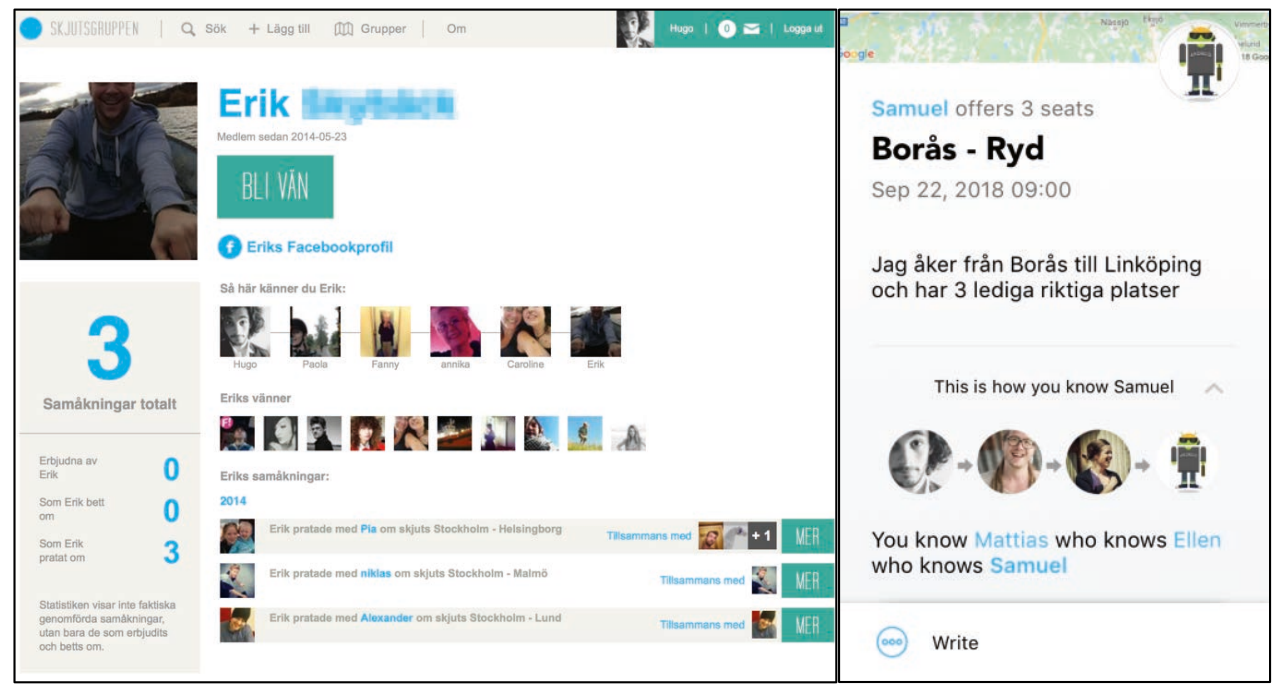

Appendix 7. Degrees of separation between platform users.

Note: Screenshots of a Skjutsgruppen member's profile (anonymized) on the platform to the left (6 October 2016), and of a ride offer on the smartphone app to the right (20 September 2018) [in Swedish]. 
Sysware is a German software company that developed several ridesharing platforms in Scandinavia, Germany, the Netherlands and Belgium during 2008-2010 functioning with the same database, and similar website design and functionalities on different domains (i.e. samåkning.se, ridefinder.eu, carpooling.nu, comoovee.com).

Sysware registered the Swedish domain names skjutsgruppen.se, skjutsgrupen.com and skjutsgruppen.net, and a trademark ("skjutsgruppen") in 2009 to the Swedish Patents and Registration Office. Then Sysware launched their own Facebook page (simply called "skjutsgruppen" with 900 followers), to redirect visitors towards its own website samakning.se. In 2011, the genuine Facebook page ("I love Skjutsgruppen" created in 2007 with 18,000 followers) was closed down due to content infringement (cf. the trademark registered to Sysware). The same modus operandi was applied onto Skjutsgruppen's Twitter account.

However, Sysware's Swedish subsidiary was actually declared bankrupt the same year, and the trademark became available to purchase. Skjutsgruppen's founder crowdfunded $€ 650$, and with the help of a probono lawyer, acquired the trademark. In 2013, the domain names were granted to Skjutsgruppen's founder after appealing to the Internet Foundation in Sweden — thanks to the trademark.

Nevertheless, a few months earlier in 2013, Sysware reiterated with the Danish platform GoMore, by registering the Swedish trademark (i.e. "GO MORE") and domain names gomore.se (when GoMore failed to renew the domain lease after 8 years due to misunderstandings with the webhost) and go-more.se (which was freely available) in order to redirect their users towards its own ridesharing platform like it had done earlier. Sysware offered GoMore to buy the domains and trademark for $€ 25,000$. GoMore appealed the Internet Foundation to claim the domain names, but they lost, due to the trademark. Eventually, the web domains and the trademark (GO MORE) were registered to GoMore in 2014without disclosing whether payment took place. ${ }^{\dagger}$

Sysware's samåkning.se (and its other domains) were operational until 2018, with a $12.5 \%$ commission on each facilitated ride, but the platform has not been improved since 2014 and it seems less popular than GoMore and Skjutsgruppen. Sysware's founder lived in Gothenburg — where Skjutsgruppen was launched in 2007 as a grassroots movement.

* The entire story "Skjutsgruppen is back" told by Skjutsgruppen's founder is available at skjutsgruppen.tumblr.com (10 October 2011). The trademark for Skjutsgruppen at the Patent and registration Office is available at https://was.prv.se/VarumarkesDb/VarumarkesDetails?lang=EN\&ansnr=2009-07308 (6 September 2011).

Skjutsgruppen's Alternativt tvistlösningsförfarande (Alternative Dispute Resolution, ADR) number 687 (2 September 2013) from the Internet Foundation is available at: https://www.iis.se/docs/beslut_skjutsgruppen.se .pdf.

$†$ GoMore's ADR number 735 (28 February 2014) is available at: https://www.iis.se/docs/beslut gomore.se mfl.pdf. The trademark for "GO MORE" at the Patent and registration Office is available at https://was.prv.se /VarumarkesDb/VarumarkesDetails?lang=EN\&ansnr=2013-00393 (5 May 2014).

Appendix 8. A vignette on Sysware. 


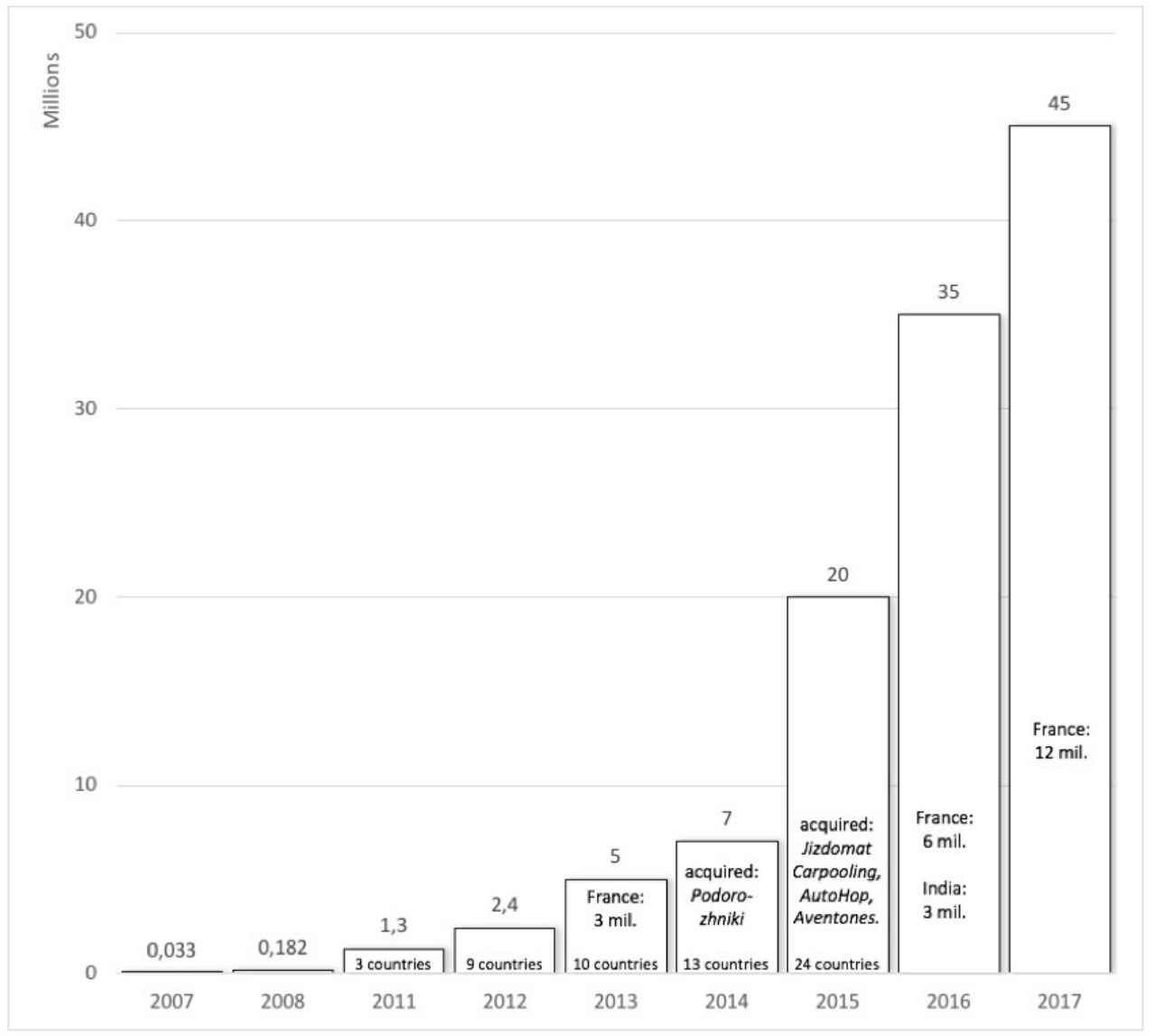

Appendix 9. BlaBlaCar: Growth from 2007 to 2017.

Note: BlaBlaCar's global market expansion:

- 2009: Spain (September).

- 2011: UK (June).

- 2012: Italy (March, via postoinauto.it acquisition); Belgium, Netherlands, Luxembourg, Portugal (November); Poland (November via superdojazd.pl).

- 2013: Germany (April).

- 2014: Russia, Ukraine (January, via podorozhniki.com); Turkey (September).

- 2015: India (January); Slovakia, Czech Republic (January, via jizdomat.cz); Austria, Switzerland (April, via carpooling.com); Hungary, Croatia, Romania, Serbia (April, via autohop.com); Mexico (April, via aventones.com); Brazil (December).

- 2016: local team in the UK is shut down (November).

- 2017: local teams in India, Turkey, and Mexico are shut down (March).

BlaBlaCar has been valued at \$1.6 billion (8 September 2015). 

GLOSSARY 
Access-based consumption: "transactions that can be market mediated but where no transfer of ownership takes place" (Bardhi and Eckhardt 2012, p. 881).

Collaborative consumption: "activity whereby a platform provider links a consumer that aims to temporarily utilize assets with a peer service provider who grants access to these assets and with this delivers the core service" (Benoit et al. 2017, p. 220).

Sharing economy: "the monetization of underutilized assets that are owned by service providers (firms or individuals) through short-term rentals" (Kumar et al. 2018, p. 148).

Peer-to-peer (P2P): the term P2P has its origins in computer science, and it refers to the marketing term $\mathrm{C} 2 \mathrm{C}$ (i.e. consumer-to-consumer). In the context of collaborative consumption, the term $P 2 P$ exchanges emphasize both the online cooperation and the person-to-person exchanges of private and tangible goods. In sum, P2P does not solely refer to Internet protocols or computer nodes, but also to direct interactions between two people.

Shared mobility: sector of activity describing shared forms of transportation such as carsharing, ridesharing, bikesharing, vanpooling, or public transportation. Auto manufacturers, tech companies, cities, transit agencies, and communities are involved into the shift to accessing a menu of mobility options at the touch of finger, largely enabled by technological breakthroughs.

Hitchhiking (also known as auto-stop and thumbing): unorganized (i.e. ad hoc) way to travel by getting free rides in passing vehicles.

Ridesharing (also known as carpooling in the US, and liftsharing in the UK): adding additional passengers to a pre-arranged car trip. Such an arrangement provides additional transportation options for riders while allowing drivers to fill otherwise empty seats in their vehicles. Examples: BlaBlaCar, Skjutsgruppen.

Ride-hailing (also known as E-hail, ride-sourcing, and ride-splitting): app-based on-demand mobility services provided by drivers for remuneration (e.g., professionally-trained and licensed drivers). Ride-splitting is when Transportation Network Companies (TNCs) that facilitate ride-hailing further offer their customers to split their itinerary and fare with other customers from the same sourced ride. Examples: Uber, Lyft. 
Carsharing: membership-based service offered by Car Sharing Organizations (CSO) providing access (i.e. without ownership) to a fleet of eco-friendly cars conveniently located in city centers. CSO members pay per use, which is cheaper than traditional car rental organizations (e.g., AVIS, Hertz).

Return carsharing (also known as round-trip): the most common model of carsharing operation, which requires customers to borrow and return vehicles at the same location. Example: Zipcar.

One-way carsharing (also known as point-to-point): enabled by GPS, network communication, and smartphone technologies, cars (most often electric) can be picked-up and dropped-off at different parking locations or charging stations (e.g., similarly to bike-sharing docking stations) within city centers. Example: AutoLib. ${ }^{43}$

Free-floating carsharing: essentially the same as one-way carsharing but without the dedicated parking spots. Instead, the fleet of vehicles is spread out within a predefined geographic region (i.e. city centers) and customers can geo-localize (and unlock) each car from a smartphone app. Examples: Car2Go (Daimler) and DriveNow $(\mathrm{BMW}){ }^{44}$

P2P car rental (also known as personal carsharing): privately owned vehicles made temporarily available to rent for members of a platform. P2P car rental is a return mode of carsharing. Example: GoMore. 

NOTES 
[1] The many popular science books on the "sharing economy" since 2010 (e.g., Botsman and Rogers 2010) are denoted with an asterisk in the reference list. While most online platforms were founded in the 2010s (see also Appendices 1 and 2), the origins of the term share economy can be traced further back (cf. Meade 1972, 1986; Weitzman 1984).

[2] Zipcar customers buy a membership plan and pay a flexible price based on their usage (i.e. access-based consumption). Zipcar was launched in 2000. Cars are positioned at different city locations, and they can be unlocked with a smart keycard, or from the app since 2009 (i.e. self-service). Carsharing is different from traditional car rental (e.g., Avis, Hertz) due to the temporality of access (longer duration, rigid contract terms), price (more expensive), and convenience (mostly airport locations).

[3] The term P2P is preferred to the term $\mathrm{C} 2 \mathrm{C}$ (i.e. consumer-to-consumer) in this thesis to emphasize the direct interactions between collaborative consumption participants who meet each other to exchange goods and services (see also Glossary) and not only interactions between a firm's customers and word-ofmouth communications (cf. Libai et al. 2010; Nicholls 2010).

[4] "A market is dual-sided if the platform can affect the volume of transactions by charging more to one side of the market and reducing the price paid by the other side by an equal amount; in other words, the price structure matters, and platforms must design it so as to bring both sides on board." (Rochet and Tirole 2006, p. 665) Most firms charge one side of the market comparatively more than the other side; i.e. making money on one side (whichever can bear it), while having costs borne out on the other side (whichever needs to increase its size).

[5] Sharewashing can also be referred to as we-washing or co-washing in the popular debate (de Malet 2015; Huang 2015; Kalamar 2013).

[6] Also called merchandization by the French anti-globalization movement ATTAC in the 2000s, this trend denotes the Age of Market Triumphalism (Sandel 2012), when almost everything in life is up for sale at the expense of morals.

[7] Commoditization is "the process of becoming a commodity" (Bishop 2016), i.e. when goods become common, widely available on the market, and cheap. A commodity was defined as "one that is subject to ready exchange or exploitation within a market" (Merriam Webster Dictionary 2018).

[8] PwC (2015) estimated global revenues from the "sharing economy" to rise to $\$ 335$ billion by 2025 (from $\$ 15$ billion in 2014).

[9] In the popular debate, the "sharing economy" has been widely adopted as a synonym for collaborative consumption (especially in the US). Another synonym is collaborative economy that puts more emphasis on the principles of decentralization, open governance and communitarianism embedded in 
communities leveraging technology to engage in new forms of collaboration and co-creation (Botsman 2015; Ertz and Leblanc-Proulz 2018; Fehrer et al. 2018; Ouishare 2015; Owyang 2015; Roberts 2015).

Collaborative consumption was the most popular term between 2011 and 2013, followed by sharing economy between 2013 and 2017, until gig economy became in vogue (peaking in July 2017), according to Google Trends (July 2018). See also Appendix 2.

[10] In line with the open-source software movement, the Platform Cooperativism movement argues that platforms facilitating P2P exchanges should be owned by the peer providers in those exchanges - not by venture capitalists - to redistribute benefits from the "sharing economy" more equitably (Gansky 2014; Gorenflo 2015; Scholz 2014, 2016a, 2016b; Schneider 2014, 2015; Scholz and Schneider 2016).

[11] Environmental concern and a sustainability mindset have become prominent in society, to which the circular economy promises to respond - often rebranded as the "sharing economy" - by using existing resources more efficiently, reducing waste and surplus, refurbishing goods, facilitating donations and recirculation systems, and discouraging new acquisitions through rental services. Previous research shows that sustainability is not the primary driver of the "sharing economy" (the economic incentive and social benefits are), but a "nice bonus" (Hartl et al. 2018), an "unintended consequence" (Botsman and Rogers 2010a, p. 74) or a byproduct (Wilhelm et al. 2017a), as it is most often not significant in survey research (Habibi et al. 2016; Hamari et al. 2016; Möhlmann 2015).

[12] Nonownership cannot be found in the dictionary despite its nearly 1,500 hits on Google Scholar (17 January, 2019). It is a portmanteau word designating the opposite of ownership, that is non-ownership.

[13] In the chapter Of the origin and use of money in The Wealth of Nations, Adam Smith wrote that no exchange could be made before the invention of money because people could not trade production surplus, and thus "Every man thus lives by exchanging, or becomes, in some measure, a merchant, and the society itself grows to be what is properly a commercial society" (Smith 1776[1976], p. 37).

[14] See ama.org (July 2013).

[15] The aim of the Consumer Odyssey was for a small group of rigorous consumer researchers to adopt a naturalistic approach to familiar consumption places like supermarkets and households, and new environments or practices such as swap meets, homeless shelters, riverboat cruises, etc. across the U.S. using qualitative observational methods such as photos and videos, interviews, participant observation, auto-ethnography (Belk et al. 1989; Bradshaw and Brown 2008; Sherry 1990). 
[16] Belk's (2007) first 'sharing' article was published in the annals of the 2006 conference of the American Academy of Political and Social Science, which also include Nelson et al.'s (2007) study (the first) of freecycle.org as a case of gift economy.

[17] Belk (2010) slightly revised his definition of sharing: "the act and process of distributing what is ours to others for their use and/or the act and process of receiving or taking something from others for our use" (p. 717, emphasis added).

[18] Bardhi and Eckhardt (2009) had already presented early findings on their "examination of market-mediated collective consumption" at the AMA 2009 summer conference, and in 2010 at the ACR conference. Based on the same Zipcar interviews, they wrote: "Our results highlight the lack of brand community, the paradox of freedom within car sharing, and the lack of responsibility present in the model." (Bardhi and Eckhardt 2010, p. 67)

[19] Judd (1964) and Berry and Maricle (1973) were actually the firsts to mention nongoods services and consumption without ownership for $\mathrm{B} 2 \mathrm{C}$ markets (respectively), but these were not empirical research papers like Johnson et al. (1998).

[20] As of 17 January, 2019:

Johnson et al. (1998): 6 citations (Scopus), 19 citations (Google Scholar). Lovelock and Gummesson (2004): 519 citations (Scopus), 1,539 citations (Google Scholar).

[21] Like Bardhi and Eckhardt (2009) at AMA, Moeller and Wittkowski presented their work on non-ownership services as early as 2009 , at the $11^{\text {th }}$ QUIS symposium in Germany, and were invited to contribute to the dedicated special issue published the following year.

[22] Schaefers et al. (2018) most recently defined "access-based services as giving customers access to a good for a period of time in return for an access payment, thereby offering a certain degree of freedom in using this product while legal ownership remains with the service provider"-which is essentially a different wording than in his earlier writings (Schaefers 2013a, 2013b; Schaefers et al. 2016a, 2016b).

[23] Schaefers, Lawson and Kukar-Kinney (2016a) had already presented their work at the Academy of Marketing Science 2014 conference (Schaefers and Lawson 2016).

[24] Lawson (2010) was among the first consumer researchers to look at nonownership consumption as a paradigm shift, by looking at commercial services in particular (i.e. B2C relationships). She defined participants in such access-based consumption as transumers, driven by experience (i.e. value-in-use) instead of ownership, living a transient lifestyle away from possessions. 
[25] Perren and Grauerholz (2015) emphasized the new role of private individuals as peer providers of services, and they differentiated collaborative consumption from brand communities (Macintosh fans, cf. Muñiz and O'Guinn 2001; Muñiz and Schau 2005), collective innovation communities (Wikipedia, cf. Tapscott and Williams 2006), and file-sharing communities (Napster, cf. Giesler 2006) due to the monetary exchange taking place between participants.

[26] The editor-in-chief of the Industrial Marketing Management journal has also visited Linköping University in November 2013, where he argued that marketing scholars aim to advance knowledge and understanding to improve marketing applications.

[27] The Critical Incident Technique - CIT, a method to collect, analyze, and classify critical incidents - was introduced to service research in the 1990s; study participants were asked to tell a story (i.e. when, why, how were employees involved) about satisfying and dissatisfying service encounters they have had.

[28] The purpose of my trip was to attend the Ouishare Fest 2015 and participate in the first workshop for "sharing economy" researchers in Europe (organized by Nesta and Ouishare at ESCP Paris) - in other words, joining the growing community of researchers and other stakeholders concerned with the phenomenon.

[29] BlaBlaCar counts more than 60 million members in more than 20 countries (30 January 2018). See also Appendix 9.

[30] I also proposed the Swedish portion of the trip (415 km) on Skjutsgruppen.nu (no fee), Samåkning.se (12\% service fee), and GoMore.se (10\% service fee), but only one person contacted me (from Samåkning) and we did not travel together. Moreover, BlaBlaCar has not actively expanded its activities to Scandinavian countries (though people post rides in/out of them), so it is unfortunate but normal that nobody reserved a seat from Sweden.

[31] Skjutsgruppen has more than 30,000 registered users and 350 specific groups on its platform - while the Facebook group counts 52,500 members who still organize ridesharing on the social media network (30 April 2018). Skjutsgruppen also has several dozens of other Facebook groups dedicated to specific cities, events, etc. with about 5,000 members, and the main Facebook page has more than 22,000 followers.

[32] The survey was translated into Swedish (i.e. original measures were published in English) by three different native colleagues in business administration, then merged and revised with a fourth native colleague. Minor wording corrections were implemented after pretesting the survey with the founder and one board member of Skjutsgruppen, as well as two social scientists familiar with survey design. 
[33] The 2018 impact factor (IF) for the Journal of Service Management (Paper I) is 3.414 (5-Year IF: 5.407), for the Journal of Cleaner Production (Paper II) it is 5.651 (5-Year IF: 6.352), and for the Journal of Services Marketing (Paper III), it is 2.408 (5-Year IF: 2.817).

[34] Botsman and Rogers (2010a, 2010b) did not coin the term collaborative consumption (cf. Felson and Spaeth 1978) or the popular locution what's mine is yours. Rifkin (2000) wrote, in the Age of Access, that "commercial success is increasingly measured by the idea of what is mine is yours and what is yours is mine. It is the sharing of economic activity that is the defining feature of networkbased commerce" (p. 50), in an attempt to describe the rise of collaboration and co-creation thanks to technology. A decade later, Botsman and Rogers described the "sharing economy" as "the rapid explosion in swapping, sharing, bartering, trading and renting being reinvented through the latest technologies and peer-topeer marketplaces in ways and on a scale never possible before" (2010a, p. xv).

[35] Frenken's diagram (Frenken and Schor 2017; Frenken 2017) was initially presented in Smarter regulation for the sharing economy, The Guardian (20 May 2015).

[36] The first carsharing initiative was a cooperative created in 1948 in Zurich, Switzerland, where people who could not afford to purchase a car could share one instead. Selbst Fahrergemeinschaft (aka Sefage) facilitated access to mobility for people with no car, by putting them in touch with other people in their local community so they could borrow their car (Shaheen et al. 1999). See also Appendix 1.

[37] Until 2011, BlaBlaCar was simply called covoiturage.fr (carpooling in French) and Comuto on international markets. BlaBlaCar's first few years mostly involved applying various business models on a trial and error basis: The firm tried a B2B service, freemium pricing, and sponsored/paid advertising, among others.

[38] CouchSurfing is often mentioned to illustrate how grassroots movements tend to become commercially-oriented. CouchSurfing was a non-profit organization and on online platform created in 2003 to enable travelers and locals to share their couches - before Airbnb's launch in 2008. In 2012, CouchSurfing became a forprofit business and changed its growth strategy (in light of the "sharing economy" phenomenon), charging users membership fees, and displaying ads on its website. This incorporation divided its (founding) grassroots community.

[39] Despite the rebranding as BlaBlaCar to emphasize that the firm is first and foremost a form of social exchange (the BlaBla onomatopoeic end) before a transportation mode (the Car end), the adoption of the platform business model (from free to fee) was highly criticized (see Paper III). 
[40] Similar to Skjutsgruppen, Zimride was launched as a Facebook app in 2007-by Lyft's founders - which allowed users to see each other's profile before sharing a ride, and then exchanging monetary compensation in the car. Around the same time, GoLoco was also launched as a Facebook app — by Zipcar's founder-with the critical difference that it also enabled the transfer of money online, on payment of a $10 \%$ commission. Both firms gave up this business model a few years later. See Two startups harness facebook's power to connect riders to rides, $\underline{A B C N e w s}$ (4 September 2007).

[41] As described in Appendix 8, Sysware actually tried to take over Skjutsgruppen's grassroots movement. GoMore also applied so-called social media hacks by advertising in Skjutsgruppen's Facebook group or to users who had liked competitors' pages, and by using a personal Facebook account to recommend the group functionality of the platform.

[42] The two Danish founders of GoMore discovered carpooling.com while studying in Germany and brought it back with them to Copenhagen in 2005- they saw "an opportunity in the Danes' concern for the environment and their discontent with public transportation prices, delays, cancellations" (Personal communication 2015).

[43] Autolib was a station-based electric carsharing service (2011-2018) in Paris.

[44] Car2Go and DriveNow were respectively launched in 2008 and 2011 in Germany and expanded globally. Daimler and BMW announced the merger of their carsharing services (i.e. not manufacturing) in April 2018. 


\section{Papers}

The papers associated with this thesis have been removed for copyright reasons. For more details about these see:

http://urn.kb.se/resolve?urn=urn:nbn:se:liu:diva-153944 
